Aus dem Institut für Neuropathologie

(Prof. Dr. med. W. Brück)

im Zentrum Pathologie und Rechtsmedizin

der Medizinischen Fakultät der Universität Göttingen

\title{
Auswirkung einer selektiven p75- \\ Neurotrophinrezeptor-Defizienz im Immun- oder \\ Zentralnervensystem auf die experimentelle autoimmune Enzephalomyelitis
}

\author{
vorgelegt von \\ Marlon Krug \\ aus \\ Göttingen
}

INAUGURAL-DISSERTATION

zur Erlangung des Doktorgrades

der Medizinischen Fakultät der

Georg-August-Universität zu Göttingen

Göttingen 2014 
Dekan:

1. Berichterstatterin:

2. Berichterstatter:
Prof. Dr. rer. nat. H. K. Kroemer

Prof. Dr. med. Ch. Stadelmann-Nessler

Prof. Dr. med. D. Liebetanz 


\section{Inhaltsverzeichnis}

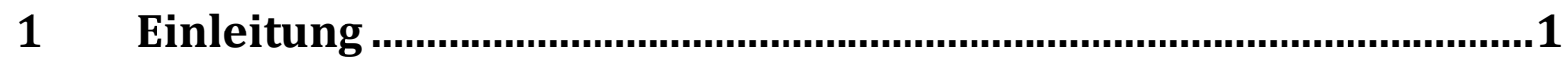

$1.1 \quad$ Multiple Sklerose ...........................................................................................1

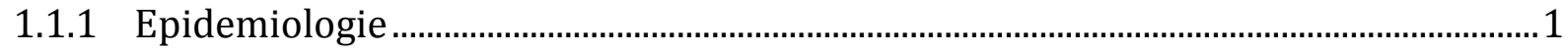

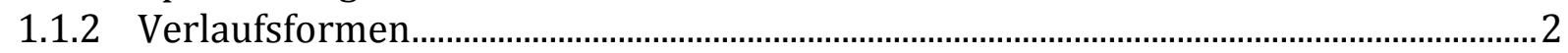

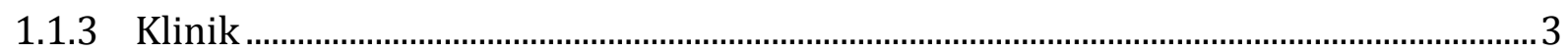

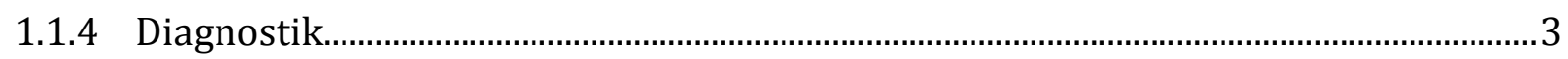

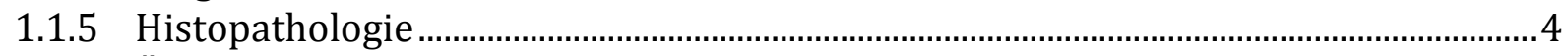

1.1.6 Ätiologie und Pathophysiologie ..................................................................................

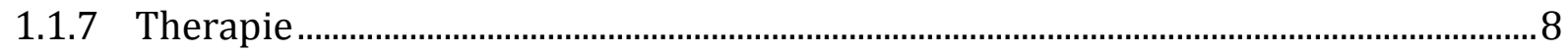

1.2 Experimentelle autoimmune Enzephalomyelitis..................................................9

1.3 Neurotrophine ........................................................................................10

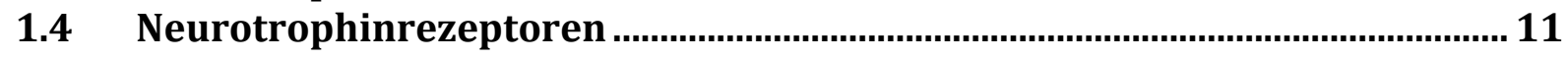

1.5 p75-Neurotrophinrezeptor...........................................................................12

1.5.1 p75-Neurotrophinrezeptor-vermittelte Signalwirkung .............................................12

1.5.2 Neurotrophin-vermittelte Interaktion zwischen Immunsystem und ZNS ...............14

1.6 Fragestellung der vorliegenden Arbeit.......................................................... 14

2 Material und Methoden …................................................................... 16

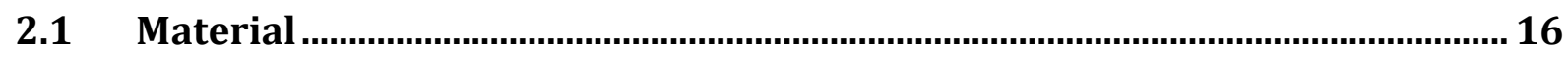

2.1.1 Verwendete Chemikalien ............................................................................................. 16

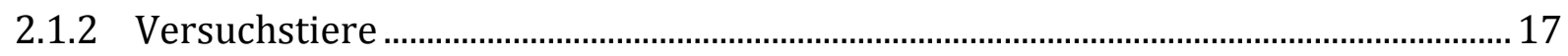

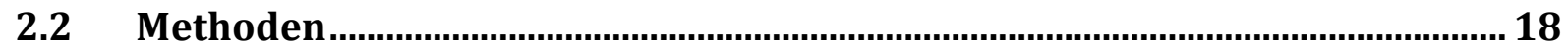

2.2.1 Herstellung von Knochenmarkschimären ..................................................................18

2.2.2 Aktiv induzierte EAE ................................................................................................... 19

2.2.3 Adoptiver Transfer (passiv induzierte EAE) ………………………………………. 20

2.2.4 Beurteilung der EAE-Symptome …………………………………………………….... 20

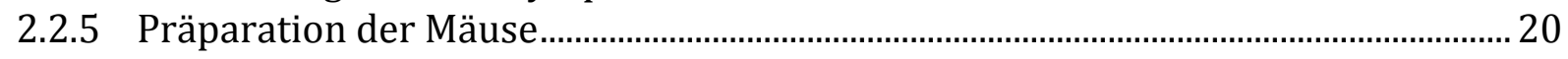

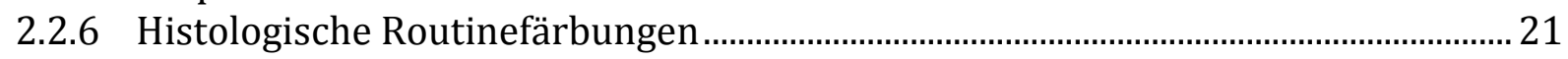

2.2.7 Immunhistochemische Färbemethoden ……………………………………………....22

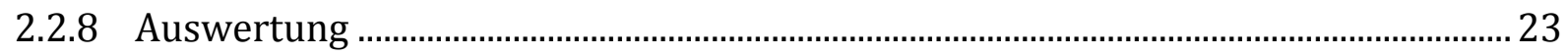

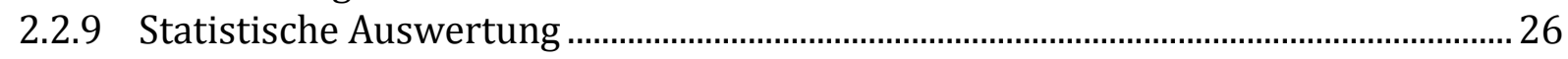

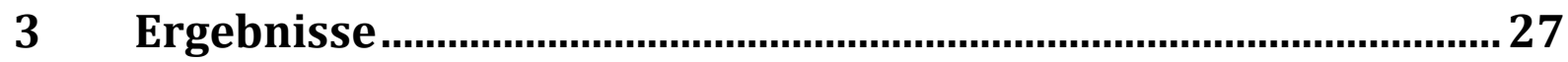

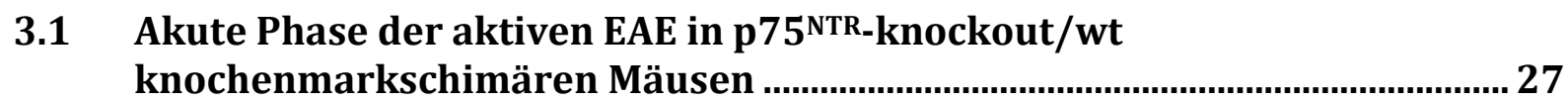

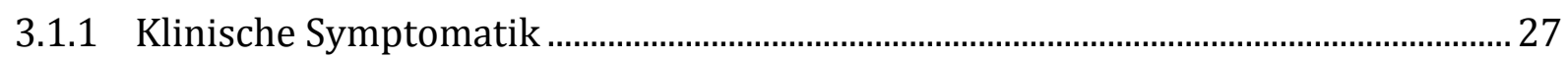

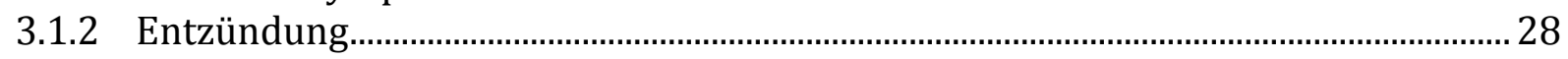

3.1.3 Analyse der Akuität der Entzündung...…………………………………………….... 29

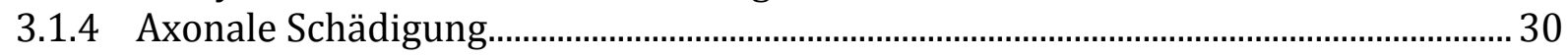

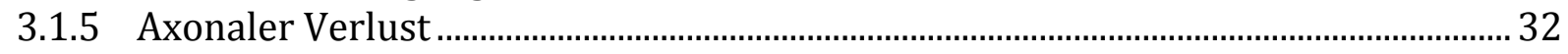

3.1.6 Entmarkung .......................................................................................................... 33

3.2 Chronische Phase der aktiven EAE in p75 ${ }^{\mathrm{NTR}}$-knockout/wt

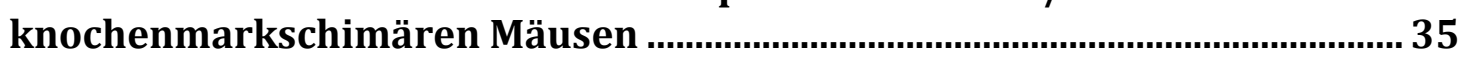




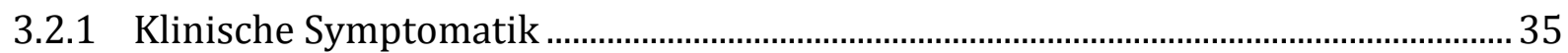

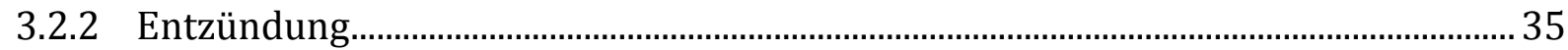

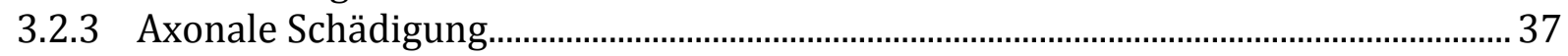



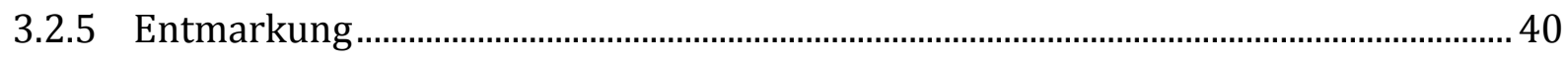

3.3 Adoptiver Transfer von enzephalitogenen MOG $_{35-55}$ spezifischen T-Zellen in

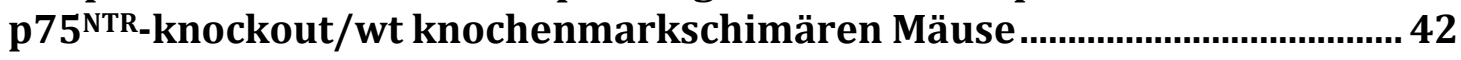



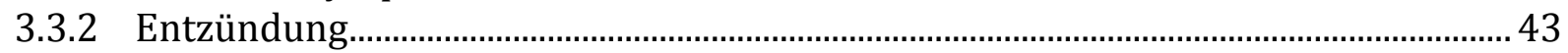

3.3.3 Infiltration von CD3+ T-Zellen und Mac-3+ Makrophagen ......................................... 43

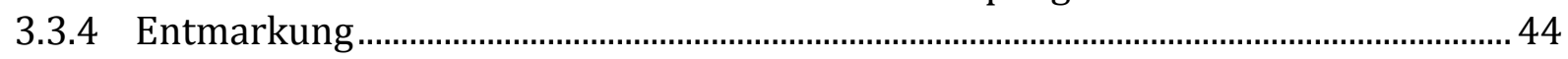

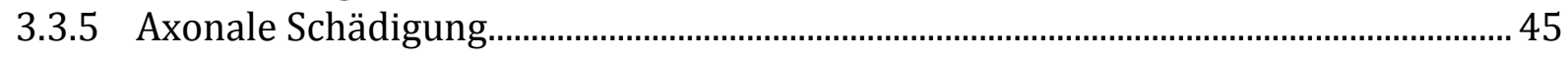

$4 \quad$ Diskussion.............................................................................................. 47

4.1 Die unterschiedlichen Rollen des p75 ${ }^{\mathrm{NTR}}$ im Immunsystem und ZNS bei der

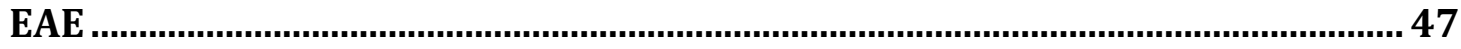

4.1.1 Die Erstellung von Knochenmarkschimären................................................................ 48

4.1.2 Der Einfluss von p75 ${ }^{\mathrm{NTR}}$ auf den klinischen Verlauf der EAE ..................................... 48

4.1.3 Der Einfluss des p75 ${ }^{\mathrm{NTR}}$ auf die entzündliche Aktivität ................................................ 49

4.1.4 Der Einfluss des p75 ${ }^{\mathrm{NTR}}$ auf die Integrität der BHS und auf das Immunsystem..... 50

4.1.5 Der Einfluss von p75 ${ }^{\text {NTR }}$ auf die axonale Schädigung sowie den axonalen Verlust

4.1.6 Der Einfluss von p75 ${ }^{\text {NTR }}$ auf die Demyelinisierung....................................................... 53

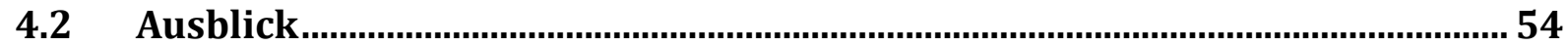

4.2.1 Der Einfluss von B-Zellen auf die EAE........................................................................ 54

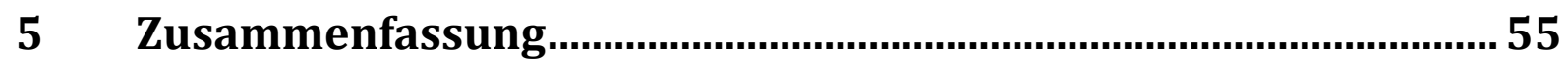

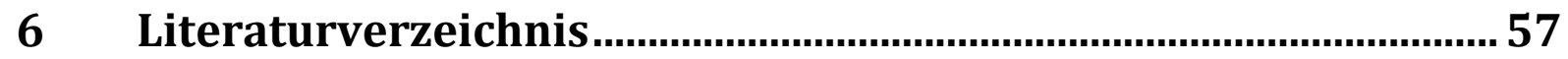




\section{Abbildungsverzeichnis}

Abb. 1: Schematische Zeichnung des p75 NTR. (Rabizadeh et al. 1993) .................................. 12

Abb. 2: Schematische Darstellung der p75 ${ }^{\text {NTR }}$-vermittelten Signalwirkung in

Abhängigkeit vom bindenden Liganden (Rabizadeh et al. 1993)............................. 14

Abb. 3: Schematische Darstellung der Herstellung von Knochenmarkschimären. ............ 19

Abb. 4: Krankheitsverlauf in murinen Knochenmarkschimären nach aktiver

Immunisierung.

Abb. 5: Entzündungsindex in der akuten Phase nach der aktiven Immunisierung von

murinen Knochenmarkschimären.

Abb. 6: Ausmaß der entzündlichen Infiltration in p75 ${ }^{\text {NTR }}$-knockout/wt

knochenmarkschimären Mäusen.

Abb. 7: Axonaler Schaden in der akuten Phase nach der aktiven Immunisierung von murinen Knochenmarkschimären.

Abb. 8: Ausmaß der axonalen Schädigung in p75NTR-knockout/wt

knochenmarkschimären Mäusen.

Abb. 9: Axonaler Verlust in der akuten Phase nach der aktiven Immunisierung von murinen Knochenmarkschimären.

Abb. 10: Ausmaß des axonalen Verlustes in p75NTR-knockout/wt

knochenmarkschimären Mäusen.

Abb. 11: Demyelinisierte Fläche in Rückenmarksquerschnitten in der akuten Phase nach der aktiven Immunisierung von murinen Knochenmarkschimären.

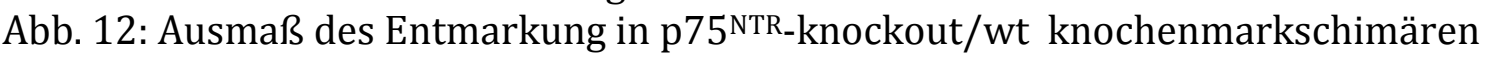
Mäusen.

Abb. 13: Krankheitsverlauf in der chronischen Phase nach der aktiven Immunisierung von murinen Knochenmarkschimären.

Abb. 14: Entzündungsindex in der chronischen Phase nach der aktiven Immunisierung von murinen Knochenmarkschimären.

Abb. 15: Ausmaß der entzündlichen Infiltration in p75 ${ }^{\mathrm{NTR}}$-knockout/wt

knochenmarkschimären Mäusen.

Abb. 16: Axonaler Schaden in der chronischen Phase nach der aktiven Immunisierung von murinen Knochenmarkschimären.

Abb. 17: Ausmaß der axonalen Schädigung in p75 NTR-knockout/wt

knochenmarkschimären Mäusen.

Abb. 18: Axonaler Verlust in der chronischen Phase nach der aktiven Immunisierung von murinen Knochenmarkschimären.

Abb. 19: Ausmaß des axonalen Verlustes in p75NTR-knockout/wt

knochenmarkschimären Mäusen.

Abb. 20: Demyelinisierte Fläche in Rückenmarksquerschnitten in der chronischen Phase nach der aktiven Immunisierung von murinen Knochenmarkschimären.

Abb. 21: Ausmaß der Entmarkung in p75 ${ }^{\mathrm{NTR}}$-knockout/wt knochenmarkschimären Mäusen.

Abb. 22: Krankheitsverlauf in der akuten Phase nach adoptivem Transfer von enzephalitogenen $\mathrm{MOG}_{35-55}$ spezifischen T-Zellen in murine $\mathrm{p} 5^{\mathrm{NTR}}$-knockout/wt Knochenmarkschimären. 
Abb. 23: Entzündungsindex in der akuten Phase nach adoptivem Transfer von enzephalitogenen $\mathrm{MOG}_{35-55}$ spezifischen T-Zellen in murine Knochenmarkschimären

Abb. 24: Entzündliche Infiltration in der akuten Phase nach adoptivem Transfer von

MOG35-55-spezifischen T-Zellen in murine Knochenmarkschimären.

Abb. 25: Demyelinisierte Fläche in Rückenmarksquerschnitten in der akuten Phase nach adoptivem Transfer von MOG $_{35-55}$-spezifischen T-Zellen in murine Knochenmarkschimären. 45

Abb. 26: Axonaler Schaden in der akuten Phase nach adoptivem Transfer von M0G $35-55^{-}$ spezifischen T-Zellen in murine Knochenmarkschimären. 


\section{Tabellenverzeichnis}

Tab. 1: Verwendete Chemikalien für histologische und immunhistochemische

Färbungen

Tab. 2: Hergestellte Lösungen für histologische und immunhistologische Färbungen .... 17

Tab. 3: Skala für die Ausprägung der klinischen Symptomatik.............................................. 20

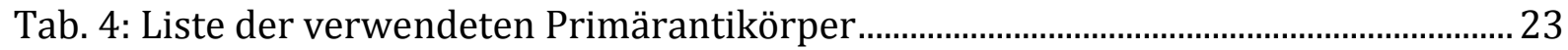

Tab. 5: Liste der verwendeten Sekundärantikörper................................................................. 23

Tab. 6: Verwendete Geräte und Materialen zur Auswertung und Mikroskopie .................. 26

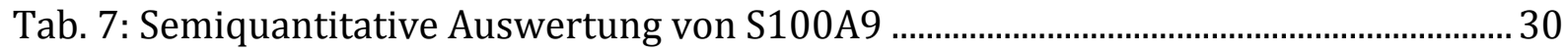

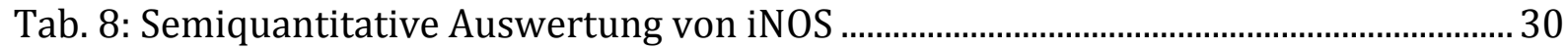




\section{Abkürzungsverzeichnis}

A. dest. : $\quad$ Aqua destillata (destilliertes Wasser)

A. bidest.: $\quad$ Aqua bidestillata (zweifach destilliertes Wasser)

APC: $\quad$ Antigen-präsentierende-Zellen

AT-EAE durch „adoptiven Transfer” hervorgerufene EAE

BHS: $\quad$ Blut-Hirn-Schranke

BDNF: brain derived neurotrophic factor

CD4+: $\quad$ cluster of differentiation 4 positive

EAE: $\quad$ Experimentelle autoimmune Enzephalomyelitis

EPO: $\quad$ Erythropoetin

$\mathrm{HCl} \quad \quad$ Chlorwasserstoff

HIF-1 $\alpha$ : Hypoxie-induzierter Faktor $1 \alpha$

$\mathrm{H}_{2} \mathrm{O}_{2}$ : Wasserstoffperoxid

IFN- $\gamma$ : Interferon-gamma

IgG: Immunglobulin G

IL: Interleukin

JNK: $\quad$ c-jun N-terminale Kinase

LINGO-1: $\quad$ leucin rich repeat and Ig domain containing 1

MAG: $\quad$ myelin associated glycoprotein

MBP: $\quad$ myelin basic protein

MHC-II: major histocompatibility complex II

MOG: $\quad$ Myelin-Oligodendrozyten-Glykoprotein

MW: $\quad$ Mittelwert

NAWM: normal appearing white matter

NGF: nerve growth factor

NogoR: neurite outgrowth inhibitor receptor

NT-3: $\quad$ neurotrophin-3

NT-4/5: neurotrophin-4/5

p75 ${ }^{\text {NTR }}$-/-: $\quad$ p75 Neurotrophinrezeptor knockout-Maus

PBA: $\quad$ Paraformaldehyd

PBS: $\quad$ Phosphat-gepufferte Salzlösung (phosphate buffered saline)

PLP: $\quad$ proteolipid protein

SD: $\quad$ Standardabweichung (standard deviation)

Th: $\quad$ T-Helfer-Zelle

TNF- $\alpha$ : Tumor-Nekrose-Faktor-alpha

Trk: tropomyosin-related kinase

VCAM-1: $\quad$ vascular cell adhesion molecule 1

VLA-4: $\quad$ very late activated antigen 4

ZNS: $\quad$ Zentralnervensystem 


\section{$1 \quad$ Einleitung}

\section{$1.1 \quad$ Multiple Sklerose}

Die Multiple Sklerose (MS) ist eine chronisch-entzündliche Erkrankung des zentralen Nervensystems (ZNS) (Gleixner et al. 2009/2010). Kennzeichnend für diese Erkrankung sind entzündliche Entmarkungsprozesse, die im späteren Verlauf zum Untergang von Axonen und neuronalen Zellkörpern führen können (Trapp et al. 1998). Vermutet wird ein autoimmunes Krankheitsgeschehen, das sich häufig im jungen Erwachsenenalter manifestiert. Die hohe Variabilität in der ethnischen und geographischen Verteilung der Erkrankung lässt zudem die Abhängigkeit von einer Vielzahl von Umweltfaktoren vermuten. Auch eine Assoziation mit viralen Infektionen wird in Betracht gezogen. Die MS präsentiert sich mit einer Vielzahl neurologischer Symptome, die sich zum Teil komplett zurückbilden, aber auch persistent sein können. Die momentane Therapiestrategie beruht auf der symptomatischen Kontrolle und Schubprophylaxe. Eine kausale Therapie steht zum jetzigen Zeitpunkt nicht zur Verfügung (Gleixner et al. 2009/2010).

\subsubsection{Epidemiologie}

Die MS weist eine sehr große Variabilität in Bezug auf Inzidenz und Prävalenz auf. Epidemiologische Studien zeigen starke Unterschiede in der geographischen und ethnischen Verteilung der Krankheit auf. Grundsätzlich folgt die Krankheitsprävalenz vom Äquator aus einem Nord-Süd-Gefälle in der nördlichen Hemisphäre und einem Süd-Nord-Gefälle in der südlichen Hemisphäre (Hogancamp et al. 1997). Am höchsten ist sie in Nordamerika, Nordeuropa, Australien und Neuseeland (Poser 1994). Abhängig scheint die Erkrankungswahrscheinlichkeit auch von der ethnischen Herkunft. So erkranken Kaukasier ca. 10mal häufiger als Nicht-Kaukasier. Aber auch unter den Kaukasiern gibt es relevante Unterschiede. So sind Skandinavier besonders anfällig (Page et al. 1993). Doch auch innerhalb von Bevölkerungen mit hoher Erkrankungswahrscheinlichkeit gibt es Gruppen, die ein signifikant niedrigeres Erkrankungsrisiko besitzen. Als Beispiel lassen sich hier die Maoris in Neuseeland und die Aborigines in Australien nennen (Poser 1994). 
Mit einer Inzidenz von 7 auf 100.000 und einer Prävalenz von ca. 150 auf 100.000 Patienten ist die MS die häufigste demyelinisierende, entzündliche Erkrankung des ZNS (Hein und Hopfenmüller 2000). Die Geschlechterverteilung der Krankheit wird mit einem Verhältnis von Frauen zu Männern mit 2,3:1 angegeben (Alonso und Hernán 2008).

\subsubsection{Verlaufsformen}

Durch die heterogene Erscheinungsform der MS ist es nötig, die verschiedenen klinischen Verläufe zu kategorisieren. Diese Verlaufsformen unterscheiden sich stark hinsichtlich der Prognose, des Erkrankungsalters, der Geschlechterverteilung (Lublin und Reingold 1996) und des Ansprechens auf verschiedene Therapiestrategien (Bitsch und Brück 2002).

Die mit ca. 80\% häufigste Verlaufsform ist die schubförmig remittierende MS (relapsingremitting MS, RR-MS) (Bitsch und Brück 2002). Diese Verlaufsform ist gekennzeichnet durch einen schubförmigen Verlauf mit teils kompletter, teils inkompletter Rückbildung der Symptomatik. In den Intervallen zwischen den Schüben sind die Patienten meistens vollständig beschwerdefrei.

Diese Verlaufsform geht im Krankheitsverlauf mit einer Wahrscheinlichkeit von über 80\% in die sekundär progressive MS (SP-MS) über (Bitsch und Brück 2002). In dieser Verlaufsform ist es möglich, dass weiterhin Schübe auftreten. Typisch ist ein progredienter Verlauf ohne komplette Rückbildung der Symptomatik und persistenter Beeinträchtigung des Patienten.

Einen grundsätzlich anderen Verlauf nimmt die primär progressive MS (PP-MS), die ca. $10 \%$ bis 20\% der Patienten betrifft (Bitsch und Brück 2002). Charakteristisch ist hier ein chronisch progredienter Krankheitsverlauf ohne typisches Schubmuster. Diese Verlaufsform hat normalerweise eine schlechtere Prognose.

Die progressiv schubförmige MS (progressive relapsing MS, PR-MS) ist eine seltene Verlaufsform. Sie zeigt einen chronischen Verlauf und zusätzlich treten sich teilweise wieder zurückbildende Krankheitsschübe auf. In Hinsicht auf die Prognose scheint die PR-MS der RR-MS ähnlich zu sein (Bitsch und Brück 2002). 


\subsubsection{Klinik}

Die symptomatische Ausprägung der Erkrankung ist abhängig von der Lokalisation der Entzündungsherde im ZNS. Häufige Erstsymptome sind einseitige Visusstörungen aufgrund einer Retrobulbärneuritis und Sensibilitätsstörungen, insbesondere der Verlust des Vibrationssinns an den unteren Extremitäten (Mumenthaler und Mattle 2008). Mit ca. 75\% ist das Fatigue-Syndrom (abnorme allgemeine Schwäche) eines der häufigsten Symptome der MS (Minden et al. 2006). Weitere vermehrt auftretende Symptome sind Kleinhirnschädigungssymptome (Intentionstremor, Gangataxie und Sprachstörungen) spastische Paraparesen und Miktions-/Defäkationsstörungen (Mumenthaler und Mattle 2008). Auch neuropsychiatrische Symptome wie Depressionen (Sadovnick et al. 1996), unangemessene Euphorie (Mumenthaler und Mattle 2008) und Psychosen (Patten et al. 2005) können auftreten.

Aufgrund der vielfältigen Symptomatik wurden Einteilungssysteme wie der expanded disability status scale (EDSS) oder multiple sclerosis severity score (MSSS) entwickelt (Roxburgh und Seaman 2005). Anhand dieser Scores wird versucht den Grad der Behinderung durch die Erkrankung in verschiedene Stadien zu unterteilen, um eine Vergleichbarkeit trotz der Symptomvielfalt zu schaffen.

\subsubsection{Diagnostik}

Um der heterogenen Erscheinungsform der MS Rechnung zu tragen, setzt die heutige Diagnostik auf das Zusammenspiel mehrerer Untersuchungsmodalitäten. Als aktueller Goldstandard gelten die überarbeiteten McDonald-Kriterien aus dem Jahre 2010 (McDonald et al. 2001; Polman et al. 2011). Das wichtigste Standbein der Diagnose ist die ausführliche neurologische Untersuchung. Bei Unklarheiten werden weitere paraklinische Untersuchungen herangezogen. Hier spielt besonders die Magnetresonanztomographie (MRT) eine tragende Rolle zur Erkennung der zeitlichen und räumlichen Dissemination der Läsionsherde im ZNS. Auch die Untersuchung des Liquor cerebrospinalis auf oligoklonale Immunglobulin G (IgG)-Antikörper kann wegweisend sein. Des Weiteren können visuell evozierte Signale (VES) diagnostisch hilfreich sein (Polman et al. 2005). 


\subsubsection{Histopathologie}

MS-Entzündungsherde können histopathologisch sowohl in der weißen als auch in der grauen Substanz gefunden werden. Diese Entzündungsherde sind durch Makrophagen-, T-Lymphozyten-, B-Lymphozyteninfiltrate, Demyelinisierung und reaktive gliale Narbenbildung gekennzeichnet (Lassmann et al. 2001). Auch axonaler Schaden ist schon während der Frühphase der Entzündung zu beobachten, der in chronischen Erkrankungsstadien zu axonalem Verlust führen kann (Ferguson et al. 1997). Während das histologische Muster der unterschiedlichen demyelinisierenden Läsionen im gleichen Patienten sehr ähnlich ist, bestehen erhebliche Unterschiede im Vergleich zu anderen Patienten. Aufgrund dieser Beobachtung wurden die verschiedenen Demyelinisierungsmuster in 4 Typen unterteilt (Lassmann et al. 2001):

Typ I: $\quad$ Die Läsionen sind hauptsächlich perivenös verteilt und breiten sich radial aus. Die entzündlichen Infiltrate bestehen hauptsächlich aus T-Zellen und Makrophagen. Die Demyelinisierung ist am ehesten auf von Makrophagen und T-Zellen freigesetzte Mediatoren zurückzuführen.

Typ II: $\quad$ Neben T-Zell- und Makrophagen-Infiltration finden sich zusätzlich Immunglobuline und aktivierte Komplementfaktoren, welche die Phagozytose von Myelin vermitteln.

Typ III: Dieses Läsionsmuster ist häufig in der Nähe von kleinen Gefäßen zu finden (small vessel vasculitis). Auch hier sind Makrophagen und T-Zellen die führenden Entzündungszellen. Für die Myelin- bzw. Oligodendrozytenschädigung wird u.a. eine ischämische Ursache vermutet.

Typ IV: Im Vordergrund stehen Oligodendrozytendegeneration am Rande der Läsionen und eine damit verbundende sekundäre Demyelinisierung. Vermutet wird ein genetischer oder erworbener Defekt im Metabolismus der Oligodendrozyten. 
Für den Großteil der Patienten wurde keine Korrelation zwischen histologischem Schädigungsmuster und dem klinischen Verlauf gefunden (Lassmann et al. 2001).

\subsection{6 Ätiologie und Pathophysiologie}

Nach der aktuellen Meinung der Wissenschaft handelt es sich bei der Multiplen Sklerose um eine Autoimmunerkrankung. Als eine wichtige Grundlage für die Entstehung der Erkrankung wird eine genetische Disposition diskutiert. Hinweise dazu liefern epidemiologische Studien, die zeigen, dass genetisch isolierte Bevölkerungsgruppen in Ländern mit hoher Prävalenz ein sehr niedriges Erkrankungsrisiko aufweisen (Poser 1994). Unterstützt wird diese Meinung auch durch Daten aus Zwillingsstudien und Studien über die Erkrankungswahrscheinlichkeiten direkter Verwandter von MSPatienten. So haben Verwandte ersten Grades von Patienten ein 3\% bis 5\%iges Erkrankungsrisiko, das damit $30 \mathrm{x}$ bis $50 \mathrm{x}$ höher ist als das Risiko von $0,1 \%$ der Normalbevölkerung (Sadovnick und Baird 1988). Eineiige Zwillinge erkranken nach Zwillingsstudien mit einer Wahrscheinlichkeit von $21,05 \%$ bis $40 \%$, wohingegen zweieiige Zwillinge ein Erkrankungsrisiko von 0\% bis 4,7\% zeigen. Diese Erkenntnisse deuten auch darauf hin, dass es sich bei der MS um eine polygenetische Erkrankung handelt. Besonders Proteine aus der MHC-Familie scheinen hier eine entscheidende Rolle zu spielen.

Zusätzlich zur genetischen Komponente wird in epidemiologischen Studien der Einfluss von Umweltfaktoren auf die Entstehung der Erkrankung deutlich. So wurde gezeigt, dass erwachsene Immigranten, die aus Ländern mit einer geringen Prävalenz in Länder mit einer hohen Prävalenz umziehen, ihr geringes Risiko beibehalten. Im Gegensatz dazu nehmen Personen, die bei Immigration unter 15 Jahren alt sind, die Erkrankungswahrscheinlichkeit ihres neuen Aufenthaltslandes an. Als mögliche Umweltfaktoren werden Infektionen, Impfungen, Stress, Klima und Essgewohnheiten diskutiert (Marrie 2004).

Vielfach in der Wissenschaft diskutiert wird auch die Rolle eines Vitamin D-Mangels in der Entstehung und Verschlechterung der Symptomatik einer bestehenden MS. Der Zusammenhang erfolgte durch die Beobachtung, dass die Prävalenz der Erkrankung mit zunehmender Entfernung von Äquator und reduzierter UVB-Strahlung ansteigt. 
UVB-Strahlung ist ein wichtiger Faktor in der körpereigenen Synthese von Vitamin D (Solomon und Whitham 2010). In Studien wurde gezeigt, dass die Einnahme von $\geq 400$ IU/d Vitamin D zusätzlich zum regulären Essen eine Reduktion der Erkrankungswahrscheinlichkeit von MS um 40\% bewirkte (Munger et al. 2004). Für eine definitive Therapieempfehlung im Sinne einer Primärprophylaxe ist die aktuelle Studienlage jedoch noch nicht ausreichend. Es wird jedoch empfohlen, dass bei MSPatienten ein nachgewiesener Vitamin D-Mangel ausgeglichen werden sollte (Solomon und Whitham 2010).

Auffällig ist auch die geschlechtliche Verteilung der MS. So sind Frauen ca. 2,3 mal häufiger betroffen als Männer (Alonso und Hernán 2008). Auch bei vielen anderen Autoimmunerkrankungen sind Frauen wesentlich häufiger betroffen (Whitacre 2001). Als Ursache dafür wird der unterschiedliche Hormonhaushalt diskutiert. So sollen die Östrogene der Frau das Immunsystem dahin gehend beeinflussen, dass eher eine Th1dominierte Immunantwort auf einen immunogenen Reiz hin generiert wird (Whitacre 2001). Im Falle einer Schwangerschaft ist besonders im 3. Trimester das Auftreten von Schüben signifikant reduziert. Hingegen besteht in den ersten 6 Monaten post partum eine erhöhte Gefahr für erneute Krankheitsschübe (Damek und Shuster 1997). Dies könnte möglicherweise damit erklärt werden, dass während der Schwangerschaft das Immunsystem in Richtung Th2-Antwort gelenkt wird (Whitacre 2001).

Im Zentrum des akuten Krankheitsschubes stehen Entzündungsherde im ZNS. Die meisten dieser Herde sind in der weißen Substanz zu finden. Dort verteilen sie sich zu ca. $50 \%$ auf das Rückenmark, zu 25\% auf die Nervi Optici, zu 20\% auf den Hirnstamm/Kleinhirn und die periventrikuläre weiße Substanz (Rejdak et al. 2010). Eine weit verbreitete Meinung ist, dass es als erster Schritt zur Entstehung eines solchen Herdes zu einer Einschränkung in der Barrierefunktion der Blut-Hirn-Schranke (BHS) kommt. Möglicherweise kommt es im Zuge einer systemischen Infektion zu einer vermehrten Bildung von Adhäsionsmolekülen an den Endothelien der versorgenden Gefäße, so dass es Leukozyten ermöglicht wird, in das normalerweise immunologisch privilegierte ZNS einzudringen. Sollte sich in diesem Infiltrat eine autoreaktive, gegen Myelinbestandteile gerichtete Immunzelle befinden, kann dies der Auslöser für eine 
Reihe von Vorgängen sein, die in der Bildung einer entzündlich demyelinisierenden Plaque enden (Frohman et al. 2006).

Als wichtigste Mediatoren der Immunantwort bei der MS werden die T-Zellen angesehen. Besonderes Augenmerk liegt in der Wissenschaft auf der Rolle von T-Helfer 1 (Th1), Th17 und regulatorischen T-Zellen ( $\mathrm{T}_{\text {regs }}$ ). Während gesunde Personen die gleiche Anzahl gegen Myelin gerichteter autoreaktiver T-Zellen zu besitzen scheinen, sind diese jedoch im MS-Patienten im aktivierten Stadium der Effektor-T-Zellen zu finden (Frohman et al. 2006). Als mögliche Autoantigene werden verschiedene Myelinbestandteile wie beispielsweise myelin basic protein (MBP), proteolipid protein (PLP) oder myelin oligodendrocyte glycoprotein (MOG) diskutiert.

In der Entstehungsphase der Erkrankung scheinen die cluster of differentiation 4positiven $\left(\mathrm{CD}^{+}\right)$Th1-Zellen eine entscheidende Rolle $\mathrm{zu}$ spielen. Ihnen wird die Fähigkeit zugesprochen, initial die Blut-Hirn-Schranke zu überwinden. Bei diesem Vorgang binden die T-Zellen mit ihren in der Zellmembran befindlichen Integrinen vom Typ very late activated antigen 4 (VLA-4) an von aktivierten Endothelien exprimierte Adhäsionsmoleküle vom Typ vascular cell adhesion molecule 1 (VCAM-1). Perivaskulär erkennen die T-Zellen durch ihren T-Zellrezeptor Antigene, die von antigenpräsentierenden Zellen auf Haupthistokompatibilitätskomplex-II-Molekülen (major histocompatibility complex class II, MHC-II) präsentiert werden (Lodygin et al. 2013). Durch diese Interaktion wird die Ausschüttung pro-inflammatorischer Zytokine wie z.B. Interferon- $\gamma$ (IFN- $\gamma$ ), Interleukin-12 (IL-12) und Tumornekrosefaktor- $\alpha$ (TNF- $\alpha$ ) bewirkt. Diese dienen der Rekrutierung und Aktivierung von weiteren Immunzellen wie z.B. Monozyten/Makrophagen (Fletcher et al. 2010; Murphy et al. 2008).

Aktuell befasst sich die Wissenschaft vermehrt mit der Rolle von CD4+ Th17-Zellen, die ebenfalls eine entscheidende Rolle in der Entstehung von Autoimmunerkrankungen spielen sollen. Diese Untergruppe von Zellen differenziert sich unter dem Einfluss von transforming growth factor- $\beta$ (TGF- $\beta$ ), IL-6 und IL-23 aus naiven CD4+ T-Zellen. Die reifen Th17-Effektorzellen schütten ihrerseits die Zytokine IL-17, IL-9 und TNF- $\alpha$ aus, welche auch in der Pathogenese von MS möglicherweise relevant sind (Fletcher et al. 2010).

Eine weitere wichtige Rolle in Bezug auf die Pathogenese von Autoimmunerkrankungen und damit auch der MS spielen CD4+ $\mathrm{T}_{\text {reg. }}$ Es werden allgemein natürliche $\mathrm{T}_{\text {reg-Zellen }}$ 


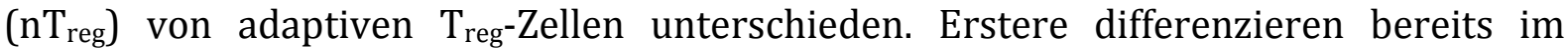

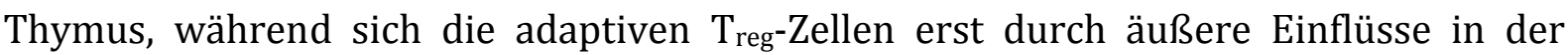
Peripherie aus naiven T-Zellen entwickeln. Die Gruppe der adaptiven $\mathrm{T}_{\text {reg-Zellen lässt }}$ sich wiederum in $\operatorname{Tr} 1-$ sowie Th3-Zellen unterteilen. Die Aktivierung von $\mathrm{nT}_{\text {reg- }}$ sowie

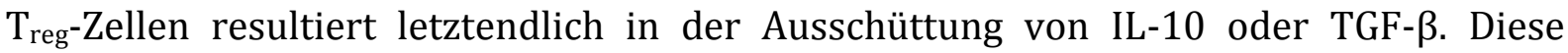
Zytokine wirken jeweils inhibierend auf andere Immunzellen und verhindern damit überschießende Entzündungsreaktionen. Auch wird vermutet, dass besonders $\mathrm{nT}_{\text {reg- }}$ Zellen für die Hemmung von autoreaktiven Immunzellen verantwortlich sind (Murphy et al. 2008). In absoluten Zahlen unterscheiden sich die $\mathrm{nT}_{\text {reg-Zellen von MS-Patienten }}$ nicht von denen gesunder Personen. Jedoch wurde bei MS-Patienten eine verminderte

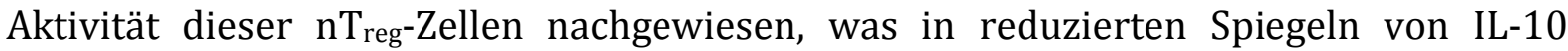
resultierte (Haas et al. 2005; Viglietta et al. 2004).

In der chronisch progredienten Phase der Erkrankung wandelt sich das (histo)pathologische Erscheinungsbild. Die akute Entzündung rückt mehr in den Hintergrund. Es finden sich immer noch demyelinisierte Läsionen mit T-Zellinfiltraten und aktivierten Mikrogliazellen, aktive Entzündungsmerkmale sind jedoch selten. Zusätzlich zu diesen Läsionen finden sich in der normal erscheinenden weißen Substanz (normal appearing white matter, NAWM) diffuse Entzündungsreaktionen mit aktivierten Mikrogliazellen und axonaler Schädigung und Verlust (Lassmann et al. 2007). Zahlreiche Untersuchungen zeigen eine Korrelation zwischen Behinderung und kognitiven Einschränkungen und der sich zum Teil über das gesamte Gehirn erstreckenden Atrophie (Grassiot et al. 2009).

\subsubsection{Therapie}

Die Therapie der MS teilt sich in verschiedene Modalitäten auf und ist im Allgemeinen abhängig von der Verlaufsform der Erkrankung. Die meisten therapeutischen Optionen stehen für die RR-MS zur Verfügung, während sich die chronisch progredienten Formen PP-MS und SP-MS in der Regel therapieresistent zeigen. Grundsätzlich unterscheidet man therapeutisch zwischen einer immunmodulatorischen Schubprophylaxe, einer immunsuppressiven Schubtherapie und der symptomatischen Behandlung von eventuell entstandenen neurologischen Schädigungen (Rejdak et al. 2010). 
In der immunmodulatorischen Therapie kommen die zwei Substanzen Interferon- $\beta$ und Glatirameracetat als Therapie der ersten Wahl zum Einsatz. Beide Medikamente reduzieren die Schubfrequenz um ca. 30\%. Interferon- $\beta$ soll zusätzlich die Krankheitsprogression um 12 Monate hinauszögern (Rejdak et al. 2010), dies konnte für Glatirameracetat nicht nachgewiesen werden (La Mantia et al. 2010). Bei der Behandlung mit Interferon- $\beta$ kann es zur Bildung von neutralisierenden Antikörpern kommen, die die Effizienz der Behandlung reduzieren (Deisenhammer 2009). Sollte die Therapie mit diesen beiden Substanzen keinen Effekt zeigen, kann der Einsatz von weiteren Zweite-Wahl-Medikamenten versucht werden. Der monoklonale Antikörper gegen die VLA-4-Integrine, Natalizumab, zeigte in Studien eine Reduzierung der Schubfrequenz im ersten Jahr um 68\% und eine Unterbrechung der Krankheitsprogression in $42 \%$ der Fälle (Polman et al. 2006). Jedoch wurde nach der Zulassung von Natalizumab das Auftreten von therapieassozierter progressiver multifokaler Leukenzephalopathie (PML) beobachtet, was zum vorübergehenden Entzug der Zulassung führte. Alternativ kann auch eine Behandlung mit anderen immunsuppressiv wirkenden Medikamenten wie Mitoxantron, Azathioprin, Methotrexat oder Cyclophosphamid versucht werden (Rejdak et al. 2010).

In der akuten Schubtherapie ist die Behandlung mit 5x 500mg/d oder 3x 1000mg/d Methylprednisolon (i.v. oder oral) noch immer Therapie der Wahl (Sellebjerg et al. 2005). Sollte sich unter Kortikoidtherapie keine Besserung der Symptomatik einstellen, bietet die Plasmapherese in einigen Fällen eine mögliche Alternative (Schilling et al. 2006).

\subsection{Experimentelle autoimmune Enzephalomyelitis}

Die experimentelle autoimmune Enzephalomyelitis (EAE) ist ein Tiermodell, welches in seiner klinischen Ausprägung, Pathophysiologie und Histopathologie viele Schnittstellen mit einigen Verlaufsformen der MS aufweist. Aus diesem Grund ist die EAE heutzutage eines der wichtigsten Werkzeuge in der Erforschung von Pathomechanismen der MS. Zuerst beschrieben im Jahr 1933 (Rivers et al. 1933), wurde die EAE inzwischen in einer Vielzahl von Tieren erfolgreich induziert. Je nach Spezies ergeben sich verschiedene klinische Bilder, die Teilaspekte der MS widerspiegeln und deren Erforschung möglich 
machen (Gold et al. 2006). Die auf Grund ihrer leichten Haltungsbedingungen und Möglichkeit der genetischen Modifikation aktuell am häufigsten verwendete Spezies ist die Maus.

Induziert wird die EAE durch die Impfung mit verschiedenen Myelinbestandteilen, zum Beispiel dem myelin basic protein (MBP), dem proteolipid protein (PLP) oder dem myelin oligodendrocyte glycoprotein (MOG) in Kombination mit komplettem Freud'schem Adjuvans (Schreiner et al. 2009). Bekannt ist diese Induktion der EAE unter dem Terminus „aktive Immunisierung“.

Im am häufigsten benutzen Mausstamm C57BL/6 sind besonders die MOG 35-55Aminosäuren stark enzephalitogen. Es entwickelt sich ein akuter monophasischer, aber selbstlimitierender Verlauf, der sich klinisch in der aufsteigenden Lähmung des Schwanzes, der Hinterläufe und später der Vorderläufe ausdrückt. Im Gegensatz zur MS befinden sich in der „klassischen EAE“ die entzündlichen Läsionen vorwiegend im Rückenmark und dem Kleinhirn (Schreiner et al. 2009).

Auslöser der Entzündung in der klassischen EAE sind autoimmune CD4+ Th1-Zellen (Ben-Nun et al. 1981; Halachmi et al. 1992). Aktiviert werden diese durch Antigenpräsentierende Zellen (APC) in der Peripherie, die das MOG $_{35-55}$ auf ihren MHC-IIKomplexen präsentieren. Diese Aktivierung ermöglicht es den Immunzellen, die BlutHirn-Schranke zu überwinden und bewirkt die Ausschüttungen der Zytokine IL-2, IFN- $\gamma$ und TNF- $\alpha$. Dies hat wiederum zur Folge, dass weitere T-Zellen und Makrophagen rekrutiert werden und die Myelinscheiden und Axone beschädigt werden (Engelhardt 2008; Tsunoda und Fujinami 1996).

EAE kann auch durch die Übertragung von bereits aktivierten, gegen Myelin gerichteten CD4+ Th1-Zellen induziert werden (Stone 1961). Diese Methode wird als „adoptiver Transfer" bezeichnet.

\section{$1.3 \quad$ Neurotrophine}

Neurotrophine sind eine Gruppe strukturell verwandter Proteine, welche der Familie der Wachstumsfaktoren zugeordnet werden. Nach heutigem Wissen erfüllen sie wichtige Aufgaben im zentralen und peripheren Nervensystem bezüglich der Entwicklung, Differenzierung und Plastizität von Neuronen (Rabizadeh und Bredesen 2003; Lewin und Barde 1996). 
Bis heute wurden 4 verschiedene Neurotrophine beim Säugetier identifiziert (Lewin und Barde 1996):

- nerve growth factor (NGF)

- brain derived neurotrophic factor (BDNF)

- neurotrophin-3 (NT-3)

- neurotrophin-4/5 (NT-4/5)

Alle 4 Neurotrophine weisen Gemeinsamkeiten in ihrer Primär-, Sekundär-, Tertiär- und Quartärstruktur auf. Zum Beispiel liegen alle Neurotrophine als Homodimere vor (Rabizadeh und Bredesen 2003).

Die reifen Neurotrophine entstehen durch die Spaltung von Vorläuferproteinen, den so genannten Proneutrophinen. Die Proneutrophine haben Einfluss auf die Ausbildung der Tertiärstruktur der reifen Neurotrophine, haben aber auch eigenständige Signalwirkung (Lu 2003).

\section{$1.4 \quad$ Neurotrophinrezeptoren}

Zum heutigen Zeitpunkt sind 2 Arten von Neurotrophinrezeptoren bekannt:

- Die zur Familie der Rezeptortyrosinkinasen (Trk) gehörigen TrkA, TrkB und TrkC

- Der niedrig-affine p75-Neurotrophinrezeptor (p75 ${ }^{\mathrm{NTR}}$ ) aus der Tumor-NekroseFaktor-Rezeptor-Superfamilie

Trk binden Neurotrophine mit hoher Affinität, wobei jedes Neurotrophin seinen spezifischen Rezeptor hat. So bindet NGF hauptsächlich an TrkA, BDNF und NT-4/5 bevorzugt an TrkB und NT-3 an TrkC (Benedetti et al. 1993).

Der p75 ${ }^{\text {NTR }}$ bindet alle Neurotrophine mit gleich niedriger Affinität. Proneurotrophine hingegen werden von p75 ${ }^{\mathrm{NTR}}$ hochaffin gebunden (Lee et al. 2001). 


\section{$1.5 \quad$ p75-Neurotrophinrezeptor}

Der p75-Neurotrophinrezeptor wurde erstmals unter dem Namen NGF-Rezeptor (NGFR) beschrieben (Johnson et al. 1986). Er hat eine Masse von 75 kDA und setzt sich aus einer Sequenz von 425 Aminosäuren zusammen. Er besteht aus einer extrazellulären Domäne am NTerminus mit vier cysteinreichen Pseudorepeatregionen, welche die Neurotrophinbindungsstelle beinhalten, einer transzellulären Domäne und einer intrazellulären Domäne mit sechs $\alpha$-Helices am C-Terminus. Posttranslational wird er durch 0 - und N-Glykolysierung und Palmitylierung modifiziert (Rabizadeh und Bredesen 2003).

Der p75 zentralen und peripheren Nervensystems exprimiert, jedoch ist er auch auf vielen Zellen

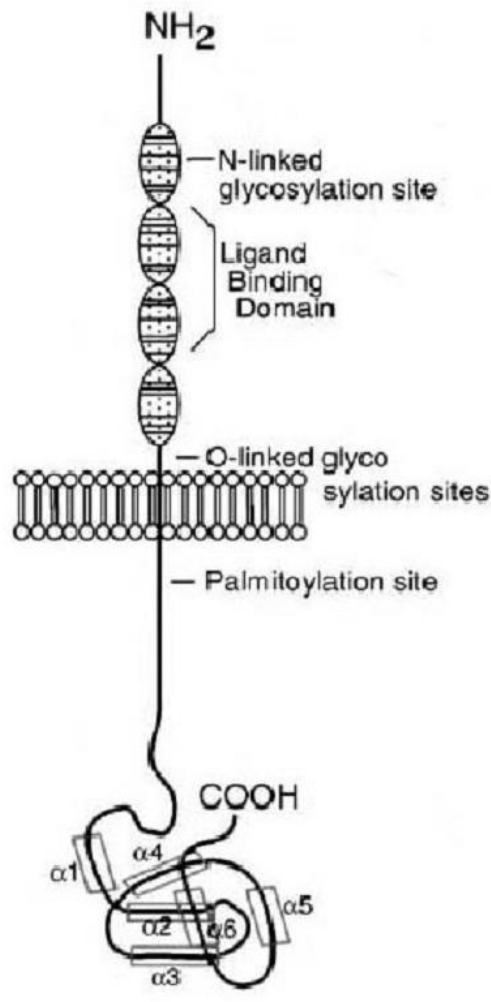

Abb. 1: Schematische Zeichnung des p75 ${ }^{\text {NTR }}$. Mit freundlicher Genehmigung (Rabizadeh et al. 1993).

des Körpers außerhalb des Nervensystems zu finden, wie zum Beispiel den Zellen des Immunsystems, der Hoden, der Bronchiolen, der Niere und des Muskels (Labouyrie et al. 1997; Wheeler et al. 1998). Viele dieser Zellen exprimieren den p75 ${ }^{\mathrm{NTR}}$ während ihrer Entwicklungsphase. Es konnte jedoch gezeigt werden, dass es unter pathologischen Bedingungen zu einer Re-Expression kommt (Dechant und Barde 2002; Passino et al. 2007).

\subsection{1 p75-Neurotrophinrezeptor-vermittelte Signalwirkung}

Die durch den p75 ${ }^{\mathrm{NTR}}$ vermittelte Signalwirkung ist sehr vielfältig. Sie ist abhängig vom gebundenen Neurotrophin, assoziierten Co-Rezeptoren, Neurotrophinkonzentrationen und den intrazellulären signal-vermittelnden Faktoren (Lu et al. 2005).

Die von p75 ${ }^{\text {NTR }}$ vermittelte Signalwirkung hat direkten Einfluss auf das Zellüberleben. Allein exprimiert, induziert p75 ${ }^{\mathrm{NTR}}$ in Abwesenheit von Stimuli eine Reaktionskaskade, die zur Apoptose der jeweiligen Zelle führt. So kommt es zu einer Aktivierung der c-jun 
N-terminalen Kinase (JNK), Freisetzung von Cytochrom c und Aktivierung von Caspase 9 (Rabizadeh et al. 1993; Harrington et al. 2002).

Durch die Bindung von NGF an den p75 ${ }^{\text {NTR }}$ kommt es über die Synthese von nuclear factor $\kappa \mathrm{B}(\mathrm{NF}-\kappa \mathrm{B})$ hingegen zu einer Verhinderung des Apoptoseweges und damit zum Zellüberleben (Rabizadeh und Bredesen 2003; Carter et al. 1996).

Die hochaffine Bindung von Proneurotrophinen führt hingegen zu Apoptose (Lee et al. 2001).

Ist p75 ${ }^{\text {NTR }}$ mit Trk assoziiert, spielt das Mengenverhältnis der beiden Rezeptoren zueinander eine wichtige Rolle für die resultierende Signalwirkung. Bei einem Überwiegen von Trk erhöht sich die Affinität für das Trk-spezifische Neurotrophin, und eine Bindung resultiert im Zellüberleben. Bindet jedoch ein für den Trk nicht spezifisches Neurotrophin (zum Beispiel BDNF bei TrkA) am p75NTR, führt dies zur Apoptose. Überwiegt die Anzahl von p75NTR im Vergleich zu Trk, führt die Bindung eines nicht Trk spezifischen Neurotrophins hingegen zum Zellüberleben.

Im ZNS hemmt p75 ${ }^{\mathrm{NTR}}$ in Assoziation mit neurite outgrowth inhibitor receptor (NogoR) und leucin rich repeat and Ig domain containing 1 (LINGO-1) die Regeneration und Aussprossung von Axonen nach Schädigung. Aktiviert wird dieser Rezeptorenkomplex durch Myelinbestandteile wie myelin associated glycoprotein (MAG) (Wang et al. 2002; Mi et al. 2004).

In manchen Zellpopulationen, wie zum Beispiel den Purkinje-Zellen des Kleinhirns, konnte gezeigt werden, dass die Bindung von NGF an p75 ${ }^{\mathrm{NTR}}$ zu einer vermehrten Expression von $\mathrm{Na}_{v} 1.8$ Natrium-Kanälen führt. Dieser Mechanismus könnte eine wichtige Rolle in der Entstehung von Kleinhirnataxie in der MS und EAE spielen (Damarjian et al. 2004). 


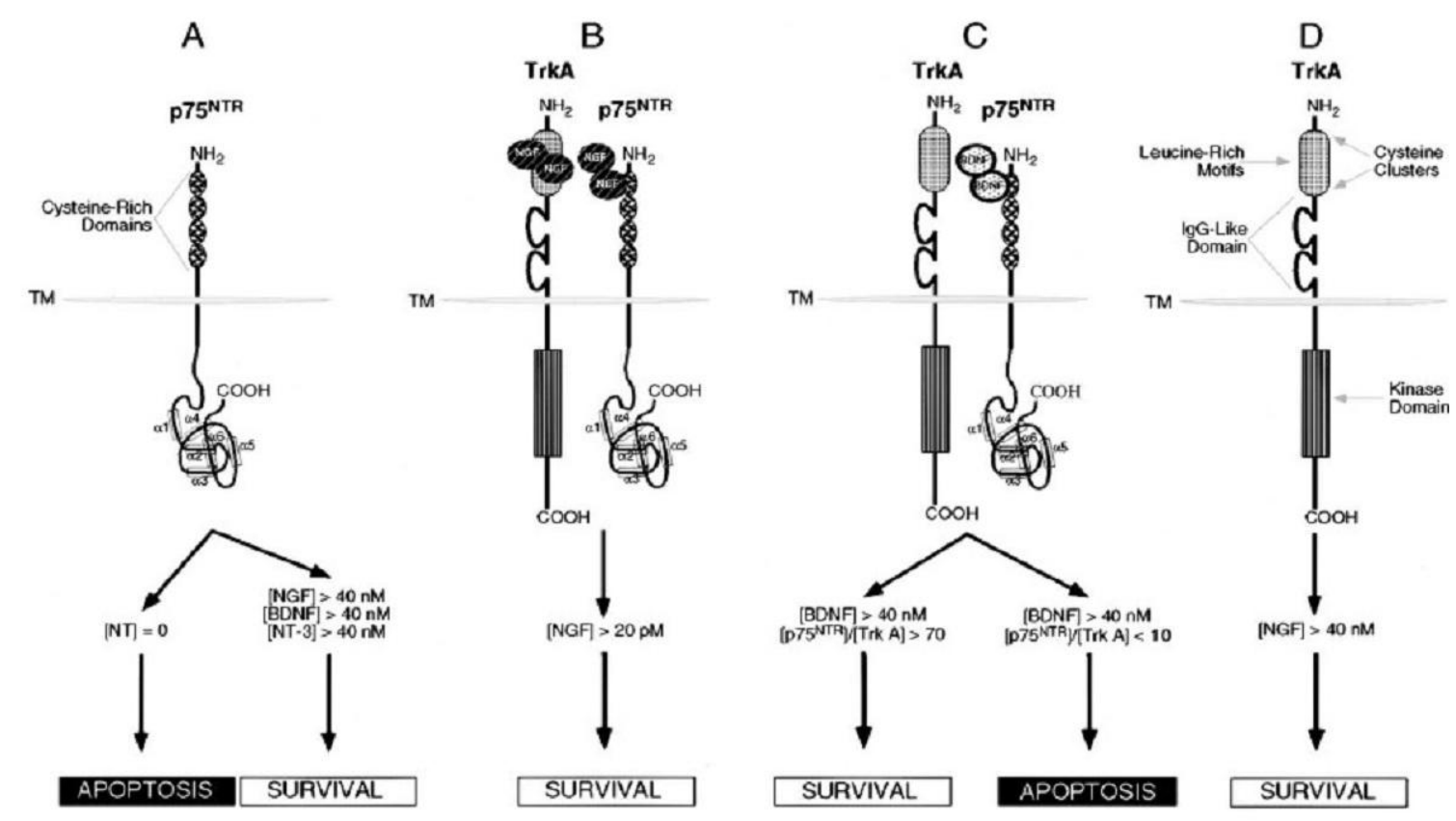

Abb. 2: Schematische Darstellung der p75NTR-vermittelten Signalwirkung in Abhängigkeit vom bindenden Liganden. Mit freundlicher Genehmigung (Rabizadeh et al. 1993).

\subsubsection{Neurotrophin-vermittelte Interaktion zwischen Immunsystem und ZNS}

Neben den bekannten Signalwirkungen auf Zellen des Nervensystems, durch die Bindung von NGF an den Neurotrophinrezeptoren wie p75 ${ }^{\mathrm{NTR}}$, sind inzwischen auch weitere Effekte auf Zellen des Immunsystems identifiziert worden (Aloe et al. 1994). Es wurde festgestellt, dass die Expression der verschiedenen Neurotrophine zum Beispiel bei allergischen Entzündungen deutlich erhöht ist. Inzwischen wurde die Expression von einem oder mehreren Neurotrophinen in fast allen Zellen des Immunsystems beschrieben. Die durch die Neurotrophinrezeptoren vermittelte Signalwirkung reicht von Zellüberleben über Proliferation bis zu Synthese und Ausschüttung von Zytokinen (Nockher und Renz 2006).

\subsection{Fragestellung der vorliegenden Arbeit}

Der Einfluss des p75 ${ }^{\text {NTR }}$ auf den klinischen Verlauf der EAE wurde bereits von mehreren Arbeitsgruppen in den letzten Jahren untersucht. Da der p75 ${ }^{\mathrm{NTR}}$ in verschiedenen Entwicklungsstadien auf vielen Zellen des Körpers, insbesondere dem ZNS und dem Immunsystem exprimiert wird, war es bisher noch nicht gelungen, den genauen Ort der Beeinflussung zu identifizieren. Vermutet wurden eine neuro- bzw. axonoprotektive 
Wirkung auf die Zellen des ZNS sowie möglicherweise auch eine immunregulatorische Wirkung auf die Zellen des Immunsystems.

Um diese beiden Systeme genauer und getrennt voneinander untersuchen zu können, benutzten wir ein murines Knochenmarkschimären-Modell, mit welchem es möglich war, den p75 ${ }^{\text {NTR }}$ gezielt in einem der beiden Kompartimente auszuschalten. Nach der Induktion der EAE wurden die Einflüsse des p75 ${ }^{\mathrm{NTR}}$ auf den klinischen Verlauf, Entzündung, Entmarkung und axonale Schädigung bzw. axonalen Verlust untersucht. Die Induktion der EAE erfolgte entweder durch die aktive Immunisierung mit MOG $35-55^{-}$ Peptid oder durch den adoptiven Transfer von aktivierten, gegen MOG $_{35-55}$ gerichteten T-Zellen.

Von diesem Versuchsaufbau erhofften wir uns, den entscheidenden Ort der Beeinflussung des Verlaufs der EAE durch den p75 ${ }^{\text {NTR }}$ gezielt eingrenzen zu können. 


\section{$2 \quad$ Material und Methoden}

\section{$2.1 \quad$ Material}

\subsubsection{Verwendete Chemikalien}

Tab. 1: Verwendete Chemikalien für histologische und immunhistochemische Färbungen

\begin{tabular}{|c|c|}
\hline Bezeichnung & Hersteller \\
\hline Eosin-G & Merck $^{1}$ \\
\hline Mayers Hämalaun & Merck $^{1}$ \\
\hline Schiff'sches Reagenz & Merck $^{1}$ \\
\hline Formalin 37\% & Merck $^{1}$ \\
\hline Citronensäure & Merck $^{1}$ \\
\hline Salpetersäure $65 \%$ & Merck $^{1}$ \\
\hline Silbernitrat $\left(\mathrm{AgNO}_{3}\right)$ & Roth $^{2}$ \\
\hline Natriumthiosulfat & Merck $^{1}$ \\
\hline Luxol-Fast-Blue (LFB) & BDH Laboratory supplies ${ }^{3}$ \\
\hline Essigsäure $10 \%$ & Merck $^{1}$ \\
\hline PBS & Biochrom $\mathrm{AG}^{4}$ \\
\hline $\mathrm{H}_{2} \mathrm{O}_{2}$ & Merck $^{1}$ \\
\hline Chlorwasserstoff $1 \mathrm{Mol} /$ Liter & Merck $^{1}$ \\
\hline Ethanol & Merck $^{1}$ \\
\hline Xylol & Merck $^{1}$ \\
\hline Iso-Xylol & Merck $^{1}$ \\
\hline Citrat-Puffer $10 \mathrm{mM}$ pH 6 & Merck $^{1}$ \\
\hline FCS (fetales Kälber-Serum) & Biochrom $\mathrm{AG}^{4}$ \\
\hline Ammoniak 32\% & $\operatorname{Merck}^{1}$ \\
\hline Paraformaldehyd (PFA) & $\operatorname{Merck}^{1}$ \\
\hline
\end{tabular}

1) Merck KGaA, Darmstadt, Deutschland 2) Roth, Karlsruhe, Deutschland 3) BDH Laboratory supplies, VWR Int. Ltd., Poole, UK 4) Biochrom AG, Berlin, Deutschland 
Tab. 2: Hergestellte Lösungen für histologische und immunhistologische Färbungen

\begin{tabular}{|c|c|}
\hline Hämatoxilin-Eosin-Färbung & Bestandteile \\
\hline Eosin-Stammlösung 1\% & $\begin{array}{l}\text { - } \text { Eosin-G } \\
\text { - } 40 \mathrm{ml} \text { - A. bidest. } \\
\text { - } 160 \mathrm{ml} \text { - Ethanol } 95 \%\end{array}$ \\
\hline Bielschowsky-Versilberung & Bestandteile \\
\hline Entwicklerlösung & $\begin{array}{l}\text { - } 20 \mathrm{ml} \text { - Formalin } 37 \% \\
\text { - } 100 \mathrm{ml} \text { - A. bidest. } \\
\text { - } \quad 0,5 \mathrm{~g} \text { - Citronensäure } \\
\text { - } \quad 0,1 \mathrm{ml} \text { - Salpetersäure } 65 \%\end{array}$ \\
\hline Silbernitratlösung 20\% & $\begin{array}{l}\text { - } 20 \mathrm{~g} \text { - Silbernitrat } \\
\text { - } 100 \mathrm{ml} \text { - A. dest. }\end{array}$ \\
\hline Natriumthiosulfat-Lösung 2\% & $\begin{array}{l}\text { - } 2 \mathrm{~g} \text { - Natriumthiosulfat } \\
\text { - } 100 \mathrm{ml}-\mathrm{A} \text {. dest. }\end{array}$ \\
\hline LFB-PAS Färbung & Bestandteile \\
\hline Luxol-Fast-Blue-Lösung & $\begin{array}{ll}\text { - } & 1 \mathrm{~g} \text { - Luxol-Fast-Blue } \\
\text { - } & 1000 \mathrm{ml} \text { - Ethanol } 96 \% \\
\text { - } & 5 \mathrm{ml} \text { - Essigsäure } 10 \%\end{array}$ \\
\hline Lithiumcarbonat-Lösung 0,05\% & $\begin{array}{l}\text { - } 50 \mathrm{mg} \text { - Lithiumcarbonat } \\
\text { - } 100 \mathrm{ml} \text { - A. dest. }\end{array}$ \\
\hline Perjodsäure 1\% & $\begin{array}{l}\text { - } 1 \mathrm{ml} \text { - Perjodsäure } \\
\text { - } 100 \mathrm{ml} \text { - A. dest. }\end{array}$ \\
\hline Immunhistochemische Färbungen & Bestandteile \\
\hline $\mathrm{H}_{2} \mathrm{O}_{2} /$ PBS-Lösung & $\begin{array}{l}\text { - } 45 \mathrm{ml}-\mathrm{PBS} \\
\text { - } 5 \mathrm{ml}-\mathrm{H}_{2} \mathrm{O}_{2} 30 \%\end{array}$ \\
\hline FCS/PBS-Lösung 10\% & \\
\hline
\end{tabular}

\subsubsection{Versuchstiere}

Verwendet wurden erstmalig von Lee et al. (Lee et al. 1992) beschriebene p75 NTR -/Knockout-Mäuse, die bis zum Alter von 6-12 Wochen in unserer hauseigenen tierexperimentellen Einrichtung gezüchtet wurden. Als Kontrollgruppe wurden C57 
BL/6-J Wildtyp-Mäuse der Firma Charles River (Charles River, Sulzfeld, Deutschland) verwendet. Die Tiere erhielten freien Zugang zu Futter und Wasser und wurden unter regulierten Licht- und Temperatur-Verhältnissen gehalten. Die Haltung der Tiere und Durchführung der Experimente erfolgte jederzeit nach den Richtlinien der Tierschutzkommission der Universität Göttingen und erfolgte mit der Genehmigung der Bezirksregierung Braunschweig (G97/08).

\section{$2.2 \quad$ Methoden}

\subsubsection{Herstellung von Knochenmarkschimären}

Da der p75NTR sowohl im ZNS als auch im Immunsystem exprimiert wird, wurden knochenmarkschimäre Mäuse hergestellt, um die Rolle des p75 ${ }^{\text {NTR }}$ in den jeweiligen Systemen nach der Induktion der EAE genauer untersuchen zu können.

Die Herstellung von Knochenmarkschimären erfolgte durch Dr. Tobias Dallenga (Dallenga 2010) schrittweise durch die Bestrahlung und anschließende Retransfusion von Spenderknochenmark einer anderen Maus. Durch eine Ganzkörperbestrahlung mit ionisierenden Strahlen in der Abteilung für Strahlentherapie und Radioonkologie (Prof. Dr. Dr. Hess, Prof. Dr. Hille) wurden die besonders sensiblen Zellen des Knochenmarks und Immunsystems abgetötet. Das Spenderknochenmark wurde aus dem Femur des Spendertieres entnommen und aufbereitet. Anschließend wurden ca. 6-8 x106 Zellen in $300 \mu \mathrm{l}$ PBS gelöst i.v. injiziert. Nach der Reperfusion begannen sich die transfundierten/injizierten Knochenmarkszellen neu anzusiedeln. In der Zeit bis zur Ausbildung eines neuen Immunsystems bekamen die Mäuse keim-reduziertes Wasser gemischt mit Neomycin (0,00016\%) zu trinken. 8 Wochen nach Knochenmarkstransplantation wurde deren Erfolg mittels Durchflusszytometrie überprüft und die Induktion der EAE vorgenommen. 


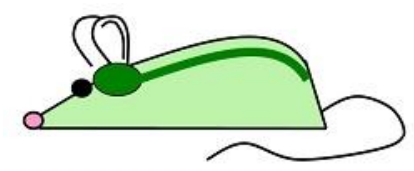

wildtype

CNS p $75+/+$

immune systerm p $75+/+$

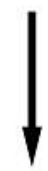

irradiation

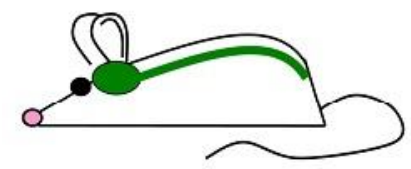

wildtype

CNS p $75+1+$

no immune system

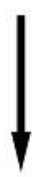

reconstitution

with p $75 \%$ - bone marrow

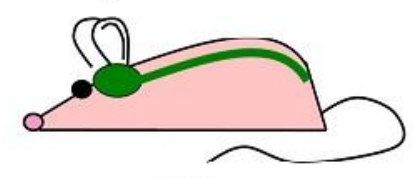

wildtype

CNS p $75+/+$

immune system p 75 -

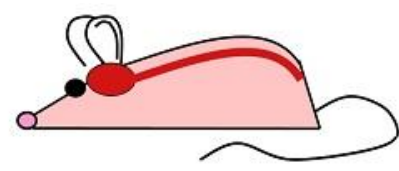

p75 - /-

CNS p $75 \%$

immune system p 75 - -

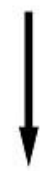

irradiation

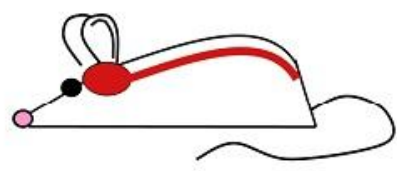

p75 -/-

CNS p75 -/-

no immune system
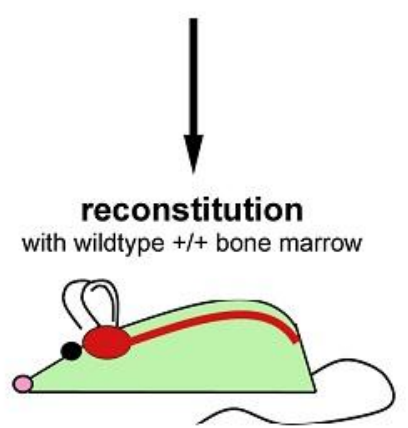

p75 -I-

CNS $75 \%$

immune system p $75+/+$

Abb. 3: Schematische Darstellung der Herstellung von Knochenmarkschimären.

Alle wt-Mäuse besitzen einen funktionierenden p75 NTR. Nach Bestrahlung und Transplantation mit p75 NTR -/- Knochenmark ist der Rezeptor nur noch im ZNS funktionsfähig, jedoch nicht mehr im Immunsystem. Bestrahlte p75 NTR -/- Mäuse besitzen nach Transplantation mit wt Knochenmark einen funktionierenden $\mathrm{p} 75^{\mathrm{NTR}}$ auf den Zellen des Immunsystems, jedoch nicht im ZNS.

Abbildung freundlicherweise bereitgestellt durch Dr. T. Dallenga (Dallenga 2010)

\subsubsection{Aktiv induzierte EAE}

Die Immunisierung der Tiere erfolgte durch die subkutane Injektion von MOG $35-55^{-}$ Peptid in Kombination mit kompletten Freud'schem Adjuvans. Während der Immunisierung wurden die Tiere inhalativ mit Diethylether betäubt. Jeweils am Immunisierungstag und 48 Stunden danach erfolgte die Injektion von 300ng PertussisToxin gelöst in $300 \mu$ l PBS i.p. zur Stimulation der Immunantwort. 


\subsubsection{Adoptiver Transfer (passiv induzierte EAE)}

Die Induktion der EAE erfolgte hier durch die intraperitoneale Injektion von MOG $35-55$ spezifischen $\mathrm{T}_{\mathrm{H}}$ 1-Zell-Klonen (welche freundlicherweise von Dr. med. Stefan Nessler zur Verfügung gestellt wurden). Vor der Injektion wurden die Zellen in vitro mit MOG35-55 restimuliert.

\subsubsection{Beurteilung der EAE-Symptome}

Nach Induktion der EAE wurden die Tiere täglich gewogen und die Ausprägung der neurologischen Symptome beurteilt. Die Beurteilungsskala findet sich in Tab. 3.

Tab. 3: Skala für die Ausprägung der klinischen Symptomatik

\begin{tabular}{cl}
\hline Skala & Symptome \\
\hline 0 & keine Symptome \\
\hline 0,5 & Teilparese des Schwanzes \\
\hline 1 & komplette Parese des Schwanzes \\
\hline 1,5 & leichte Schwäche der Hinterbeine \\
\hline 2 & deutliche Hinterbeinschwäche, watschelnder Gang \\
\hline 2,5 & schwere Hinterbeinschwäche, kein normaler Gang möglich \\
\hline 3 & komplette Hinterbeinparese \\
\hline 3,5 & leichte Vorderbeinschwäche \\
\hline 4 & Tetraparese \\
\hline 4,5 & moribund \\
\hline 5 & tot \\
\hline
\end{tabular}

\subsubsection{Präparation der Mäuse}

Am Ende des Versuchszeitraumes wurden die Mäuse für die weitere histopathologische Untersuchung durch eine intraperitoneale Injektion von Chloralhydrat narkotisiert. Anschließend wurde der Thorax eröffnet, mit einer Kanüle die linke Herzkammer punktiert und anterograd mit PBS perfundiert. Anschließend erfolgte eine weitere Spülung mit 4\% Paraformaldehyd (PFA) zur Fixierung des Gewebes. Danach wurden Gehirn und Rückenmark präpariert, entnommen und über Nacht zur weiteren Fixierung bei $4^{\circ} \mathrm{C}$ in $4 \%$ PFA eingelegt. Es folgte ein Waschschritt mit $4^{\circ} \mathrm{C}$ PBS für eine weitere Nacht. Die Präparate wurden dann in 3-4mm dicke Scheiben geschnitten und in einer 
aufsteigenden Alkoholreihe (50\%, 70\%, 90\%, 100\%) dehydriert und in Paraffin eingebettet. Schließlich wurden mit Hilfe eines Mikrotoms $1 \mu \mathrm{m}$ dicke Schnitte angefertigt und diese für die weitere histologische Färbung auf Objektträger aufgebracht.

\subsubsection{Histologische Routinefärbungen}

\section{$\underline{\text { Hämatoxilin-Eosin }}$}

- Entparaffinieren der Schnitte in Xylol (4 x 5min) und Rehydrierung in absteigender Alkoholreihe (100\%, 90\%, 70\%, 50\%) und A. dest. (jeweils 3min)

- Einstellen der Schnitte in Hämalaun-Lösung nach Mayer (5min)

- Spülen mit A. dest.

- Differenzieren in 1\%igem HCl-Alkohol

- Bläuen in Leitungswasser (10min)

- Einstellen in 1\%ige Eosin-Lösung (5min)

- Spülen mit A. dest.

- Dehydrierung in aufsteigender Alkoholreihe (50\%, 70\%, 90\%; schnell, 100\%; je 3min) und Inkubieren in Xylol (4 x 3min)

- Eindeckeln der Schnitte

\section{Bielschowsky-Versilberung}

- Aufbringen der Paraffin-Schnitte auf silanisierte Objektträger

- Entparaffinieren in Xylol (4 $\mathrm{x}$ 5min) und Rehydrierung in absteigender Alkoholreihe (je 3min)

- Einstellen in 20\%ige Silbernitrat-Lösung (20min)

- Spülen mit A. bidest.

- Tropfenweise Hinzufügen von 32\%igem Ammoniak in die Silbernitrat-Lösung, bis der entstandene Niederschlag verschwindet

- Schnitte in dieser Lösung im Dunkeln inkubieren (15min)

- Eine Küvette mit A. bidest. füllen und 3 Tropfen 32\%igen Ammoniak hinzufügen

- Schnitte in dieser Lösung schwenken

- 10 Tropfen Entwicklerlösung zur Silbernitrat-Ammoniak-Lösung hinzufügen

- Schnitte in diese Lösung einstellen ( $<1 \mathrm{~min}$.)

- Stoppen der Reaktion mit A. dest.

- Einstellen der Schnitte in 2\%ige Natriumthiosulfat-Lösung (2min)

- Spülen mit Leitungswasser

- Dehydrierung in aufsteigender Alkoholreihe und Inkubation in Xylol

- Eindeckeln der Schnitte 
LFB-PAS (Luxol-Fast-Blue/Perjodsäure-Schiff) Reaktion

- Entparaffinieren der Schnitte in Xylol (4 $\mathrm{x}$ 5min) und Rehydrieren in absteigender Alkoholreihe (bis 90\%)

- Einstellen der Schnitte in LFB-Lösung und Inkubation bei $60^{\circ} \mathrm{C}$ (24 Std.)

- Weiterführen der Rehydrierung in absteigender Alkoholreihe (bis 70\%)

- Differenzieren der Schnitte durch 0,05\%ige Lithiumcarbonatlösung und 70\%igen Alkohol

- Spülen in A. dest.

- Färben in 1\%iger Periodsäure (5min)

- Spülen in Leitungswasser (5min)

- Gründliches Spülen in A. dest.

- Einstellen in das Schiff'sche Reagenz (20min)

- Spülen in Leitungswasser (5min)

- Einstellen der Schnitte in Hämalaun-Lösung nach Mayer (2min)

- Spülen in A. dest.

- Differenzieren in 1\%igem HCl-Alkohol

- Bläuen in Leitungswasser

- Dehydrieren in aufsteigender Alkoholreihe und Inkubation in Xylol

- Eindeckeln der Schnitte

\subsubsection{Immunhistochemische Färbemethoden}

- Entparaffinieren der Schnitte in Xylol (4 x 10min) und Rehydrieren in absteigender Alkoholreihe (je 5min)

- Spülen mit A. dest.

- Vorbehandlung ist abhängig vom Primärantikörper; meist: Antigendemaskierung durch Einstellen in kochenden Citratpuffer 10mM pH 6 (5 x 3min)

- Spülen mit PBS

- Blockieren der endogenen Peroxidase mit 3\%iger $\mathrm{H}_{2} \mathrm{O}_{2}$ /PBS-Lösung (10min)

- Spülen mit PBS

- Blockieren unspezifischer Bindungsstellen durch 120 $\mu$ 10\%ige FCS/PBS-Lösung (10min)

- Hinzufügen des Primär-Antikörpers (über Nacht bei $4^{\circ} \mathrm{C}$ )

- Spülen mit PBS

- Hinzufügen des Sekundär-Antikörpers, verdünnt auf 1:100 mit 10\%iger FCS/PBS-Lösung (1Std)

- Spülen mit PBS

- Hinzufügen der Avidin-Peroxidase, verdünnt auf 1:1000 (45min)

- Spülen mit PBS

- Hinzufügen von $1 \mathrm{ml}$ 3-3-Diaminobenzidin-Tetrahydrochlorid (DAB)Stammlösung und $16 \mu \mathrm{l} 30 \%$ igem $\mathrm{H}_{2} \mathrm{O}_{2}$; Entwickeln der Schnitte unter Sicht 
- Spülen mit A. dest.

- Einstellen der Schnitte in Hämalaun-Lösung nach Mayer (1min)

- Spülen mit A. dest.

- Dippen in HCl-Alkohol

- Spülen mit Leitungswasser (7min)

- Dehydrierung in aufsteigender Alkoholreihe und Inkubation in Xylol (jeweils $5 \mathrm{~min}$ )

- Eindeckeln der Schnitte

Tab. 4: Liste der verwendeten Primärantikörper

\begin{tabular}{cccc}
\hline Antigen & Spezies & Hersteller & Verdünnung \\
\hline APP & Maus & Chemicon & $1: 3000$ \\
\hline CD3 & Ratte & Serotec & $1: 200$ \\
\hline iNOS & Ratte & Assay Designs & $1: 500$ \\
\hline Mac-3 & Ratte & Becton Dickinson & $1: 200$ \\
\hline S100A9 & Ratte & C. Sorg, Münster & $1: 2000$ \\
\hline
\end{tabular}

Tab. 5: Liste der verwendeten Sekundärantikörper

\begin{tabular}{cclc}
\hline Antigen & Spezies & Hersteller & Verdünnung \\
\hline Maus Ig & Schaf & Amersham & $1: 200$ \\
\hline Ratten Ig & Ziege & Amersham & $1: 200$ \\
\hline
\end{tabular}

\subsubsection{Auswertung}

Mikroskopie

Die gefärbten Schnitte wurden lichtmikroskopisch ausgewertet. Für bestimmte Auszählungen wurden standardisierte Axon- und Zellzählgitter verwendet. Einige Auswertungen erforderten das Abfotografieren von Rückenmarksquerschnitten und die weitere digitale Bearbeitung mit dem Grafikprogramm Cell^F. Die verwendeten Materialien wurden in Tab. 6 auf Seite 26 zusammengefasst.

\section{Hämatoxilin-Eosin}

In der HE-Färbung färben sich durch den basischen Farbstoffanteil Zellkerne und andere intrazelluläre Bestandteile wie z.B. Ribosomen oder Mitochondrien, dunkelblau-violett 
an. Der saure Farbstoffanteil färbt Zytoplasma und Interzellulärbestandteile hellrosapink an. Da sich in der ansonsten relativ zellarmen weißen Substanz des Rückenmarks kernhaltige Entzündungszellen stark abheben, ist diese Färbung gut geeignet, um sich eine Übersicht über die entzündliche Infiltration zu verschaffen. Gezählt werden bei 200facher Vergrößerung die Läsionsherde pro Rückenmarksquerschnitt (inflammatory index).

\section{Bielschowsky-Versilberung}

Durch die Versilberungsmethode nach Bielschowsky werden Axone schwarz angefärbt. Bei 400facher Vergrößerung wird nun durch ein standardisiertes Axonzählgitter die relative Axondichte in einer Rückenmarksläsion bestimmt. Zuvor wird die Axondichte in einem läsionfreien Areal (normal appearing white matter, NAWM) ermittelt und auf 100\% gesetzt. Das Ergebnis dieser Zählung innerhalb der Läsion wird dann als axonale Dichte in Prozent in Relation zur NAWM angegeben.

\section{$\underline{\text { LFB-PAS }}$}

Der LFB Anteil dieser Färbung lagert sich bevorzugt an die Lipoproteine der Markscheiden an und färben sie in ein helles Blau. PAS hingegen färbt Polysaccharide (wie Glykogen), Bindegewebsfasern und Basalmembranen rot an. Durch diesen Kontrast lassen sich entmarkte Bereiche gut von gesunder weißer Substanz abgrenzen. Für die Auswertung wurden alle Rückenmarksquerschnitte pro Objektträger digital fotografiert und mit Hilfe des Programms Cell^ F die Fläche der entmarkten Bereiche im Verhältnis zur Fläche der gesamten weißen Substanz ermittelt.

\section{Immunhistochemische Färbemethoden}

Die Immunhistochemie beruht auf dem Sichtbarmachen von Molekülen durch die Bindung von spezifischen, gegen dieses Antigen gerichteten Antikörpern. Nach der Bindung eines primären Antikörpers an den anzufärbenden Stoff bindet ein sekundärer, biotingekoppelter Antikörper an dessen Fc-Teil. An das Biotin dieses sekundären Antikörpers bindet nun eine Avidin-gekoppelte Peroxidase, die unter Verbrauch von $\mathrm{H}_{2} \mathrm{O}_{2}$ farbiges 3,3'-Diaminobenzidin oxidiert. 
$\underline{\text { APP }}$

Das Amyloid-Vorläufer-Protein (APP) ist ein Protein, das in den Zellkörpern der Neurone produziert und dann durch anterograden, axonalen Transport in die Nervenfortsätze gebracht wird. Bei Schädigung der Axone (z.B. durch Entzündung und Demyelinisierung) wird die Transportfähigkeit eingeschränkt und APP akkumuliert im Axon. Gezählt wurde unter Zuhilfenahme eines standardisierten Zählgitters die Dichte APP-positiver axonaler Sphäroide in den drei größten entmarkten Läsionen pro Objektträger in 400facher Vergrößerung.

\section{$\underline{\mathrm{iNOS}}$}

Die induzierbare NO-Synthase ist ein Enzym, welches für die Spaltung von Arginin zu Citrullin unter Abspaltung von reaktivem NO zuständig ist. In der akuten EAE-Läsion wird iNOS hauptsächlich von aktivierten Makrophagen und Mikrogliazellen exprimiert. Gezählt wurde die Dichte der iNOS-positiven Zellen in den drei größten Läsionen, die vorher in der LFB-PAS Färbung ausgewählt wurden, pro Objektträger in 400facher Vergrößerung.

\section{$\underline{\mathrm{S} 100 \mathrm{~A} 9}$}

Das S100A9 Protein (auch MIF-related protein 14, MBP14) wird vor allem von im Blut zirkulierenden Monozyten und neutrophilen Granulozyten exprimiert. Gewebsmakrophagen stellen die Expression von S100A9 nach einiger Zeit ein, so dass es als Marker für vor kurzem aus dem Blutkreislauf ausgewanderten Monozyten/Makrophagen geeignet ist. Gezählt wurde die Dichte der S100A9-positiven Zellen in den drei größten Läsionen, die vorher in der LFB-PAS Färbung ausgewählt wurden, pro Objektträger in 400facher Vergrößerung.

\section{$\underline{\mathrm{CD} 3}$}

CD3 ist ein Protein, das auf allen Zellen der T-Zellreihe exprimiert wird und dient damit als universeller Marker für diese Zellen. Gezählt wurde unter Zuhilfenahme eines standardisierten Zählgitters die Dichte der CD3-positiven Zellen in den drei größten Läsionen pro Objektträger in 400facher Vergrößerung. 
$\underline{\text { Mac-3 }}$

Mac-3 ist ein Protein, welches zum Anfärben von Makrophagen und Mikroglia dient. Gezählt wurde unter Zuhilfenahme eines standardisierten Zählgitters die Dichte der Mac-3-positiven Zellen in den drei größten Läsionen pro Objektträger in 400facher Vergrößerung.

Tab. 6: Verwendete Geräte und Materialen zur Auswertung und Mikroskopie

\begin{tabular}{ll}
\hline Gerät & Hersteller \\
\hline Lichtmikroskop BX41 und BX51 & Olympus \\
\hline Okulare (10fache Vergrößerung) & Olympus \\
\hline Objektive (40fache und 100fache Vergrößerung) & Olympus \\
\hline Standardisiertes Zellzählgitter & Olympus \\
\hline Standardisiertes Axonzählgitter & Olympus \\
\hline Tabellenkalkulationsprogramm Microsoft Excel & Microsoft Cooperation \\
\hline Cell^F & Olympus Europe \\
\hline
\end{tabular}

\subsubsection{Statistische Auswertung}

Die experimentellen Daten wurden mit dem Programm Microsoft Office Exel 2007 (Microsoft Cooperation, Redmont, USA) erfasst und mit dem Programm Prism 5 (GraphPad Software Inc., CA, USA) statistisch ausgewertet. Alle Daten sind als Mittelwerte mit Standardabweichung angegeben. Für die Vergleiche zwischen mehreren unabhängigen Gruppen wurde die Varianzanalyse ANOVA mit anschließendem Bonferroni-Posttest herangezogen. Als statistisch signifikant wurden $\mathrm{p}$-Werte $\leq 0,05$ angesehen. In den Abbildungen ist das Signifikanzniveau mit Sternchen angegeben $(*=\mathrm{p}<0,05 ; * *=\mathrm{p}<0,01 ; * * *=\mathrm{p}<0,001)$. 


\section{Ergebnisse}

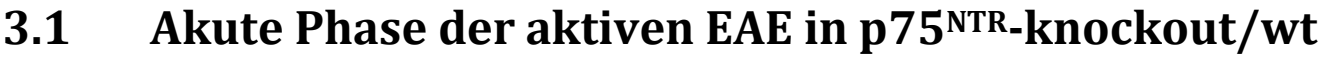 knochenmarkschimären Mäusen}

\subsubsection{Klinische Symptomatik}

Um herauszufinden, ob die beobachtete Verschlimmerung des klinischen Verlaufs einer aktiven EAE in Abwesenheit von p75 ${ }^{\mathrm{NTR}}$ auf dessen Fehlen im Immunsystem oder im ZNS beruht (Copray et al. 2004; Dallenga 2010; Jäger 2007), wurden knochenmarkschimäre Mäuse hergestellt und die EAE durch aktive Immunisierung mit MOG $_{35-55}$ induziert. Verglichen wurden jeweils Tiere mit wt Immunzellen in der

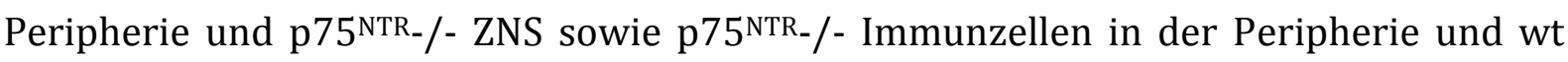

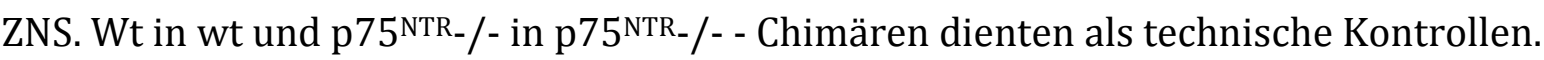

Die klinische Untersuchung zeigte keine Unterschiede im Krankheitsverlauf zwischen den einzelnen Gruppen. Abb. 4 zeigt den Krankheitsverlauf der Tiere, gemessen am Zeitpunkt des Symptombeginns.

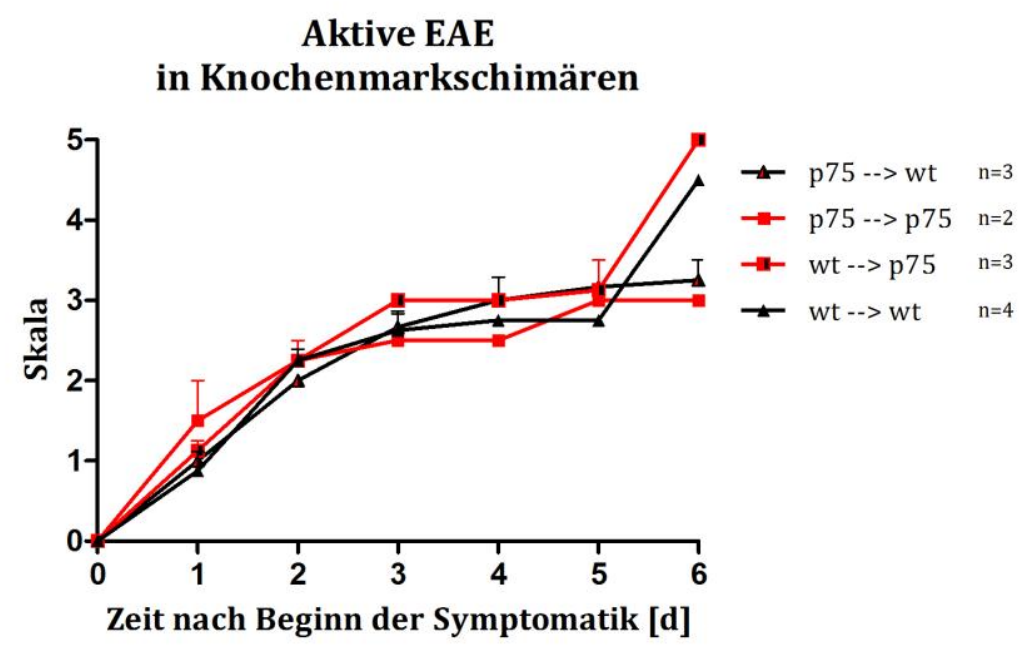

Abb. 4: Krankheitsverlauf in murinen Knochenmarkschimären nach aktiver Immunisierung.

Es sind keine erheblichen Unterschiede im Krankheitsverlauf zwischen den einzelnen Versuchsgruppen zu erkennen. Die Anzahl der Versuchstiere (n) pro Gruppe ist in der Grafik angegeben. 


\subsubsection{Entzündung}

Die Anzahl der perivaskulären und subpialen entzündlichen Infiltrate pro Rückenmarksquerschnitt wurde in der HE-Färbung quantifiziert (inflammatory index, II). Es zeigten sich in allen Versuchsgruppen vergleichsweise wenige entzündliche Infiltrate pro Rückenmarksquerschnitt. Es wurden keine signifikanten Unterschiede beobachtet (II, p75 NTR $-/-\rightarrow$ p75 ${ }^{\mathrm{NTR}}-/-2,97+/-0,19$ (MW+/-SD) Infiltrate pro RMQuerschnitt, p75NTR -/- $\rightarrow$ wt 3,72 +/- 0,21 Infiltrate pro RM-Querschnitt, wt $\rightarrow$ p75NTR -/- 3,67 +/- 0,5 Infiltrate pro RM-Querschnitt, wt $\rightarrow$ wt 3,39+/- 1,37 Infiltrate pro RMQuerschnitt; $F(3,8)=0,36 ; p=0,78$; ANOVA, Bonferroni-Posttest)(Abb. 5).

\section{Entzündungsindex}

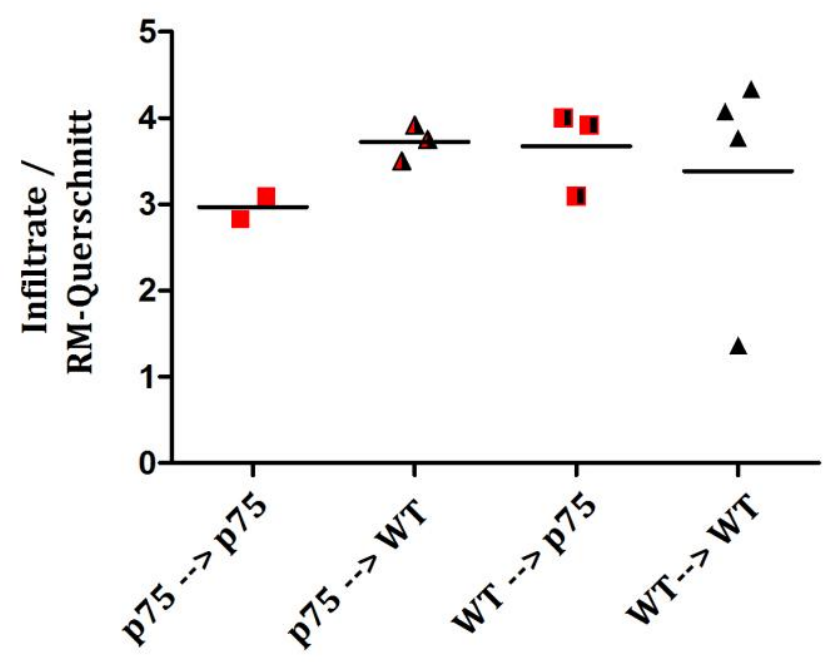

Abb. 5: Entzündungsindex in der akuten Phase nach der aktiven Immunisierung von murinen Knochenmarkschimären.

Keine signifikanten Unterschiede in der Anzahl von entzündlichen Infiltraten pro Rückenmarksquerschnitt zwischen den Versuchsreihen (ANOVA, Bonferroni-Posttest). 


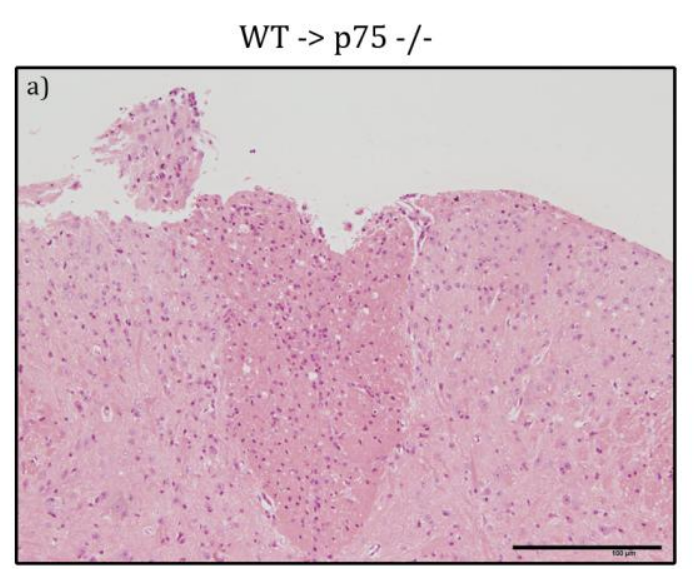

p75 -/- -> p75 -/-

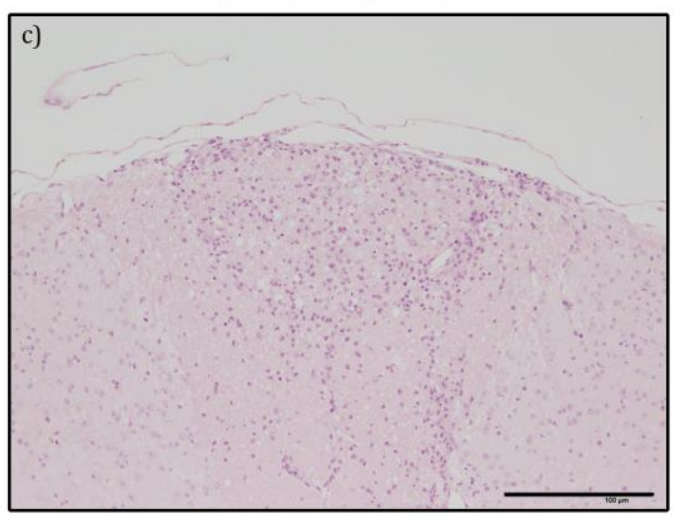

p75 -/- -> WT
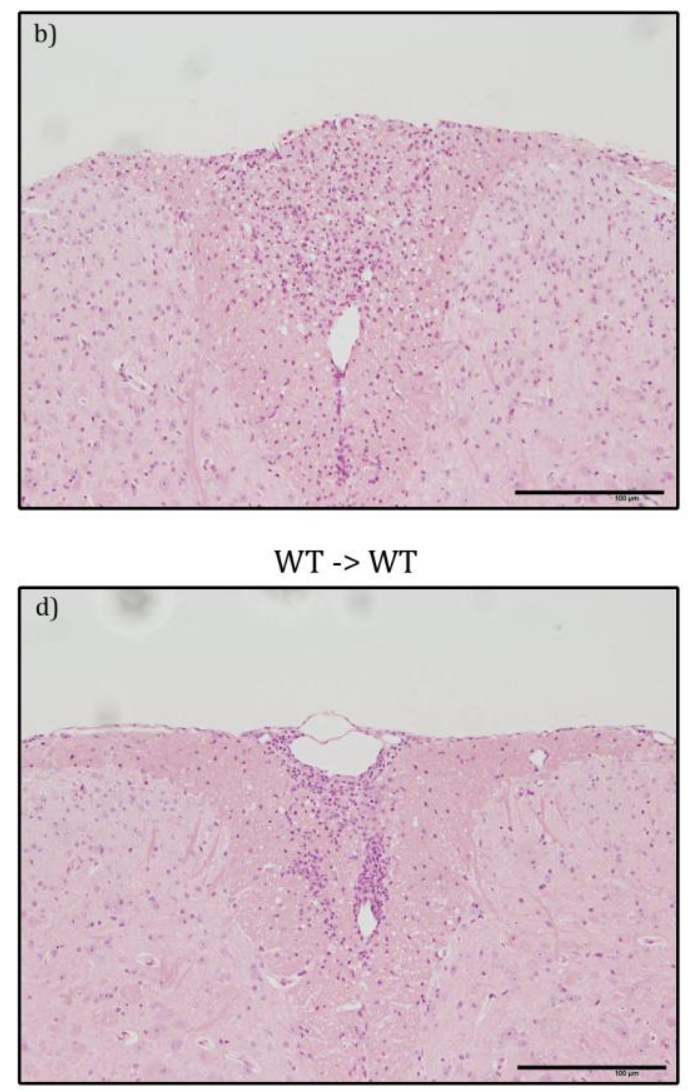

Abb. 6: Ausmaß der entzündlichen Infiltration in p75 ${ }^{\text {NTR }}$-knockout/wt knochenmarkschimären Mäusen.

Keine Unterschiede im Ausmaß der entzündlichen Infiltration zwischen den Versuchsgruppen (Balken: $200 \mu \mathrm{m})$

\subsubsection{Analyse der Akuität der Entzündung}

Als Marker für die Akuität der Entzündung wurden immunhistochemische Färbungen gegen iNOS zur Darstellung von Makrophagen durchgeführt. Diese Makrophagen werden durch Interferon- $\gamma$ aktiviert und schütten daraufhin axonotoxisches NO aus.

S100A9 dient zur Darstellung von frisch aus der Peripherie eingewanderten Granulozyten und Makrophagen. Die Auswahl der Läsionen erfolgte in der LFB-PAS Färbung. In der semiquantitativen Auswertung zeigten sich insgesamt mehr S100A9positive Granulozyten im Vergleich zu iNOS-positiven Makrophagen. Innerhalb der Versuchsgruppen fanden sich hingegen keine wesentlichen Unterschiede hinsichtlich der Expression von iNOS und S100A9 und somit der Akuität der Entzündung. 
Tab. 7: Semiquantitative Auswertung von S100A9

\begin{tabular}{ll}
\hline Versuchsgruppe & Semiquantitative Auswertung S100A9 \\
\hline p75 $\rightarrow$ p75 & ++ \\
\hline p75 $\rightarrow$ wt & + \\
\hline wt $\rightarrow$ p75 & ++ \\
\hline wt $\rightarrow$ wt & ++ \\
\hline$+=$ wenige positive Zellen, $++=$ viele positive Zellen,,+++ sehr viele positive Zellen
\end{tabular}

Tab. 8: Semiquantitative Auswertung von iNOS

\begin{tabular}{ll}
\hline Versuchsgruppe & Semiquantitative Auswertung iNOS \\
\hline $\mathrm{p} 75 \rightarrow \mathrm{p} 75$ & $(+)$ \\
\hline $\mathrm{p} 75 \rightarrow \mathrm{wt}$ & 0 \\
\hline $\mathrm{wt} \rightarrow \mathrm{p} 75$ & + \\
\hline $\mathrm{wt} \rightarrow \mathrm{wt}$ & $(+)$ \\
\hline $\begin{array}{l}\text { = keine positiven Zellen, }(+)=\text { sehr wenig positive Zellen, + = wenige positive Zellen, }++ \text { = viele positive Zellen, }+++=\text { sehr viele } \\
\text { positive Zellen }\end{array}$
\end{tabular}

\subsubsection{Axonale Schädigung}

Als Hinweis für einen akuten axonalen Schaden wurde eine immunhistochemische Färbung APP-positiver ( $\left.\mathrm{APP}^{+}\right)$Axone angefertigt. In den ausgewählten Läsionen konnten keine signifikanten Unterschiede zwischen den Versuchsgruppen gefunden werden $\left(\right.$ p75 ${ }^{\mathrm{NTR}}-/-\rightarrow$ p75 ${ }^{\mathrm{NTR}}$-/- $1622+/-346(\mathrm{MW}+/-\mathrm{SD})$ APP+ Axone pro mm², p75 ${ }^{\mathrm{NTR}}-/-\rightarrow$ wt $1801+/-134 \mathrm{APP}^{+}$Axone pro $\mathrm{mm}^{2}$, wt $\rightarrow$ p75 $\mathrm{NTR}^{\mathrm{NT}}$ /- $1805+/-221 \mathrm{APP}^{+}$Axone pro $\mathrm{mm}^{2}$, wt $\rightarrow$ wt $1788+/-271 \mathrm{APP}^{+}$Axone pro $\mathrm{mm}^{2} ; \mathrm{F}(3,8)=0,29 ; \mathrm{p}=0,83 ;$ ANOVA, Bonferroni-Posttest)(Abb. 7). 


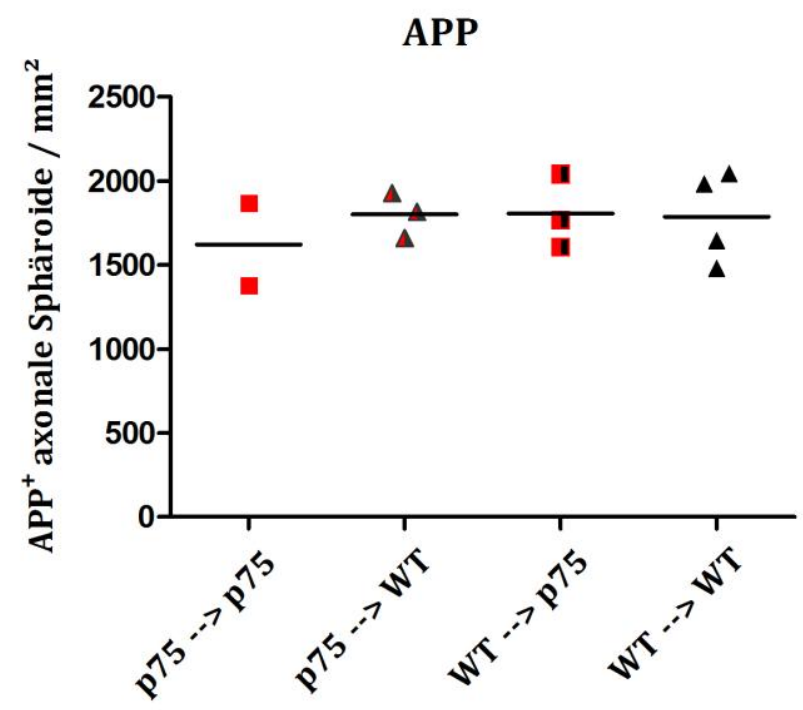

Abb. 7: Axonaler Schaden in der akuten Phase nach der aktiven Immunisierung von murinen Knochenmarkschimären.

Kein signifikanter Unterschied in der Dichte von $\mathrm{APP}^{+}$-Axonen in den Läsionen zwischen den Versuchsreihen (ANOVA, Bonferroni-Posttest).
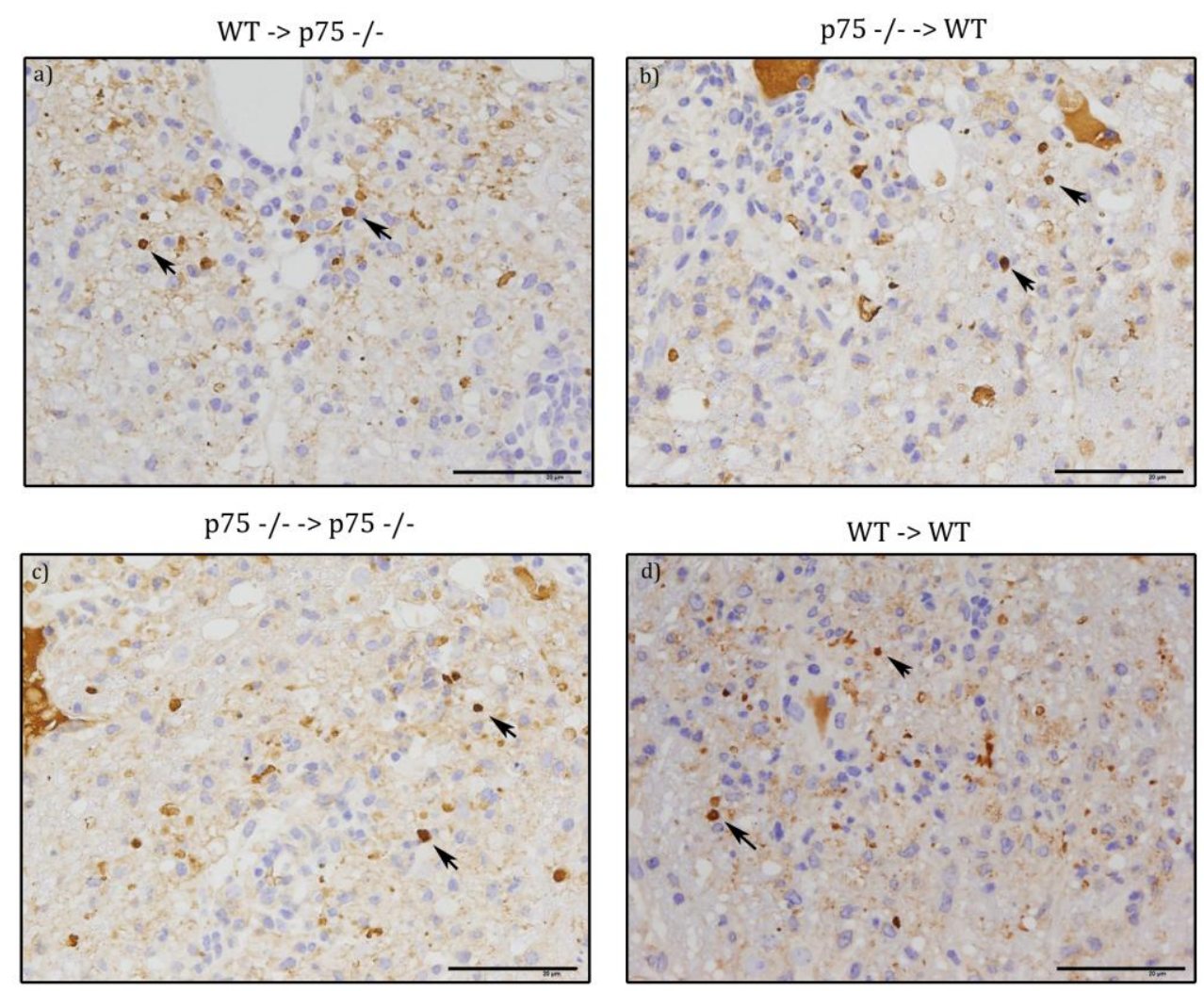

Abb. 8: Ausmaß der axonalen Schädigung in p75 $^{\text {NTR }}$-knockout/wt knochenmarkschimären Mäusen.

Keine Unterschiede in der Dichte der APP+-Sphäroide zwischen den Versuchsgruppen (Balken: $50 \mu \mathrm{m}$ ) 


\subsubsection{Axonaler Verlust}

Die Höhe des axonalen Verlustes in den Läsionen, dargestellt als axonale Dichte, wird durch die Bielschowsky-Versilberung gezeigt. Das Ergebnis dieser Auswertung wurde als axonale Dichte innerhalb der Läsion in Prozent der axonalen Dichte in der NAWM angegeben. Analog zum axonalen Schaden finden sich ebenfalls keine signifikanten Unterschiede im axonalen Verlust zwischen den Versuchsgruppen (p75 ${ }^{\mathrm{NTR}}-/-\rightarrow$ p75 ${ }^{\mathrm{NTR}}$ -/- 52,5 +/- 4,95\% (MW+/-SD), p75 ${ }^{\mathrm{NTR}}-/-\rightarrow$ wt 54,3 +/- 16,5\%, wt $\rightarrow$ p75 ${ }^{\mathrm{NTR}}-/-51+/-$ 10,4\%, wt $\rightarrow$ wt $45+/-12,73 \% ; \mathrm{F}(3,8)=0,36 ; \mathrm{p}=0,78$; ANOVA, Bonferroni-Posttest)(Abb. 9).

\section{Bielschowsky}

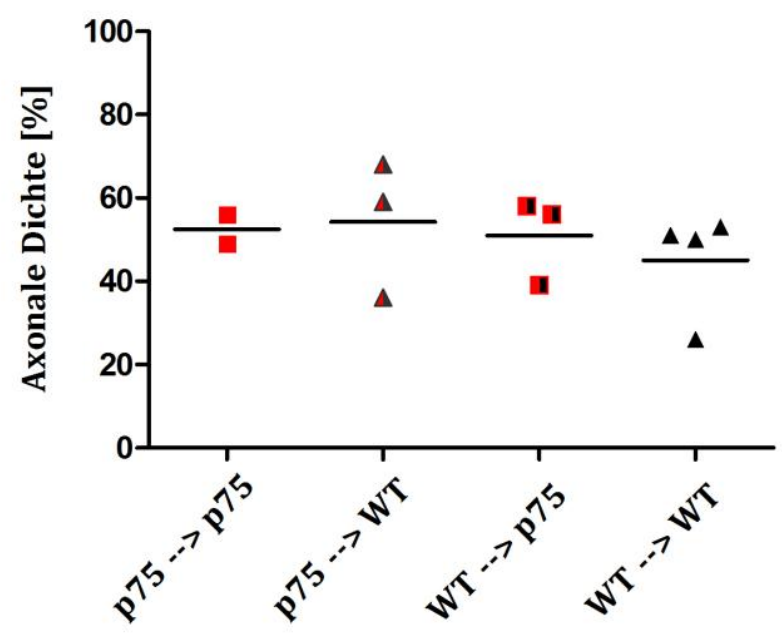

Abb. 9: Axonaler Verlust in der akuten Phase nach der aktiven Immunisierung von murinen Knochenmarkschimären.

Keine signifikanten Unterschiede hinsichtlich des axonalen Verlustes in den Läsionen zwischen den Versuchsgruppen (ANOVA, Bonferroni-Posttest). 

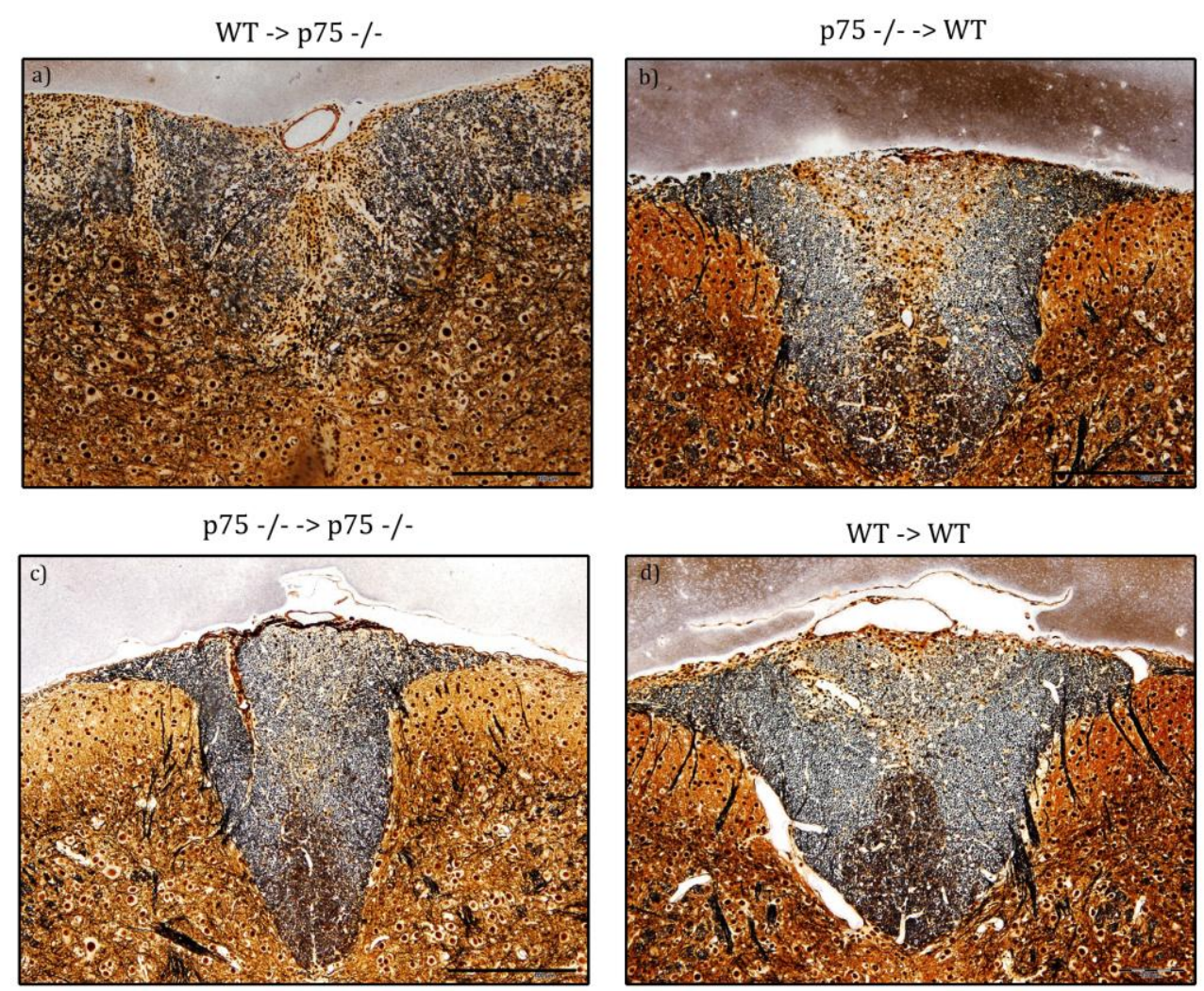

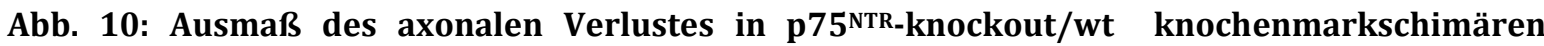
Mäusen.

Keine Unterschiede in der Höhe des axonalen Verlustes zwischen den Versuchsgruppen (Balken: $200 \mu \mathrm{m})$

\subsubsection{Entmarkung}

Um das Ausmaß der Demyelinisierung zu zeigen, wurde eine LFB-PAS-Färbung vorgenommen. Angegeben sind die durchschnittlichen Flächen der entmarkten weißen Substanz in Prozent bezogen auf die gesamte weiße Substanz. Es zeigten sich keine signifikanten Unterschiede in der flächigen Entmarkung zwischen den Versuchsgruppen

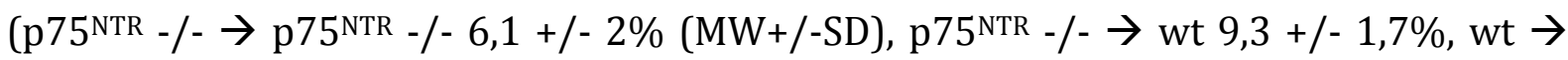
p75 ${ }^{\text {NTR }}-/-6,5+/-1,8 \%$, wt $\rightarrow$ wt 5,2 +/- 2,3\%; F(3,8)=2,46; p=0,14; ANOVA, BonferroniPosttest)(Abb. 11). 


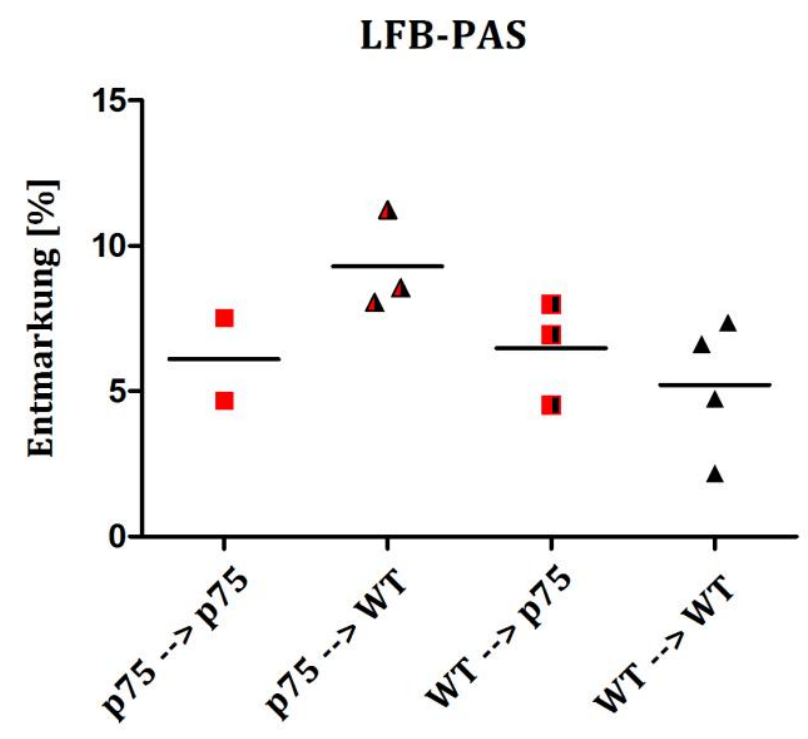

Abb. 11: Demyelinisierte Fläche in Rückenmarksquerschnitten in der akuten Phase nach der aktiven Immunisierung von murinen Knochenmarkschimären.

Keine signifikanten Unterschiede zwischen den Versuchsgruppen im Bezug auf die Größe der entmarkten Fläche in \% an der gesamten weißen Substanz (ANOVA, Bonferroni-Posttest).
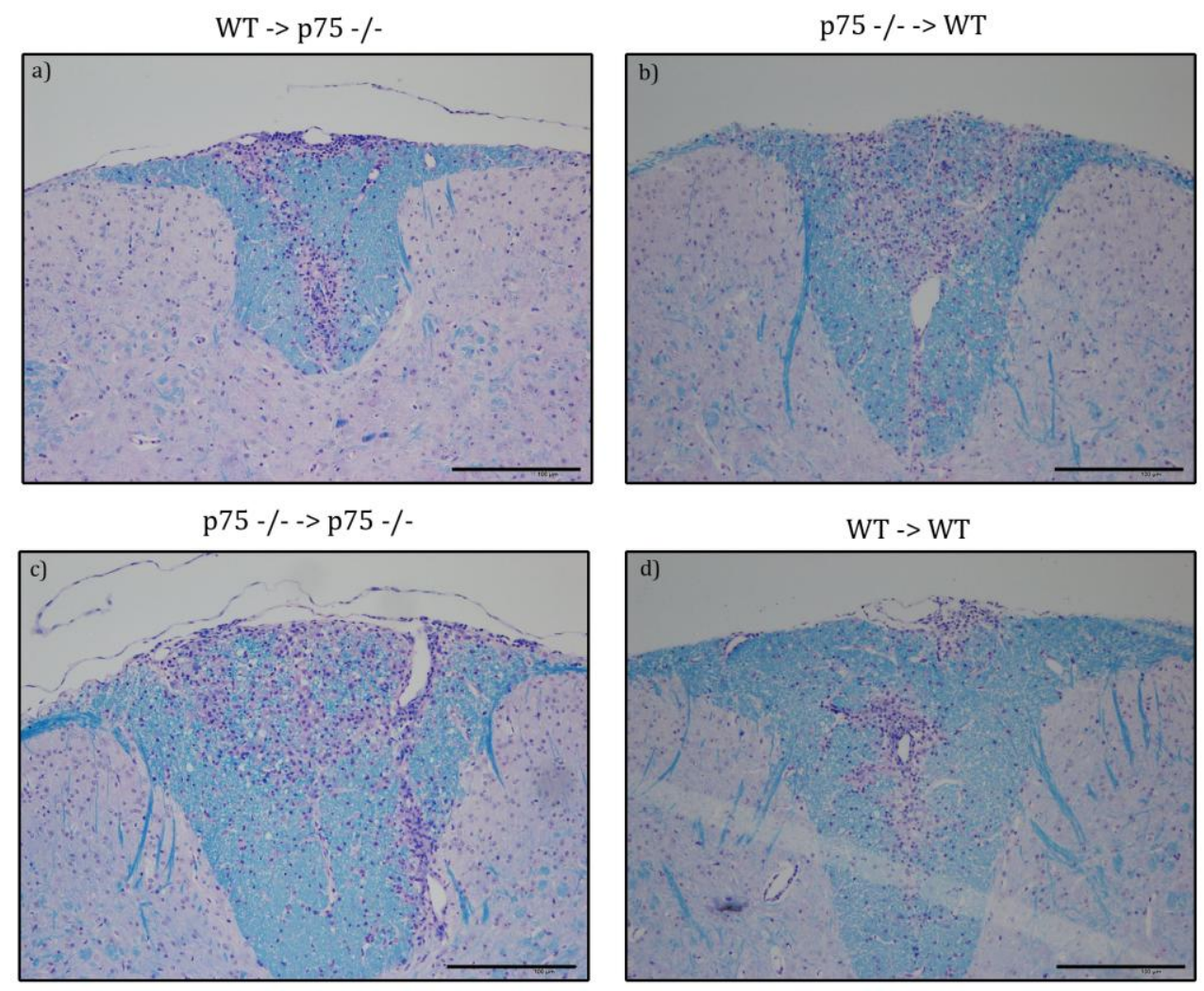

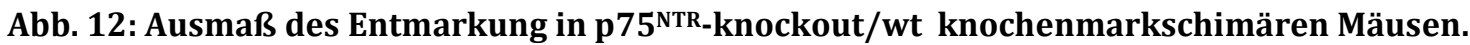

Keine Unterschiede im Ausmaß der Entmarkung zwischen den Versuchsgruppen (Balken: 200 $\mu \mathrm{m}$ ) 


\subsection{Chronische Phase der aktiven EAE in p75 ${ }^{\text {NTR-knockout/wt }}$ knochenmarkschimären Mäusen}

\subsubsection{Klinische Symptomatik}

Nach der Induktion der EAE zeigten sich an Tag 51 eine signifikant schwerere Ausprägung der klinischen Symptomatik in den wt $\rightarrow$ wt Chimären (2,9 +/- 0,2 (MW+/SD)) verglichen mit den p75 ${ }^{\mathrm{NTR}}$-/- $\rightarrow$ p75 ${ }^{\mathrm{NTR}}$-/- Chimären $(2,2+/-0,3$ (MW+/-SD), $\mathrm{p}<0,05$, ANOVA, Bonferroni-Posttest) bzw. den wt $\rightarrow$ p75 $5^{\text {NTR }}$-/- Chimären $(2,+/-0,2$ $(\mathrm{MW}+/-\mathrm{SD}) \mathrm{p}<0,05 ; \mathrm{F}(3,11)=6,55 ; \mathrm{p}=0,0084 ;$ ANOVA, Bonferroni-Posttest). Die p75 /- $\rightarrow$ p75 ${ }^{\text {NTR }}$-/- Chimären zeigten einen verspäteten Krankheitsbeginn (Abb. 13).

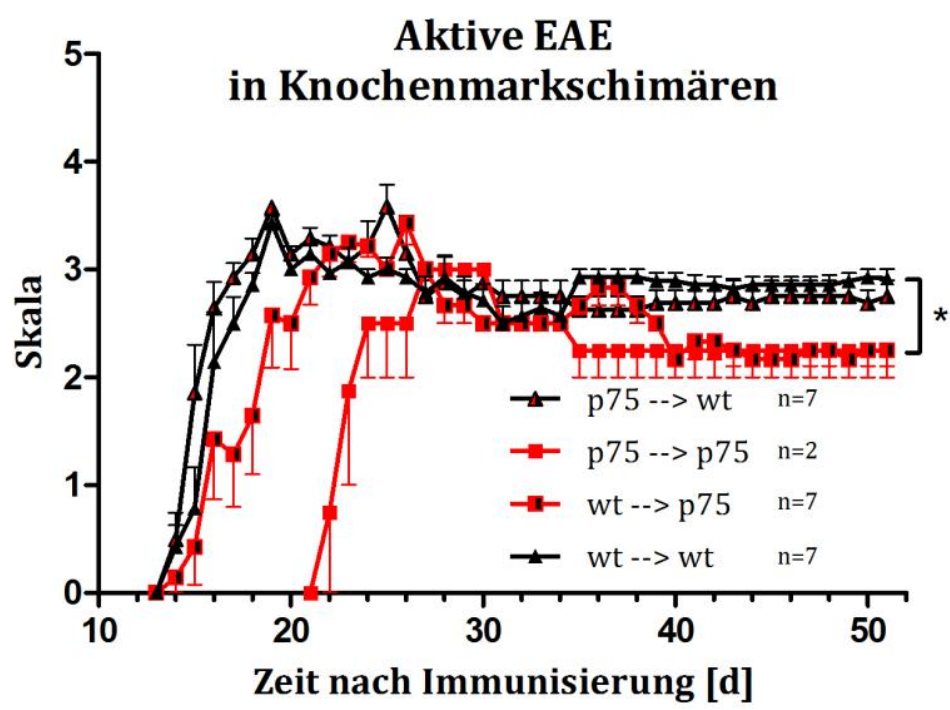

Abb. 13: Krankheitsverlauf in der chronischen Phase nach der aktiven Immunisierung von murinen Knochenmarkschimären.

An Tag 51 zeigen sich signifikante Unterschiede in der Ausprägung der klinischen Symptome zwischen den wt $\rightarrow$ wt Chimären und den p75 NTR $-/-\rightarrow$ p75 NTR $-/-$ Chimären bzw. den wt $\rightarrow$ p75 ${ }^{\mathrm{NTR}}$-/- Chimären (ANOVA, Bonferroni-Posttest). Die p75NTR -/- $\rightarrow$ p75 ${ }^{\mathrm{NTR}}$-/- Chimären zeigen einen verzögerten Symptombeginn. Die Anzahl der Versuchstiere (n) pro Gruppe ist in der Grafik angegeben $\left({ }^{*}=\mathrm{p}<0,05 ;{ }^{* *}=\mathrm{p}<0,01 ;^{* * *}=\mathrm{p}<0,001\right)$.

\subsubsection{Entzündung}

Insgesamt zeigte sich in allen Versuchsgruppen, entsprechend dem späten Untersuchungszeitpunkt, eine vergleichsweise niedrige Anzahl von entzündlichen Infiltrationen in den Rückenmarksquerschnitten. Es wurden keine signifikanten Unterschiede in der durchschnittlichen Zahl der Infiltrationen pro Rückenmarksquerschnitt zwischen den Versuchsgruppen beobachtet (II, p75 ${ }^{\mathrm{NTR}}-/-\rightarrow$ p75 ${ }^{\mathrm{NTR}}-/-1,05$ 
+/- 1,22 (MW+/-SD) Infiltrate pro RM-Querschnitt, p75 NTR -/- $\rightarrow$ wt 0,77 +/- 0,57 Infiltrate pro RM-Querschnitt, wt $\rightarrow$ p75 NTR -/- 0,65 +/- 0,81 Infiltrate pro RMQuerschnitt, wt $\rightarrow$ wt 0,32 +/- 0,33 Infiltrate pro RM-Querschnitt; $F(3,19)=0,92 ; p=0,45$; ANOVA, Bonferroni-Posttest)(Abb. 14).

\section{Entzündungsindex}

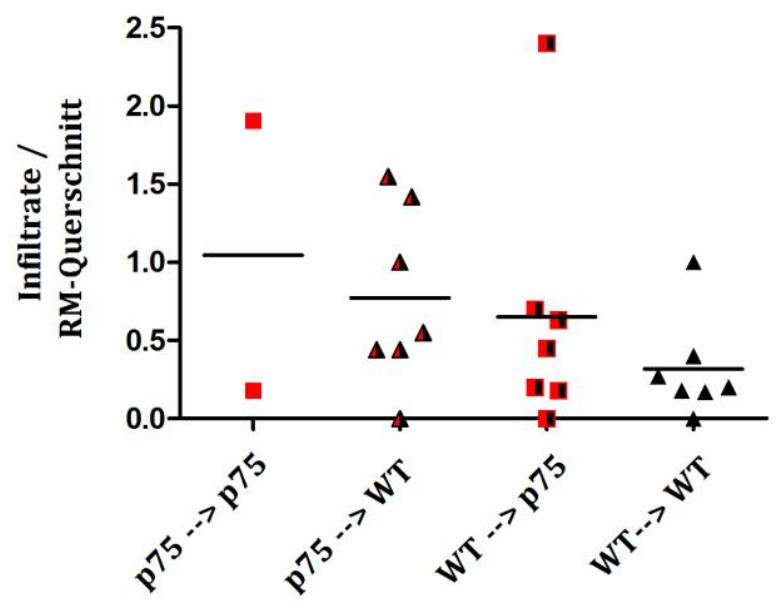

Abb. 14: Entzündungsindex in der chronischen Phase nach der aktiven Immunisierung von murinen Knochenmarkschimären.

Keine signifikanten Unterschiede in der Anzahl von entzündlichen Infiltraten pro Rückenmarksquerschnitt zwischen den Versuchsreihen (ANOVA, Bonferroni-Posttest). 
WT $->$ p75 -/-

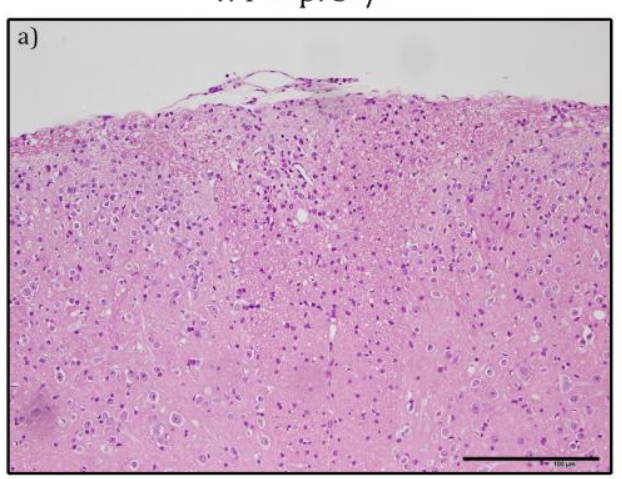

p75 -/- -> p75 -/-
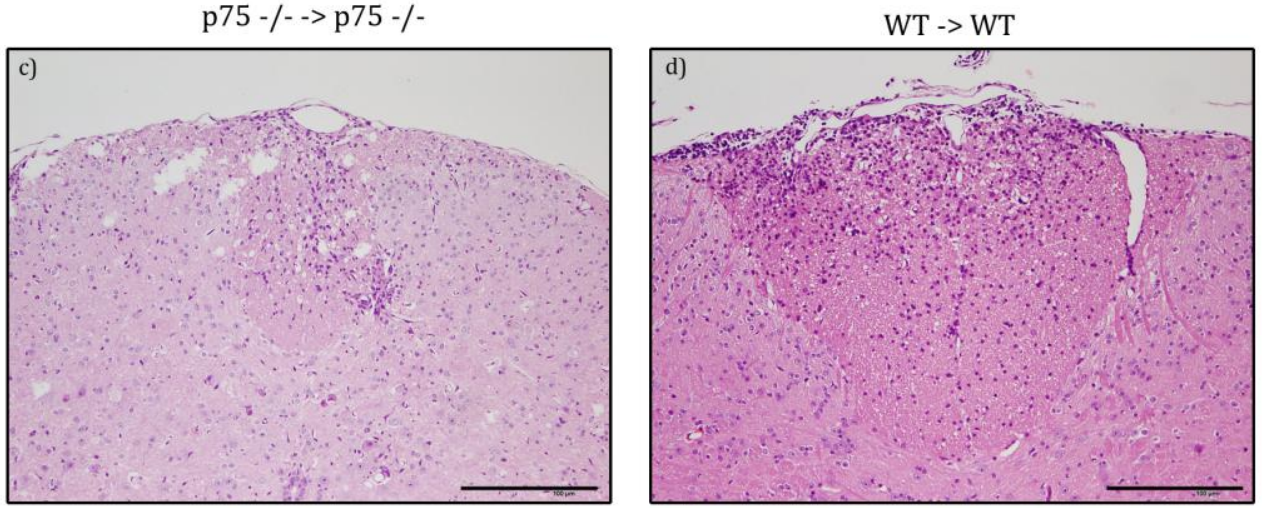

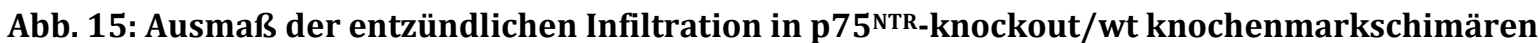
Mäusen.

Keine Unterschiede in der durchschnittlichen Anzahl der entzündlichen Infiltrate pro

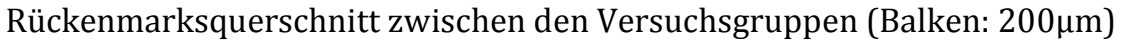

\subsubsection{Axonale Schädigung}

Analog zur akuten, aktiven EAE zeigten sich keine signifikanten Unterschiede zwischen den Versuchsgruppen in Bezug auf das Ausmaß der axonalen Schädigung. Jedoch war die durchschnittliche Anzahl der $\mathrm{APP}^{+}$-Axone deutlich niedriger als im akuten Stadium der Erkrankung (p75 ${ }^{\mathrm{NTR}}-/-\rightarrow$ p75 ${ }^{\mathrm{NTR}}$-/- $289+/-8$ (MW+/-SD) APP+-Axone pro mm², p75 ${ }^{\mathrm{NTR}}-/-\rightarrow$ wt $331+/-76 \mathrm{APP}^{+}$Axone pro mm ${ }^{2}$, wt $\rightarrow$ p75 ${ }^{\mathrm{NTR}}-/-414+/-143 \mathrm{APP}+$ Axone pro $\mathrm{mm}^{2}$, wt $\rightarrow$ wt $341+/-70 \mathrm{APP}^{+}$Axone pro $\mathrm{mm}^{2} ; \mathrm{F}(3,19)=1,3 ; \mathrm{p}=0,3$; ANOVA, Bonferroni-Posttest)(Abb. 16). 


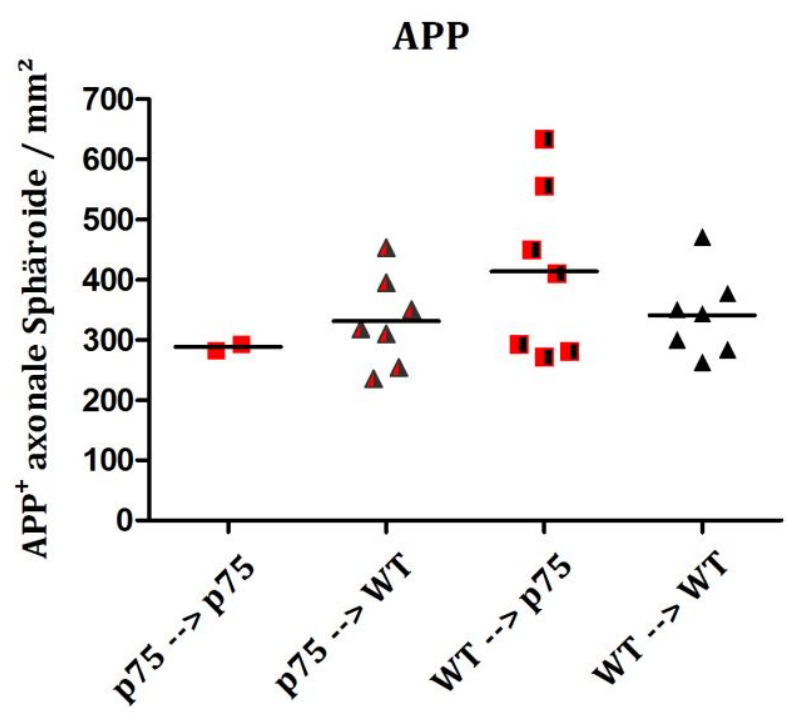

Abb. 16: Axonaler Schaden in der chronischen Phase nach der aktiven Immunisierung von murinen Knochenmarkschimären.

Kein signifikanter Unterschied im Ausmaß der akuten axonalen Schädigung in den Läsionen zwischen den Versuchsgruppen (ANOVA, Bonferroni-Posttest).

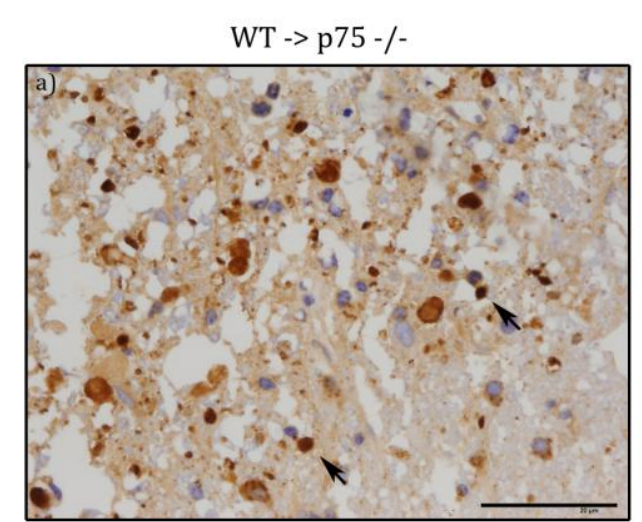

p75 -/- -> p75 -/-

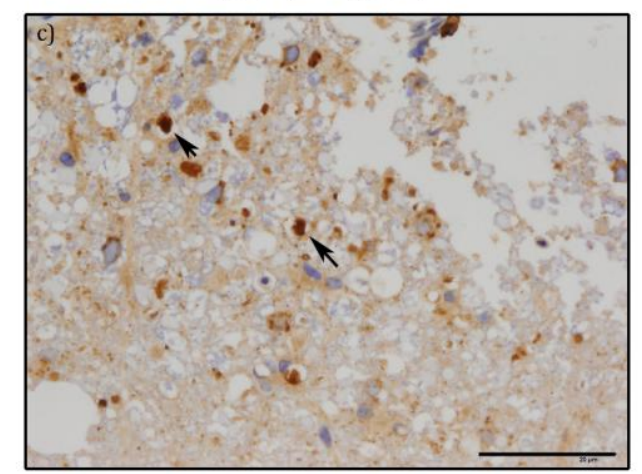

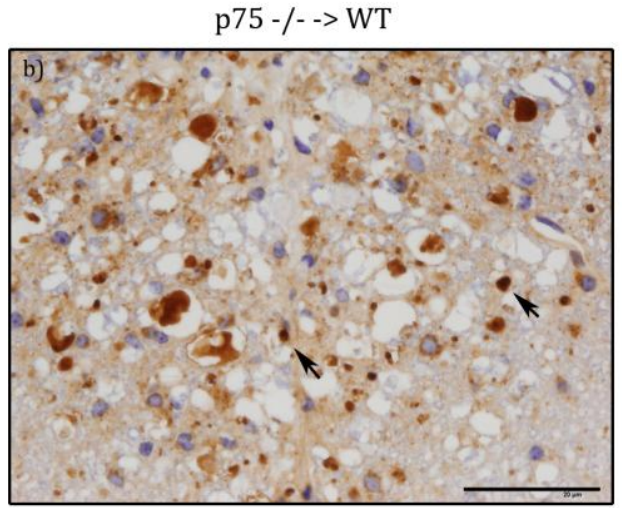

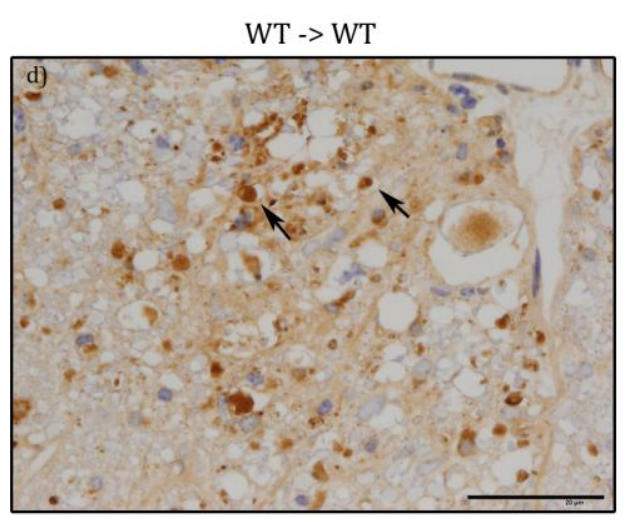

Abb. 17: Ausmaß der axonalen Schädigung in p75 ${ }^{\mathrm{NTR}}$-knockout/wt knochenmarkschimären Mäusen.

Keine Unterschiede in der Dichte der APP+-Sphäroide zwischen den Versuchsgruppen (Balken: $50 \mu \mathrm{m}$ ) 


\subsubsection{Axonaler Verlust}

Genau wie bei der akuten, aktiven EAE bestehen keine signifikanten Unterschiede zwischen den Versuchsgruppen, jedoch ist die axonale Dichte in der chronischen Phase im Vergleich zur akuten Phase der EAE geringfügig niedriger. Das Ergebnis dieser Auswertung wurde als axonale Dichte innerhalb der Läsion in Prozent der axonalen Dichte in der NAWM angegeben. (p75 NTR $-/-\rightarrow$ p75 ${ }^{\mathrm{NTR}}-/-42+/-11,3 \%$ (MW+/-SD), p75 ${ }^{\mathrm{NTR}}-/-\rightarrow$ wt $47+/-11,6 \%$, wt $\rightarrow$ p75NTR $-/-44+/-5,4 \%$, wt $\rightarrow$ wt $43+/-7,6 \%$; $F(3,19)=0,37 ; p=0,77 ;$ ANOVA, Bonferroni-Posttest)(Abb. 18).

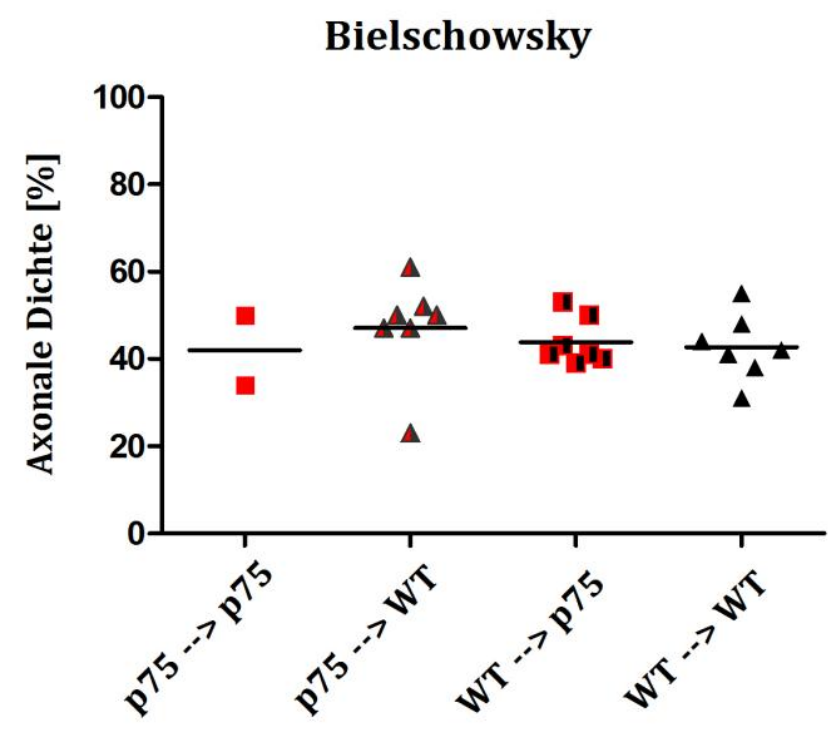

Abb. 18: Axonaler Verlust in der chronischen Phase nach der aktiven Immunisierung von murinen Knochenmarkschimären.

Keine Unterschiede zwischen den Versuchsgruppen im Bezug auf den axonalen Verlust in den Läsionen (ANOVA, Bonferroni-Posttest). 

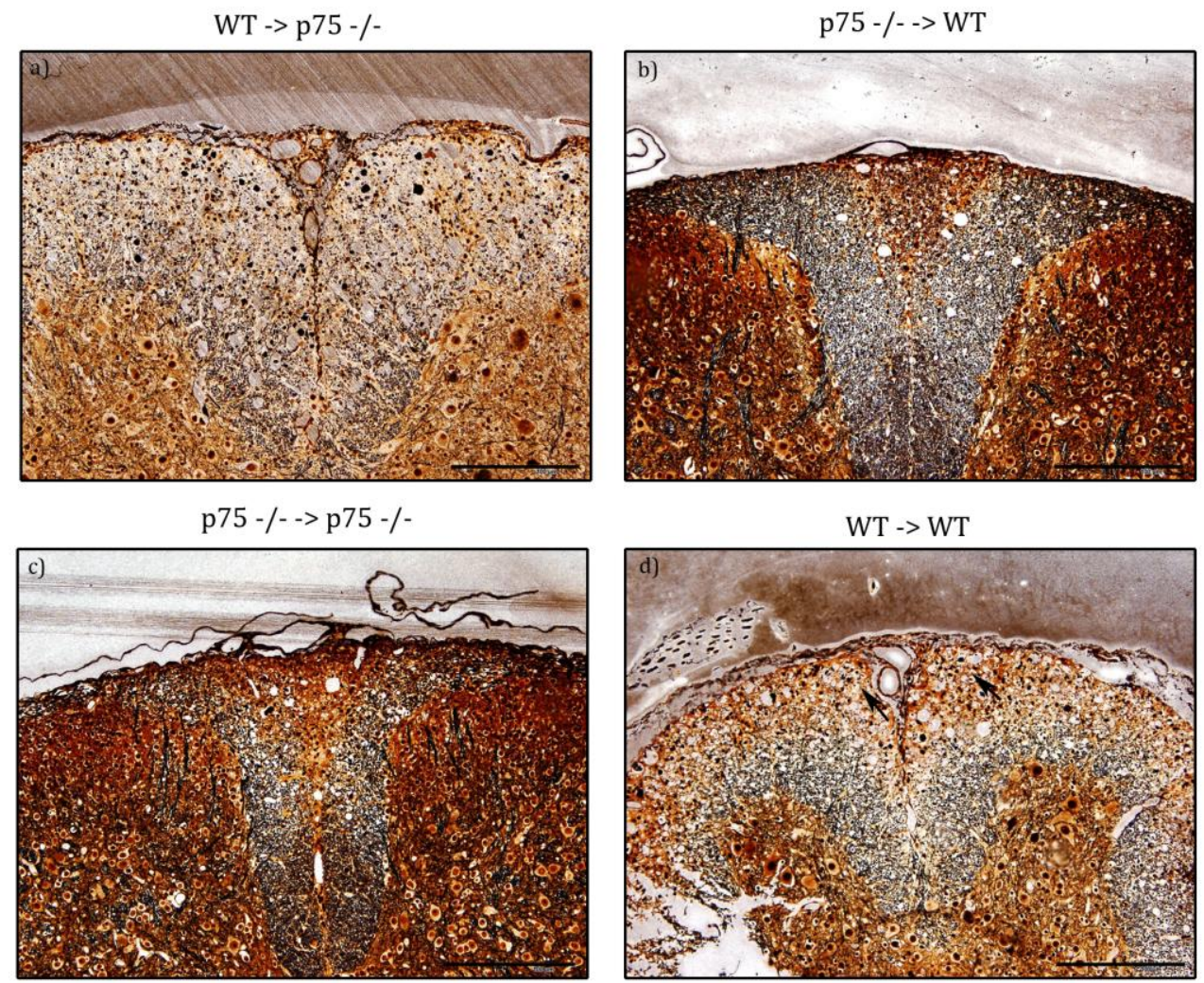

Abb. 19: Ausmaß des axonalen Verlustes in p75 ${ }^{\text {NTR }}$-knockout/wt knochenmarkschimären Mäusen.

Keine Unterschiede im Ausmaß des axonalen Verlustes in den Läsionen zwischen den Versuchsgruppen (Balken: $200 \mu \mathrm{m}$ )

\subsubsection{Entmarkung}

Die durchschnittlich entmarkten Flächen waren in den verschiedenen Versuchsgruppen im Vergleich zum akuten Experiment insgesamt etwas höher, jedoch unterscheiden sich die einzelnen Versuchsgruppen untereinander ebenfalls nicht signifikant. Angegeben sind die durchschnittlichen Flächen der entmarkten weißen Substanz in Prozent bezogen auf die gesamte weiße Substanz (p75NTR $-/-\rightarrow$ p75 $(\mathrm{MW}+/-\mathrm{SD}), \mathrm{p} 75^{\mathrm{NTR}}-/-\rightarrow$ wt 9,33 +/- 2,87\%, wt $\rightarrow$ p75 ${ }^{\mathrm{NTR}}-/-9,74+/-5,18 \%$, wt $\rightarrow$ wt 14,66 +/- 2,7\%; $F(3,19)=2,82 ; p=0,066$; ANOVA, Bonferroni-Posttest)(Abb. 20). 


\section{LFB-PAS}

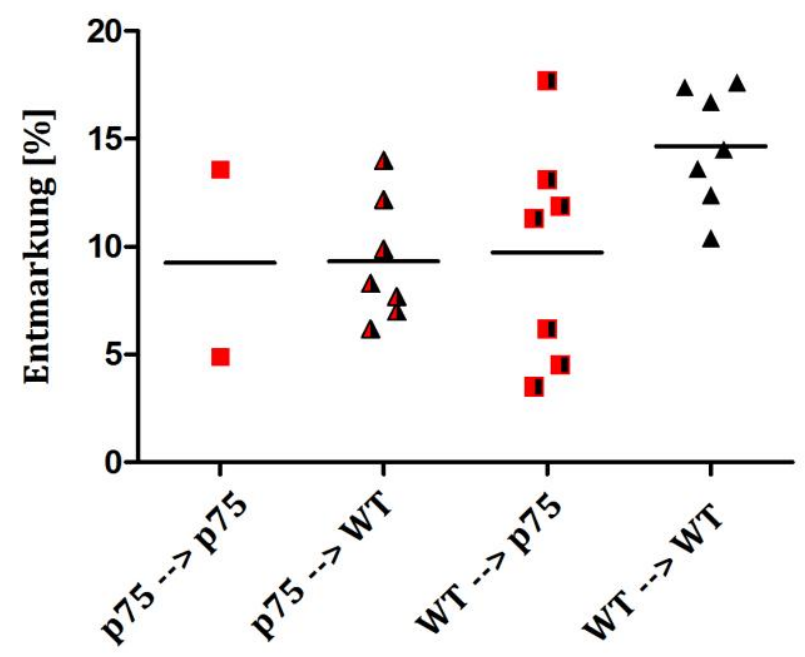

Abb. 20: Demyelinisierte Fläche in Rückenmarksquerschnitten in der chronischen Phase nach der aktiven Immunisierung von murinen Knochenmarkschimären.

Keine signifikanten Unterschiede zwischen den Versuchsgruppen im Bezug auf die Größe der entmarkten Fläche in \% an der gesamten weißen Substanz (ANOVA, Bonferroni-Posttest).
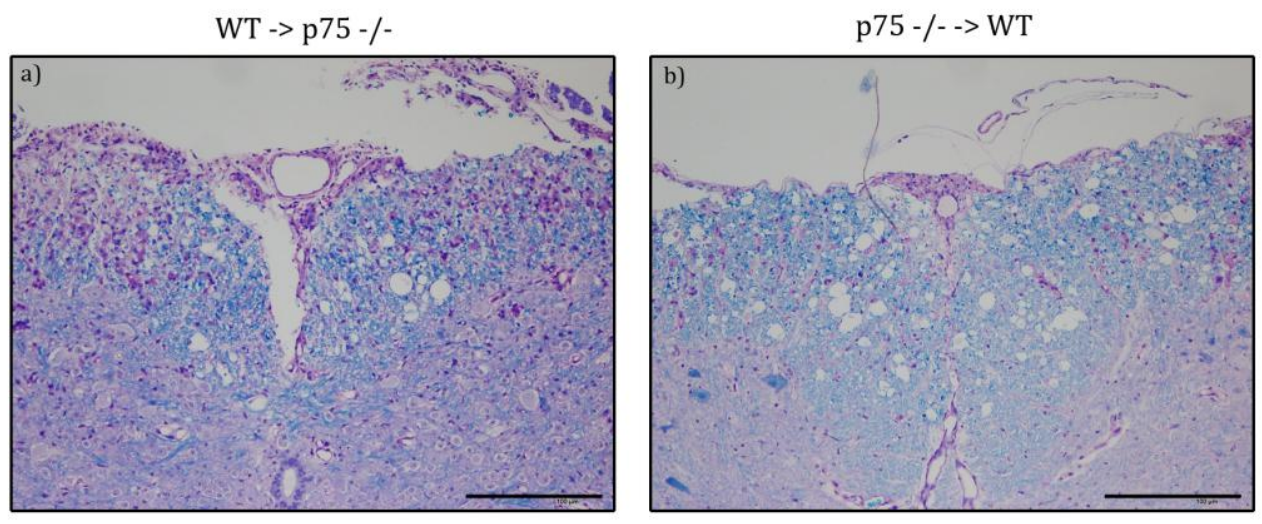

p75 -/- -> p75 -/-
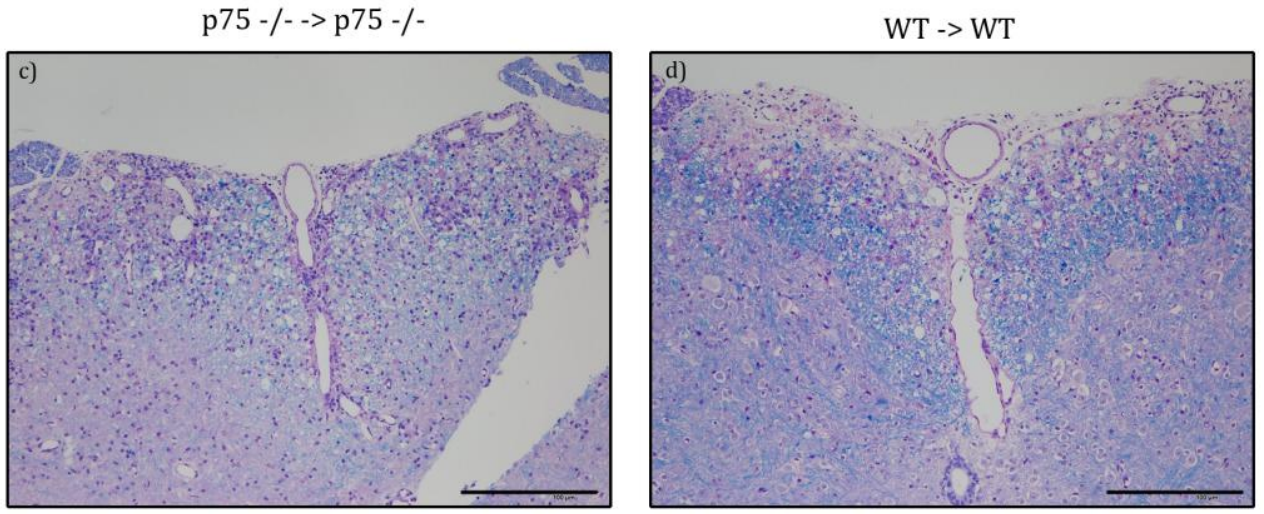

Abb. 21: Ausmaß der Entmarkung in p75NTR-knockout/wt knochenmarkschimären Mäusen.

Keine Unterschiede im Ausmaß der Entmarkung zwischen den Versuchsgruppen. (Balken: 200 $\mu \mathrm{m}$ ) 


\subsection{Adoptiver Transfer von enzephalitogenen MOG $_{35-55}$ spezifischen}

\section{T-Zellen in p75 ${ }^{\mathrm{NTR}}$-knockout/wt knochenmarkschimären Mäuse}

\subsubsection{Klinische Symptomatik}

Nach der Induktion der EAE durch den adoptiven Transfer (AT) von MOG $35-55$ spezifischen T-Zellklonen entwickelten alle Versuchstiere innerhalb kürzester Zeit (3 Tage post injectionem) schwere klinische Symptomatik, so dass die Tiere am 5. Tag nach Zellinjektion geopfert werden mussten. Es wurden keine signifikanten Unterschiede zwischen den Gruppen hinsichtlich der Schwere der Symptomatik gefunden. Da in diesem Experiment in der p75 NTR $-/-\rightarrow$ p75 $\rightarrow$ TR $-/-$ Kontrollgruppe nur ein Tier auszuwerten war $(\mathrm{n}=1)$, konnte diese Versuchsgruppe in den statistischen Analysen nicht berücksichtigt werden und wurde deswegen in den folgenden Grafiken nicht aufgenommen.

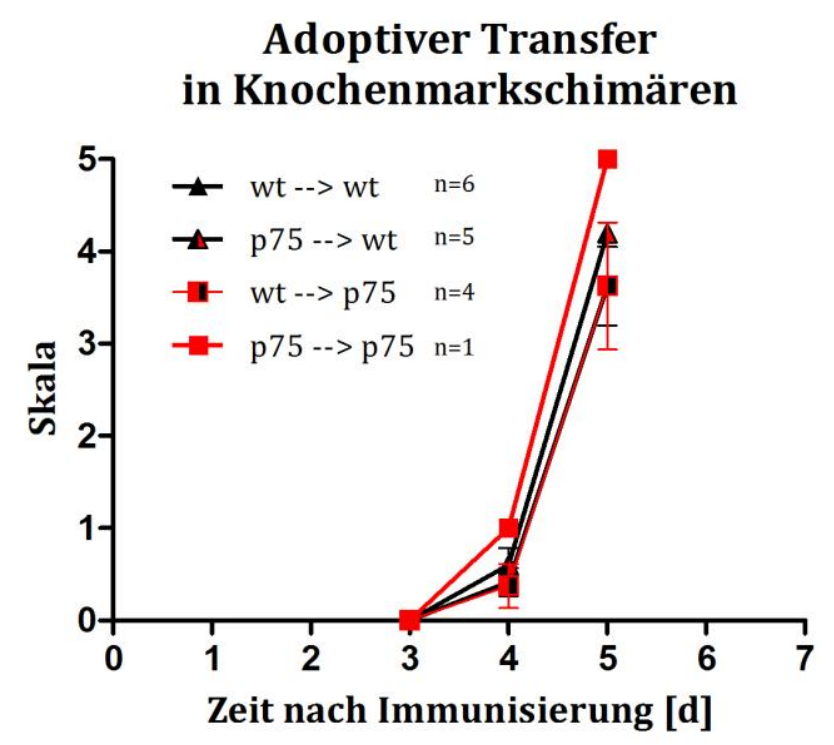

Abb. 22: Krankheitsverlauf in der akuten Phase nach adoptivem Transfer von enzephalitogenen

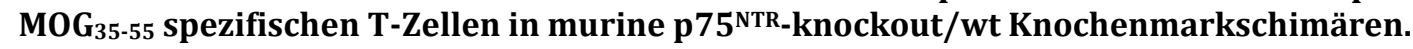

Rascher Krankheitsbeginn und schnelle Entwicklung schwerer neurologischer Symptomatik, so dass die Tiere am 5. Tag nach Induktion der EAE geopfert wurden. Keine Unterschiede zwischen den Versuchsgruppen. Die Anzahl der Versuchstiere (n) pro Gruppe ist in der Grafik angegeben. 


\subsubsection{Entzündung}

Es wurden keine signifikanten Unterschiede im Auftreten entzündlicher Infiltrate im Rückenmark der Tiere zwischen den Versuchsgruppen beobachtet (II, p75 ${ }^{\mathrm{NTR}}-/-\rightarrow w t$ 8,1 +/- 0,87 (MW+/-SD) Infiltrate pro RM-Querschnitt, wt $\rightarrow$ p75NTR -/- 7,35 +/- 1,23 Infiltrate pro RM-Querschnitt, wt $\rightarrow$ wt 8,24 +/- 1,12 Infiltrate pro RM-Querschnitt; $F(2,10)=0,73 ; p=0,51 ;$ ANOVA, Bonferroni-Posttest)(Abb. 23).

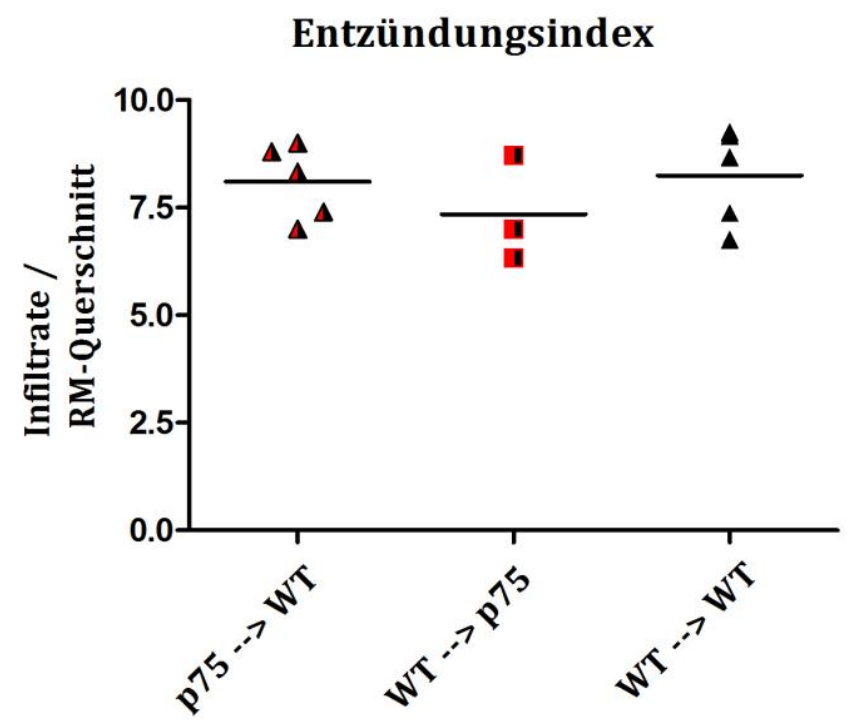

Abb. 23: Entzündungsindex in der akuten Phase nach adoptivem Transfer von enzephalitogenen MOG $_{35-55}$ spezifischen T-Zellen in murine Knochenmarkschimären.

Keine signifikanten Unterschiede in der durchschnittlichen Anzahl der entzündlichen Infiltrate pro Rückenmarksquerschnitt zwischen den Versuchsgruppen. (ANOVA, Bonferroni-Posttest). Die p75 ${ }^{\text {NTR }}-/-\rightarrow$ p75 $^{\text {NTR }}$-/- Kontrollgruppe wurde auf Grund zu kleiner Fallzahl (n=1) nicht berücksichtigt.

\subsubsection{Infiltration von CD3+ T-Zellen und Mac-3+ Makrophagen}

Um die infiltrierenden Zellen näher zu charakterisieren und deren Anteil am entzündlichen Infiltrat zu quantifizieren, wurden immunhistochemische Färbungen für Mac- $3^{+}$Makrophagen/aktivierte Mikroglia angefertigt (p75 NTR $-/-\rightarrow$ wt $610+/-$ 211(MW+/-SD) Mac-3+ Zellen pro $\mathrm{mm}^{2}$, wt $\rightarrow$ p75NTR -/- 647 +/- 334 Mac-3+ Zellen pro

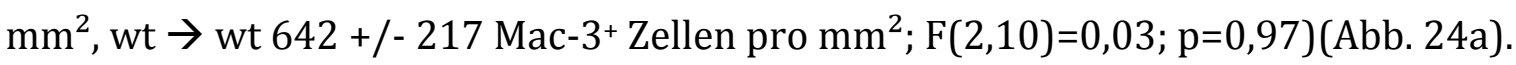
Zusätzlich erfolgte die Anfärbung von CD3+ T-Lymphozyten (p75NTR -/- $\rightarrow$ wt $1604+/-$ $275(\mathrm{MW}+/-\mathrm{SD}) \mathrm{CD}^{+}$Zellen pro $\mathrm{mm}^{2}$, wt $\rightarrow$ p75 ${ }^{\mathrm{NTR}}-/-1244+/-362 \mathrm{CD}^{+}$Zellen pro $\mathrm{mm}^{2}$, wt $\rightarrow$ wt $1765+/-307 \mathrm{CD}^{+}$Zellen pro $\left.\mathrm{mm}^{2} ; \mathrm{F}(2,10)=2,72 ; \mathrm{p}=0,11\right)(\mathrm{Abb} .24 \mathrm{~b})$. 
In beiden Färbungen konnten keine signifikanten Unterschiede in der Anzahl der gefärbten Zellen zwischen den Versuchgruppen festgestellt werden. (ANOVA, Bonferroni-Posttest).

Mac3

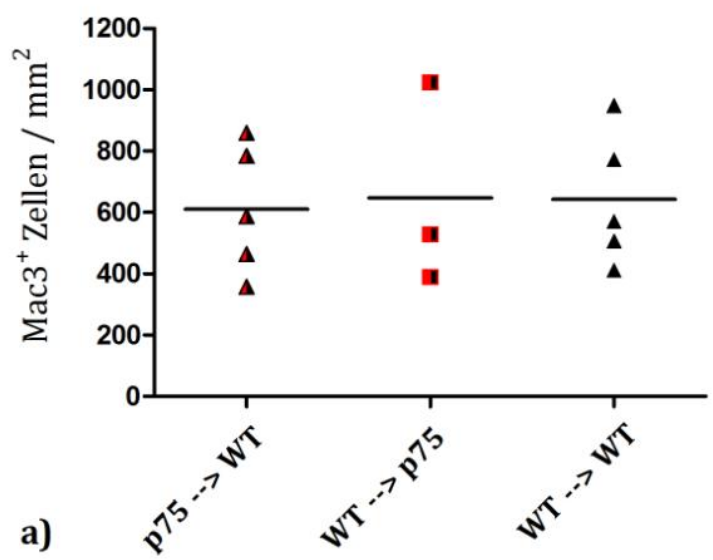

CD 3

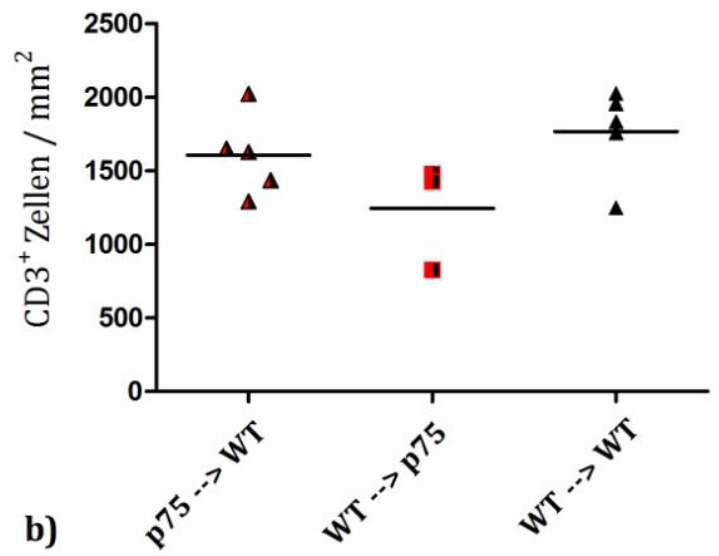

Abb. 24: Entzündliche Infiltration in der akuten Phase nach adoptivem Transfer von MOG $_{35-55^{-}}$ spezifischen T-Zellen in murine Knochenmarkschimären.

Keine signifikanten Unterschiede zwischen den Versuchsgruppen in beiden Experimenten (ANOVA, Bonferroni-Posttest). Die p75 NTR $-/-\rightarrow$ p75 NTR $-/$ - Kontrollgruppe wurde auf Grund zu kleiner Fallzahl $(n=1)$ nicht berücksichtigt.

\subsubsection{Entmarkung}

Auch in Bezug auf die Fläche der Demyelinisierung in den Rückenmarksquerschnitten, bezogen auf die gesamte weiße Substanz, zeigten sich keine Unterschiede zwischen den einzelnen Versuchsgruppen. Insgesamt war das Ausmaß der demyelinisierten Fläche in allen Gruppen gering (p75 NTR -/- $\rightarrow$ wt 2,45 +/- 0,73\% (MW+/-SD), wt $\rightarrow$ p75 ${ }^{\mathrm{NTR}}-/-2,3$ $+/-0,59 \%$, wt $\rightarrow$ wt 1,84 +/- 0,16\%; $\mathrm{F}(2,10)=1,79 ; \mathrm{p}=0,22$; ANOVA, BonferroniPosttest)(Abb. 25). 


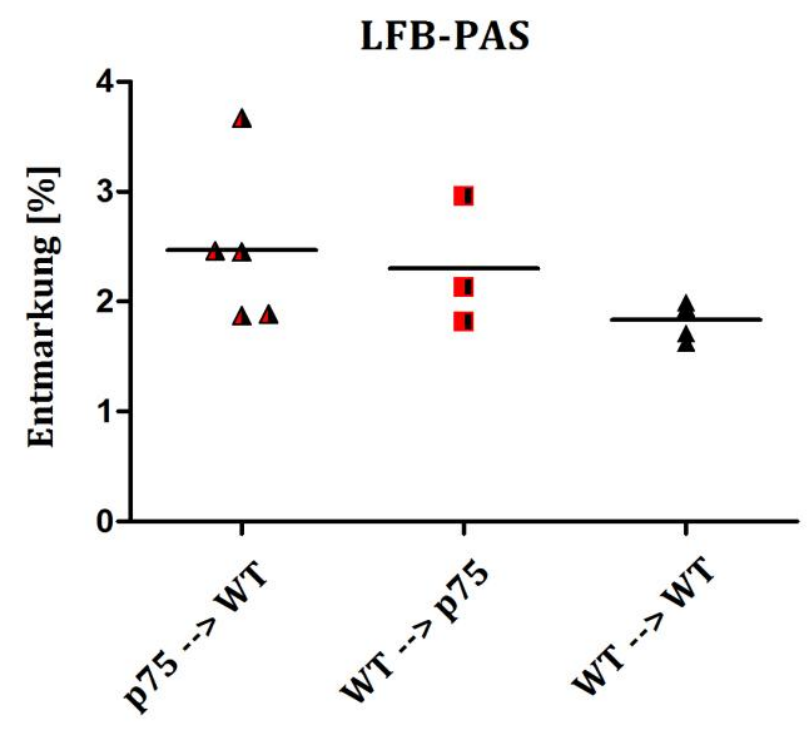

Abb. 25: Demyelinisierte Fläche in Rückenmarksquerschnitten in der akuten Phase nach adoptivem Transfer von MOG $_{35-55}$-spezifischen T-Zellen in murine Knochenmarkschimären.

Keine signifikanten Unterschiede zwischen den Versuchsgruppen im Bezug auf die Größe der entmarkten Fläche in \% an der gesamten weißen Substanz (ANOVA, Bonferroni-Posttest). Die p75 NTR -/- $\rightarrow$ p75 NTR -/- Kontrollgruppe wurde auf Grund zu kleiner Fallzahl (n=1) nicht berücksichtigt.

\subsubsection{Axonale Schädigung}

Die wt $\rightarrow$ p75 ${ }^{\text {NTR }}$-/- Chimären zeigten eine hochsignifikant höhere Dichte von APP+ Axonen in den Läsionen (2078 +/- 135 (MW+/-SD) APP+ Axone pro $\mathrm{mm}^{2}$ ) im Vergleich zu p75 ${ }^{\text {NTR }}-/-\rightarrow$ wt Chimären $\left(777+/-201 \mathrm{APP}^{+}\right.$Axone pro $\mathrm{mm}^{2}, \mathrm{p}<0,001$, ANOVA, Bonferroni-Posttest) sowie eine signifikant höhere Dichte von Sphäroiden im Vergleich zu wt $\rightarrow$ wt Chimären $\left(1267+/-432 \mathrm{APP}^{+}\right.$Axone pro mm² ${ }^{2}$ p $<0,05$, ANOVA, BonferroniPosttest). Zwischen den p75 NTR $-/-\rightarrow$ wt und wt $\rightarrow$ wt Chimären konnte kein signifikanter Unterschied festgestellt werden $(F(2,10)=16,82 ; p=0,0006)$. 


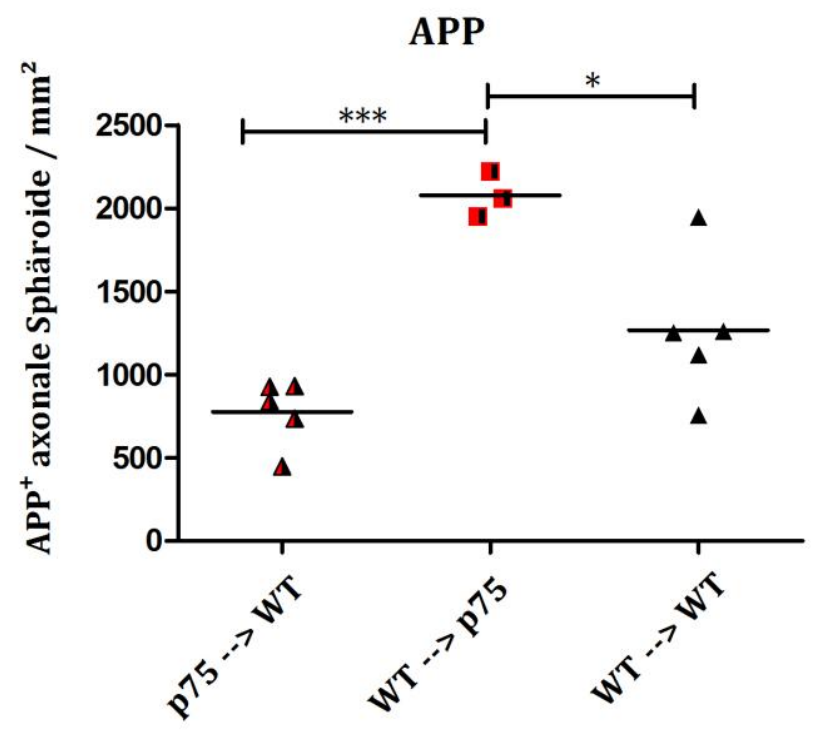

Abb. 26: Axonaler Schaden in der akuten Phase nach adoptivem Transfer von MOG 35-55- $^{-}$ spezifischen T-Zellen in murine Knochenmarkschimären.

Signifikant höhere Dichte von APP+-Axonen in den wt $\rightarrow$ p75 ${ }^{\mathrm{NTR}}$-/- Chimären im Vergleich zu den beiden anderen Versuchsgruppen. Zwischen diesen besteht kein signifikanter Unterschied. (ANOVA, Bonferroni-Posttest). $\left({ }^{*}=\mathrm{p}<0,05 ;{ }^{* *}=\mathrm{p}<0,01 ;{ }^{* * *}=\mathrm{p}<0,001\right)$

Die p75 ${ }^{\text {NRR }}-/-\rightarrow$ p75 ${ }^{\text {NTR }}-/-$ Kontrollgruppe wurde auf Grund zu kleiner Fallzahl (n=1) nicht berücksichtigt. 


\section{Diskussion}

\subsection{Die unterschiedlichen Rollen des p75 ${ }^{\mathrm{NTR}}$ im Immunsystem und ZNS bei der EAE}

Diese Arbeit untersucht die Rolle des p75-Neurotrophinrezeptors bei der Pathogenese der EAE. Die EAE ist aktuell das gebräuchlichste Versuchsmodell zur Erforschung der Pathogenese der MS. In dieser Arbeit wurden zwei verschiedene Methoden zur Induktion der EAE im Mausmodell benutzt. Zum einen die aktive EAE durch die Immunisierung mit MOG 35 -55-Peptid und zum anderen die „adoptive transfer“-EAE (ATEAE) durch den „passiven“ bzw. adoptiven Transfer von gegen MOG $35-55$-Peptid gerichteten, aktivierten T-Zellen. Durch die „passive“ Immunisierung wurde die Aktivierung und Differenzierung der T-Zellen in den Lymphknoten komplett umgangen und die Rolle des p75 ${ }^{\text {NTR }}$ bei der Aktivierung der T-Zellen adressiert.

Schwerpunkt dieser Arbeit ist die Differenzierung der Rolle des p75 ${ }^{\text {NTR }}$ in den beiden Kompartimenten Immunsystem und ZNS. Durch die Herstellung von Knochenmarkschimären war es möglich, den Einfluss von p75 ${ }^{\text {NTR }}$ gezielt in einem der beiden Kompartimente zu untersuchen. Dazu wurden zwei Versuchsgruppen hergestellt und zwei Kontrollgruppen. In den p75 ${ }^{\mathrm{NTR}}-/-\rightarrow$ wt Chimären wurde nach Bestrahlung der wt-Maus ein p75 ${ }^{\text {NTR }}$-defizientes Immunsystem transplantiert, um die Auswirkung eines Fehlens von p75 ${ }^{\text {NTR }}$ im Immunsystem unabhängig von der gleichzeitigen Abwesenheit im ZNS zu untersuchen. p75 ${ }^{\text {NTR }}$ wird im Immunsystem hauptsächlich von B-Zellen exprimiert, die zur T-Zell-Aktivierung, auch im Rahmen der EAE, beitragen.

Genau gegensätzlich dazu können in den wt $\rightarrow$ p75 ${ }^{\mathrm{NTR}}$-/- Chimären die Folgen eines Fehlens von p75NTR im ZNS genauer untersucht werden. Im ZNS wird p75 NTR überwiegend von einer Subpopulation von Neuronen, von Astrozyten und möglicherweise auch von Oligodendrozyten exprimiert.

In früheren Studien zu diesen Themen zeigten Copray et al. (Copray et al. 2004), dass

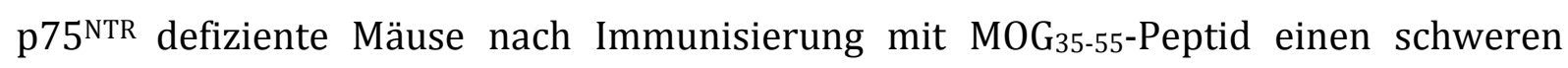
klinischen Verlauf sowie eine erhöhte Entzündungsaktivität aufwiesen. Als mögliche Erklärung wurde eine Erhöhung der Barrierefunktion der Blut-Hirn-Schranke (BHS) durch p75 NTR diskutiert. Diese Hypothese wurde von Flügel et al. (Flügel et al. 2001) 
unterstützt, die zeigten, dass lokal erhöhte Konzentrationen von NGF über den p75 ${ }^{\mathrm{NTR}} \mathrm{zu}$ einer Reduktion der Makrophagen- und Monozytenmigration über die BHS führen.

\subsubsection{Die Erstellung von Knochenmarkschimären}

Eine Frage, die sich zu Beginn der Experimente stellte, war die nach der Vergleichbarkeit der EAE in Knochenmarkschimären mit konventionellen EAE-Experimenten. Da zur Ermöglichung der Knochenmarkstransplantation die Mäuse ganzkörperbestrahlt wurden, musste eine wesentliche Beeinflussung der Entzündungsreaktion nach Induktion der EAE durch die Bestrahlung ausgeschlossen werden. Mildner et al. zeigten in ihrer Arbeit, dass ganzköperbestrahlte knochenmarkschimäre Mäuse eine erhöhte zerebrale Zytokinproduktion aufwiesen (Bitsch et al. 2000). Um solch eine Beeinflussung auszuschließen, wurden vor den ersten KnochenmarkschimärenExperimenten von T. Dallenga in einer ersten Versuchsreihe bestrahlte Mäuse mit naiven Mäusen in Bezug auf Gehirn- und Rückenmarksinfiltration durch Entzündungszellen histologisch und auf Veränderungen von Zyto- und Chemokinexpression mittels quantitativer Real-time-PCR verglichen. Dort zeigten sich bis auf ein vierfach bis sechsfach erhöhtes CXCL10 keine erhöhten Zell- oder Chemokinkonzentrationen. Auf histologischer Ebene konnte eine relevante Infiltration von Entzündungszellen sowie eine deutliche Aktivierung der Mikroglia ausgeschlossen werden (Dallenga 2010).

\subsubsection{Der Einfluss von p75 ${ }^{\mathrm{NTR}}$ auf den klinischen Verlauf der EAE}

Nach der erfolgreichen Induktion der aktiven EAE mittels Immunisierung mit MOG $35-55^{-}$ Peptid konnten wir in der akuten Phase keine signifikanten Unterschiede in der Schwere der klinischen Symptomatik zwischen den einzelnen Versuchsgruppen finden. Diese Ergebnisse stehen im Widerspruch zu der Arbeit von Copray et al. (2004), die zeigte, dass p75-defiziente Tiere einen schwereren klinischen Verlauf präsentieren.

In der chronischen Phase der Erkrankung stellten wir (stichprobenartig an Tag 51 bestimmt) signifikante Unterschiede hinsichtlich der klinischen Symptomatik zwischen den Versuchsgruppen fest. Die Tiere, die eine p75-Defizienz im ZNS auswiesen, zeigten einen signifikant milderen klinischen Verlauf als die wt $\rightarrow$ wt Chimären. Vergleicht man diese beiden Experimente mit den bisherigen Erkenntnissen anderer Autoren, muss 
festgestellt werden, dass ein schwerwiegenderer klinischer Verlauf in p75-defizienten Tieren, wie er von Copray et al. (2004) beschrieben wurde, nach unseren Ergebnissen nicht nachvollziehbar ist. Möglicherweise liegt der dort gefundene Unterschied innerhalb eines möglichen Standardfehlers, so dass größere Experimentgruppen nötig wären, um die von Copray et al. gefundenen Ergebnisse zu reproduzieren bzw. zu widerlegen.

Auffällig war der extrem fulminante klinische Verlauf bei den Tieren aller Versuchsgruppen in der durch adoptiven Transfer von gegen MOG $_{35-55}$ gerichteten TZellen hervorgerufenen EAE. Die klinische Symptomatik war so ausgeprägt, dass alle Tiere am 5. Tag nach Transfer der T-Zellen geopfert werden mussten. Auf Grund der schnellen Entwicklung der Symptomatik ist nachvollziehbar, dass leichtere Unterschiede in der Ausprägung der klinischen Symptomatik nicht nachvollzogen werden konnten. Anhand der Ergebnisse aus den aktiven EAE-Experimenten wären jedoch keine Unterschiede zu erwarten gewesen. Vorangegangene Arbeiten von Dallenga und Jäger (Dallenga 2010; Jäger 2007) kamen zu ähnlichen Ergebnissen bezüglich der akuten, durch adoptiven Transfer hervorgerufenen EAE. Dies legt nahe, dass ein Fehlen von p75 ${ }^{\text {NTR }}$ an der Blut-Hirn-Schranke den Durchtritt aktivierter T-Zellen nicht wesentlich beeinflusst.

\subsubsection{Der Einfluss des p75 ${ }^{\mathrm{NTR}}$ auf die entzündliche Aktivität}

Wir konnten in unseren Versuchen in der akuten Phase der aktiven, durch Immunisierung mit MOG 35 -55-Peptid induzierten EAE ebenso wie Dallenga (2010) keine erhöhte entzündliche Infiltration sowie Entzündungsaktivität (semiquantitative Quantifizierung von frühen S100A9+-Makrophagen und iNOS-produzierenden Makrophagen und Mikroglia) in den p75 ${ }^{\text {NTR }}$-defizienten Tieren feststellen. Die bisherigen Vermutungen durch Copray et al. (2004) und Küst et al. (2006), dass der p75 ${ }^{\text {NTR }}$ einen Einfluss auf die Schrankenfunktion der BHS hat, konnten demzufolge durch diese Experimente nicht unterstützt werden.

In der chronischen Phase der aktiven EAE war das Ausmaß der entzündlichen Infiltration sehr gering, was dem späteren Zeitpunkt im Krankheitsverlauf entspricht (höheres Alter der Läsionen). Unterschiede zwischen den Versuchsgruppen wurden wiederum nicht beobachtet. 
In der durch adoptiven Transfer von gegen $\mathrm{MOG}_{35-55}$ gerichteten T-Zellen hervorgerufenen EAE ergaben sich ebenfalls hinsichtlich der entzündlichen Infiltration keine Unterschiede zwischen den Versuchsgruppen. In der Analyse der Zusammensetzung der entzündlichen Infiltrate fand sich ca. die dreifache Anzahl an $\mathrm{CD}^{+}$T-Zellen im Gegensatz zu Mac-3+-Makrophagen bzw. aktivierten Mikroglia. Zwischen den Versuchsgruppen bestanden keine Unterschiede.

Auch diese Daten weisen somit in die Richtung, dass im von uns angewandten Modell der p75 ${ }^{\mathrm{NTR}}$ nicht wesentlich zur Stabilität der BHS beiträgt.

\subsubsection{Der Einfluss des p75 ${ }^{\mathrm{NTR}}$ auf die Integrität der BHS und auf das}

\section{Immunsystem}

In der bisherigen Literatur wurde von verschiedenen Autoren ein Einfluss von p75NTR auf die BHS vermutet. Copray (2004) und Küst (2006) vermuten einen stabilisierenden Effekt von p75 ${ }^{\text {NTR }}$ auf die BHS. Soilu-Hänninen et al. (2000) hingegen zeigten, dass es nach Gabe von antisense-Oligonukleotiden gegen p75 $^{\text {NTR }} \mathrm{zu}$ einer verminderten Rezeptor-Konzentration an den Endothelzellen der BHS kam, was in einer Abschwächung der klinischen Symptome durch die EAE resultiere.

Unsere Beobachtungen bezüglich der entzündlichen zellulären Infiltration widersprechen diesen Vermutungen. In allen unseren Experimenten konnten wir zeigen, dass es keine signifikanten Unterschiede im Ausmaß der entzündlichen Infiltrationen gibt. Dies lässt den Schluss zu, dass die autoreaktiven T-Zellen sowohl in Wildtyptieren als auch in p75 NTR-defizienten Tieren die BHS gleich gut durchwandern können.

Es kann möglich sein, dass durch den meist sehr fulminanten klinischen Verlauf der EAE kleinere Unterschiede im Ausmaß der zellulären Infiltration nicht zu erkennen waren. Jedoch spricht auch hier die Tatsache, dass es in keinem der Experimente zu einem signifikanten Unterschied im klinischen Verlauf kam, gegen einen möglichen Einfluss von p75 NTR auf die Integrität der BHS.

$\mathrm{Zu}$ ähnlichen Ergebnissen kommen wir auch in der Frage um eine mögliche Rolle des p75 ${ }^{\text {NTR }}$ auf die Zellen des Immunsystems. Hier sprechen wieder der fehlende Unterschied bezüglich des klinischen Verlaufs zwischen den Versuchsgruppen, insbesondere den p75 ${ }^{\mathrm{NTR}}-/-\rightarrow$ wt Chimären, gegen einen starken Einfluss von p75 ${ }^{\mathrm{NTR}}$ auf die Reifung, Aktivierung und Proliferation der T-Zellen. Unterstützt wird diese Aussage dadurch, dass im Vergleich $\mathrm{zu}$ den aktiven EAE-Experimenten die 
Versuchsgruppen, welche mittels adoptiven Transfers induziert wurden, ebenfalls keine Unterschiede im klinischen Verlauf sowie im Ausmaß der entzündlichen Infiltration zeigten.

\subsubsection{Der Einfluss von p75 ${ }^{\mathrm{NTR}}$ auf die axonale Schädigung sowie den axonalen Verlust}

In allen Versuchsgruppen der akuten, aktiv induzierten EAE konnte eine axonale Schädigung sowie eine Verminderung der axonalen Dichte innerhalb der Läsionen nachgewiesen werden. Im Gegensatz zur Arbeit von Dallenga (2010) war jedoch das Ausmaß des axonalen Schadens sowie des axonalen Verlustes bei aktiver Immunisierung in allen Versuchsgruppen annähernd gleich. Diese Ergebnisse sprechen gegen die von Dallenga vermutete Neuroprotektion bei der aktiven EAE durch den

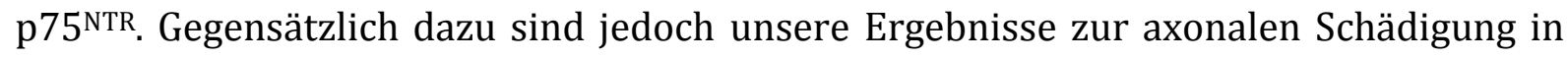
der akuten Phase der durch adoptiven Transfer von gegen $\mathrm{MOG}_{35-55}$ gerichteten T-Zellen hervorgerufenen EAE:

Im Gegensatz zu den aktiven EAE-Experimenten zeigte sich hier in den wt $\rightarrow$ p75 Chimären eine signifikante Erhöhung der $\mathrm{APP}^{+}$-Axone, verglichen sowohl mit den $\mathrm{p}^{\mathrm{N} 5^{\mathrm{NTR}}}$ $-/-\rightarrow$ wt als auch den wt $\rightarrow$ wt Chimären. Da durch den adoptiven Transfer die Aktivierung der T-Zellen in den primären Lymphorganen umgangen wurde, kann in Kombination mit dem Knochenmarkschimären-Modell die Rolle des p75NTR sehr spezifisch im ZNS untersucht werden. Dazu kommt, dass die transferierten T-Zellen in wt-Mäusen gezüchtet wurden, so dass diese ebenfalls über einen intakten p75 verfügen.

Die Ergebnisse dieses Experiments sprechen daher für einen möglichen neuroprotektiven Einfluss durch den p75 ${ }^{\mathrm{NTR}}$ und decken sich damit mit den Ergebnissen von Jäger (2007) und Dallenga (2010), die beide in adoptiven Transfer-EAEExperimenten eine erhöhte axonale Schädigung bei p75NTR-defizienten Mäusen beobachten konnten.

Nun stellt sich die Frage nach der Ursache der Diskrepanz der Ergebnisse zur axonalen Schädigung zwischen der aktiven und durch adoptiven Transfer hervorgerufenen EAE. In unseren Versuchsreihen verlief die AT-EAE sehr fulminant. Dies könnte unter Umständen erklären, warum eine Defizienz des p75 ${ }^{\text {NTR }}$ einen entsprechenden Effekt 
zeigte und die im weniger aggressiven EAE-Modell der aktiven Immunisierung für das

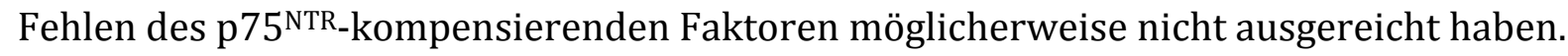
Außerdem lag der Zeitpunkt der Opferung mit anschließender histologischer Untersuchung durch den fulminanten klinischen Verlauf bei den „adoptiven Transfer“Experimenten früher. Trotzdem bleibt noch im Detail zu klären, wie es zu dieser Diskrepanz zwischen aktiver EAE und AT-EAE bezüglich der axonalen Schädigung kommt.

In der chronischen Phase der aktiven EAE konnte eine im Vergleich zum akuten Stadium reduzierte axonale Dichte gefunden werden, jedoch zeigten sich auch hier, wie im akuten Stadium der aktiv induzierten EAE, keine Unterschiede zwischen den Genotypen. Die akute axonale Schädigung war ebenfalls in keiner Versuchsgruppe unterschiedlich, jedoch insgesamt gegenüber der akuten Phase erniedrigt. Dies liegt am ehesten darin begründet, dass die der APP-Akkumulation $\mathrm{zu}$ Grunde liegende axonale Transportstörung durch den kompletten Verlust bzw. auch teilweise durch eine Erholung des Axons abgelöst wurde.

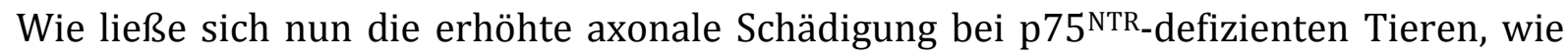
sie in der AT-EAE beobachtet wurde, begründen? Als ein Erklärungsversuch könnte der Hypoxie-induzierte-Faktor-1 $\alpha$-Signalweg (HIF-1 $\alpha)$ dienen. HIF-1 $\alpha$ ist ein Transkriptionsfaktor, der unter normalen Bedingungen in der Zelle schnell degradiert und abgebaut wird. Unter Sauerstoffmangel, aber auch unter entzündlichen Bedingungen, kommt es zu einer Stabilisierung und damit Aktivierung von HIF-1 $\alpha$. Der aktivierte Transkriptionsfaktor HIF-1 $\alpha$ ist für die Expression von mehr als 100 Genen verantwortlich, die hauptsächlich der Anpassung des Zellmetabolismus an den Sauerstoffmangel dienen (Nizet und Johnson 2009; Majmundar et al. 2010). Beispielsweise erfolgt eine HIF-1 $\alpha$-induzierte Expression von c-Myc (Zellüberleben und Mitose)(Gordan et al. 2007) und PDK-1 (Anpassung des Zellmetabolismus an Hypoxie, Förderung von anaerober Glykolyse)(Kim et al. 2006). Le Moan et al. (2012) zeigten, dass bei Vorhandensein des p75 ${ }^{\text {NTR }}$ spezielle Hypoxie-induzierte $\gamma$-Sekretasen eine Proteolyse des p75 Aktivierung von HIF-1 $\alpha$ führt . Ebenfalls konnte gezeigt werden, dass die Abwesenheit von p75 zu einer verminderten Stabilisierung und folgendem Abbau von HIF-1 $\alpha$ führt (Le Moan 
et al. 2011). Auch wird die Möglichkeit nicht ausgeschlossen, dass die Bindung von Neurotrophinen an den p75 ${ }^{\text {NTR }}$ zu einer Stabilisierung von HIF-1 $\alpha$ führen könnte (Le Moan et al. 2012). Ferner konnten Kim et al. (2006) zeigen, dass das Fehlen von HIF-1 $\alpha$ unter Hypoxie zur Induktion von Apoptose führt. Dies lässt sich möglicherweise dadurch erklären, dass unter Mangel von HIF-1 $\alpha$ die normalerweise erhöhte Expression von

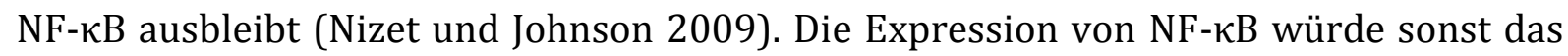
Zellüberleben begünstigen (Liu et al. 1996). Ebenfalls wurde eine neuroprotektive Wirkung für das Zytokin Erythropoetin (EPO) nachgewiesen, das durch HIF-1 $\alpha$ Aktivierung synthetisiert wird (Ostrowski et al. 2011).

In den Wildtyptieren kann die durch die autoimmune Entzündung hervorgerufene lokale Gewebshypoxie („histotoxische Hypoxie“) (Nizet und Johnson 2009; Aboul-Enein

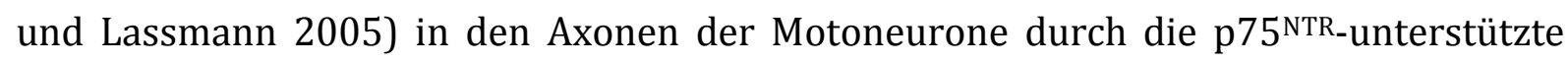
(Rabizadeh und Bredesen 2003) Stabilisierung von HIF-1 $\alpha$ kompensiert werden. In den p75-defizienten Tieren funktioniert dieser Schutzmechanismus nur noch eingeschränkt, so dass es dadurch möglicherweise zu einer erhöhten Vulnerabilität der Axone gegenüber der durch die Entzündung hervorgerufenen lokalen Gewebshypoxie kommt.

\subsubsection{Der Einfluss von p75 ${ }^{\mathrm{NTR}}$ auf die Demyelinisierung}

Im Gegensatz zu der Arbeit von Dallenga (2010) war bei den vorliegenden Versuchen bei p75-defizienten Tieren in der chronischen Phase der aktiv induzierten EAE im Vergleich zu den Wildtyp-Mäusen in der LFB-PAS-Färbung keine erhöhte Demyelinisierung zu finden.

Auch in der durch adoptiven Transfer von gegen MOG $_{35-55}$ gerichteten T-Zellen hervorgerufenen EAE war der Grad der Entmarkung in allen Versuchsgruppen, wie bei einer T-Zell-EAE zu erwarten, niedrig.

Somit hat aus unserer Sicht ein Fehlen des p75 ${ }^{\text {NTR }}$ keinen wesentlichen Effekt auf die Demyelinisierung beziehungsweise den Untergang von Oligodendrozyten im Verlauf beider Formen der EAE. 


\subsection{Ausblick}

\subsubsection{Der Einfluss von B-Zellen auf die EAE}

Die mittels MOG $35-55$ Peptid in B6-Mäusen induzierte EAE wurde lange Zeit als rein TZell mediierte Erkrankung verstanden. In den letzten Jahren ist das Augenmerk nun stärker auf die Rolle der B-Zellreihe in der EAE gelenkt worden. Matsushita et al. (2008) konnten in ihren Experimenten zeigen, dass die Beeinflussung der B-Zellfunktion gravierenden Einfluss auf den Verlauf der EAE haben kann. So bewirkt eine Depletion von B-Zellen mittels eines anti-CD20-Antikörpers vor der Induktion der EAE eine Exazerbation der Erkrankung. Verantwortlich hierfür sollen aus der Milz stammende IL-10 produzierende, regulatorische B10-Zellen sein. Ihre durch IL-10 vermittelten immunsuppressiven Eigenschaften entfallen durch die B-Zelldepletion und führen so zu einer überschießenden Immunreaktion und damit ausgeprägteren klinischen Symptomatik nach Induktion der EAE (Matsushita et al. 2010).

Im Gegensatz dazu bewirkt die Gabe von anti-CD20-Antikörpern 14 Tage nach der EAEInduktion eine Verhinderung des Auftretens bzw. eine Reduktion der klinischen Symptomatik. Argumentiert wird, dass die vorher genannten regulatorischen B10-Zellen ihren Einfluss nur in der Anfangsphase der Erkrankung entfalten. Vielmehr überwiegt im späteren Krankheitsverlauf die Rolle der B-Zellen als antigenpräsentierende Zellen, die zur Aktivierung von zytotoxischen, IL-17a produzierenden T-Zellen vonnöten sind (Matsushita et al. 2008; Jagessar et al. 2012).

Mit der möglicherweise doch stärkeren Rolle der B-Zellen in der bisher alleine von T-Zellen abhängig geglaubten EAE erscheint es logisch, die Wirkungen und Einflüsse des p75 ${ }^{\text {NTR }}$ auf die B-Zellreihe ebenfalls genauer zu untersuchen. Dafür spricht ebenfalls, dass der p75 ${ }^{\mathrm{NTR}}$ auch im erwachsenen Tier auf B-Zellen exprimiert wird (Torcia et al. 1996). 


\section{$5 \quad$ Zusammenfassung}

Die klinische Manifestation der multiplen Sklerose (MS) resultiert weitestgehend aus der entzündungs- und entmarkungsbedingten axonalen Schädigung bzw. dem axonalen Verlust. Als Erklärung für das unterschiedliche Ausmaß der axonalen Schädigung und damit der klinischen Beeinträchtigung zwischen den einzelnen Patienten werden unter anderem Polymorphismen in Neurotrophinrezeptor-Signalwegen diskutiert. Als Modell zur Erforschung der Pathogenese der MS hat sich in den letzten Jahrzehnten im Besonderen die experimentelle autoimmune Enzephalomyelitis (EAE) etabliert.

2004 zeigten Copray et al., dass p75-Neurotrophinrezeptor (p75 NTR)-defiziente Mäuse einen schwereren klinischen Verlauf nach Induktion der EAE aufwiesen. Postuliert wurde ein stabilisierender Effekt von p75 ${ }^{\text {NTR }}$ auf die Integrität der Blut-Hirn-Schranke (BHS). p75 ${ }^{\mathrm{NTR}}$ wird allerdings nicht nur auf Endothelzellen, sondern auch auf Zellen des ZNS und des Immunsystems exprimiert.

Ich untersuchte in dieser Arbeit, ob und wie eine selektive Defizienz des p75 NTR im ZNS bzw. im Immunsystem die EAE beeinflusst. Hierzu erstellten wir knochenmarkschimäre

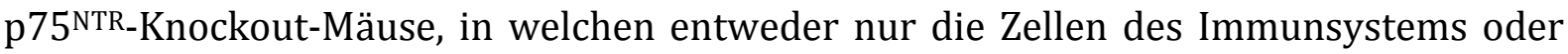
nur des ZNS einen funktionierenden p75 ${ }^{\text {NTR }}$ besaßen. Untersucht wurden die akute und chronische Phase der aktiven EAE sowie die akute Phase der durch adoptiven Transfer aktivierter T-Zellen induzierten EAE. Es erfolgte eine histologische Auswertung der Mäuse im Hinblick auf Qualität und Quantität der Entzündung, Demyelinisierung und des axonalen Schadens bzw. Verlusts.

Hinsichtlich der klinischen Symptomatik beobachtete ich keinen schwerwiegenderen Verlauf bei den p75 ${ }^{\mathrm{NTR}}$-defizienten Tieren. In der späten chronischen Phase der aktiven

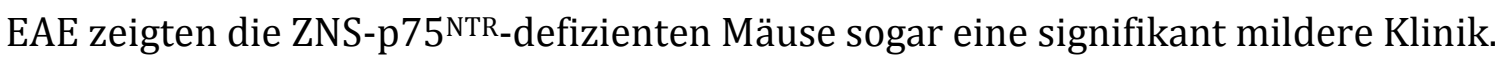

In den Experimenten zur akuten adoptiven Transfer - EAE stellte ich jedoch einen

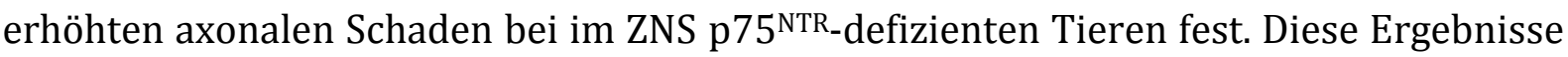
stützen die Hypothese, dass der p75 ${ }^{\text {NTR }}$ eine axonoprotektive Funktion ausübt. Als mögliche Erklärung könnte der HIF-1 $\alpha$-Signalweg angeführt werden, der in seiner

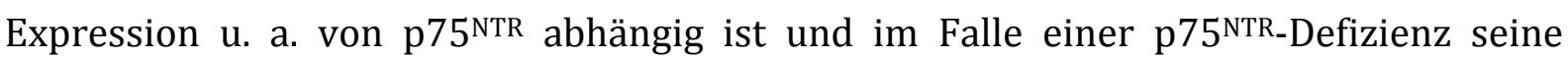
zellprotektive Funktion nicht mehr uneingeschränkt entfalten kann. 
Ferner ziehe ich, ausgehend von unseren Ergebnissen, den Schluss, dass aufgrund des gleichen Ausmaßes der Entzündung in allen Versuchsgruppen die Integrität der BHS durch eine p75 ${ }^{\mathrm{NTR}}$-Defizienz allenfalls gering beeinflusst wird. Ebenso sprechen unsere Ergebnisse gegen eine wesentliche Bedeutung des p75 ${ }^{\text {NTR }}$ bei der Reifung, Aktivierung und Proliferation von T-Zellen. 


\section{Literaturverzeichnis}

Aboul-Enein F, Lassmann H (2005): Mitochondrial damage and histotoxic hypoxia: a pathway of tissue injury in inflammatory brain disease? Acta Neuropathol $\underline{109}$, 49-55 Aloe L, Skaper SD, Leon A, Levi-Montalcini R (1994): Nerve Growth Factor and Autoimmune Diseases: Autoimmunity. Autoimmunity 19, 141-150

Alonso A, Hernán MA (2008): Temporal trends in the incidence of multiple sclerosis: A systematic review. Neurology 71, 129-135

Benedetti M, Levi A, Chao MV (1993): Differential expression of nerve growth factor receptors leads to altered binding affinity and neurotrophin responsiveness. Proc Natl Acad Sci USA 90, 7859-7863

Ben-Nun A, Wekerle H, Cohen IR (1981): Vaccination against autoimmune encephalomyelitis with T-lymphocite line cells reactive against myelin basic protein. Nature 292, 60-61

Bitsch A, Brück W (2002): Differentiation of Multiple Sclerosis Subtypes: Implications for Treatment. CNS Drugs $\underline{16}$, 405-418

Bitsch A, Schuchardt J, Bunkowski S, Kuhlmann T, Brück W (2000): Acute axonal injury in multiple sclerosis: Correlation with demyelination and inflammation. Brain $\underline{123}$, 1174-1183

Carter BD, Kaltschmidt C, Kaltschmidt B, Offenhäuser N, Böhm-Matthaei R, Baeuerle PA, Barde YA (1996): Selective activation of NF-kappa B by nerve growth factor through the neurotrophin receptor p75. Science $\underline{272}, 542-545$

Copray S, Küst B, Emmer B, Lin MY, Liem R, Amor S, Vries H de, Floris S, Boddeke E (2004): Deficient p75 low-affinity neurotrophin receptor expression exacerbates experimental allergic encephalomyelitis in C57/BL6 mice. J Neuroimmunol 148, 41-53

Dallenga T: The Role of the p75 Neurotrophin Receptor in Experimental Inflammation of the Central Nervous System. Diss. Göttingen 2010

Damarjian TG, Craner MJ, Black JA, Waxman SG (2004): Upregulation and colocalization of p75 and Nav1.8 in Purkinje neurons in experimental autoimmune encephalomyelitis. Neurosci Lett $\underline{369}, 186-190$

Damek DM, Shuster EA (1997): Pregnancy and multiple sclerosis. Mayo Clin Proc 72 , 977-989

Dechant G, Barde Y (2002): The neurotrophin receptor p75NTR: novel functions and implications for diseases of the nervous system. Science $\underline{5}, 1131$

Deisenhammer F (2009): Neutralizing Antibodies to Interferon- $\hat{I}^{2}$ and other Immunological Treatments for Multiple Sclerosis. CNS Drugs 23, 379-396

Engelhardt B (2008): Immune cell entry into the central nervous system: Involvement of adhesion molecules and chemokines: Treatment Targets in Multiple Sclerosis: 'The ends and the means', European Charcot Foundation Symposium 2007. J Neurol Sci $\underline{274}$ 23-26 
Ferguson B, Matyszak MK, Esiri MM, Perry VH (1997): Axonal damage in acute multiple sclerosis lesions. Brain 120, 393-399

Fletcher JM, Lalor SJ, Sweeney CM, Tubridy N, Mills KHG (2010): T cells in multiple sclerosis and experimental autoimmune encephalomyelitis. Clin Exp Immunol 162, 1-11

Flügel A, Matsumuro K, Neumann H, Klinkert WEF, Birnbacher R, Lassmann H, Otten U, Wekerle H (2001): Anti-inflammatory activity of nerve growth factor in experimental autoimmune encephalomyelitis: inhibition of monocyte transendothelial migration. Eur J Immunol $\underline{31}, 11-22$

Frohman EM, Racke MK, Raine CS (2006): Multiple Sclerosis - The Plaque and Its Pathogenesis. N Engl J Med 354, 942-955

Gleixner C, Müller M, Wirth S: Neurologie und Psychiatrie: Für Studium und Praxis. Unter Berücksichtigung des Gegenstandskataloges der mündlichen Examina in den Ärztlichen Prüfungen, 7. Auflage; Medizinische Verlags- und Informationsdienste, Breisach 2009/2010

Gold R, Linington C, Lassmann H (2006): Understanding pathogenesis and therapy of multiple sclerosis via animal models: 70 years of merits and culprits in experimental autoimmune encephalomyelitis research. Brain $\underline{129}$ 1953-1971

Gordan JD, Thompson CB, Simon MC (2007): HIF and c-Myc: Sibling Rivals for Control of Cancer Cell Metabolism and Proliferation. Cancer Cell 12, 108-113

Grassiot B, Desgranges B, Eustache F, Defer G (2009): Quantification and clinical relevance of brain atrophy in multiple sclerosis: a review. J Neurol $\underline{256}$, 1397-1412

Haas J, Hug A, Viehöver A, Fritzsching B, Falk C, Filser A, Vetter T, Milkova L, Korporal M, Fritz B et al. (2005): Reduced suppressive effect of CD4+CD25high regulatory $T$ cells on the $\mathrm{T}$ cell immune response against myelin oligodendrocyte glycoprotein in patients with multiple sclerosis. Eur J Immunol 35, 3343-3352

Halachmi E, Ben-Nun A, Lehmann D, Karussis D, Wekerle H, Berke G (1992): Delineation of tissue damage mechanisms in experimental autoimmune encephalomyelitis (EAE). I. Cell detachment and lysis induced by encephalitogenic CD4+ T lymphocytes. J

Autoimmun $\underline{5}, 411-425$

Harrington AW, Kim JY, Yoon SO (2002): Activation of Rac GTPase by p75 Is Necessary for c-jun N-Terminal Kinase-Mediated Apoptosis. J Neurosci 22 , 156-166

Hein T, Hopfenmüller W (2000): Hochrechnung der Zahl an Multiple Sklerose erkrankten Patienten in Deutschland. Nervenarzt 71, 288-294

Hogancamp WE, Rodriguez M, Weinshenker BG (1997): The epidemiology of multiple sclerosis. Mayo Clin Proc 72, 871-878

Jäger W: Die Bedeutung des p75-Neurotrophinrezeptors bei der experimentellen autoimmunen Enzephalomyelitis (EAE). Med. Diss. Göttingen 2007

Jagessar SA, Heijmans N, Bauer J, Blezer ELA, Laman JD, Hellings N, 't Hart BA (2012): BCell depletion abrogates T Cell-mediated demyelination in an antibody-nondependent common marmoset experimental autoimmune encephalomyelitis model. J Neuropathol Exp Neurol $\underline{71}$ 
Johnson D, Lanahan A, Buck CR, Sehgal A, Morgan C, Mercer E, Bothwell M, Chao M (1986): Expression and structure of the human NGF receptor. Cell 47, 545-554

Kim J, Tchernyshyov I, Semenza GL, Dang CV (2006): HIF-1-mediated expression of pyruvate dehydrogenase kinase: A metabolic switch required for cellular adaptation to hypoxia. Cell Metab $\underline{3}, 177-185$

Küst B, Mantingh-Otter I, Boddeke E, Copray S (2006): Deficient p75 low-affinity neurotrophin receptor expression does alter the composition of cellular infiltrate in experimental autoimmune encephalomyelitis in C57BL/6 mice. J Neuroimmunol 174 , 92-100

La Mantia L, Munari LM, Lovati R (2010): Glatiramer acetate for multiple sclerosis. Cochrane Database Syst Rev $\underline{12}$

Labouyrie E, Parrens M, Mascarel A de, Bertrand Bloch, Merlio J (1997): Distribution of NGF receptors in normal and pathologic human lymphoid tissues. J Neuroimmunol $\underline{77}$, 161-173

Lassmann H, Brück W, Lucchinetti C (2001): Heterogeneity of multiple sclerosis pathogenesis: implications for diagnosis and therapy. Trends Mol Med Z 115-121

Lassmann H, Brück W, Lucchinetti CF (2007): The Immunopathology of Multiple Sclerosis: An Overview. Brain Pathol 17, 210-218

Le Moan N, Houslay DM, Christian F, Houslay MD, Akassoglou K (2011): Oxygendependent cleavage of the p75 neurotrophin receptor triggers stabilization of HIF-1 $\alpha$. Mol Cell 44, 476-490

Le Moan N, Baeza-Raja B, Akassoglou K (2012): p75 ${ }^{\text {NTR }}$ and hypoxia: A breath of fresh air in neurotrophin receptor signaling. Cell Cycle $11,829-830$

Lee K, Li E, Huber LJ, Landis SC, Sharpe AH, Chao MV, Jaenisch R (1992): Targeted mutation of the gene encoding the low affinity NGF receptor p75 leads to deficits in the peripheral sensory nervous system. Cell $\underline{69}$, 737-749

Lee R, Kermani P, Teng KK, Hempstead BL (2001): Regulation of Cell Survival by Secreted Proneurotrophins. Science 294, 1945-1948

Lewin GR, Barde Y (1996): Physiology of the Neurotrophins: Annual Review of Neuroscience. Annu Rev Neurosci 19, 289-317

Liu Z, Hsu H, Goeddel DV, Karin M (1996): Dissection of TNF Receptor 1 Effector Functions: JNK Activation Is Not Linked to Apoptosis While NF- $\kappa B$ Activation Prevents Cell Death. Cell 87, 565-576

Lodygin D, Odoardi F, Schlager C, Korner H, Kitz A, Nosov M, van den Brandt, Jens, Reichardt HM, Haberl M, Flugel A (2013): A combination of fluorescent NFAT and H2B sensors uncovers dynamics of $\mathrm{T}$ cell activation in real time during CNS autoimmunity. Nat Med 19, 784-790

Lu B (2003): Pro-Region of Neurotrophins: Role in Synaptic Modulation. Neuron 39 , 735-738

Lu B, Pang PT, Woo NH (2005): The yin and yang of neurotrophin action. Nat Rev Neurosci $\underline{6}, 603-614$ 
Lublin FD, Reingold SC (1996): Defining the clinical course of multiple sclerosis: Results of an international survey. Neurology $\underline{46}, 907-911$

Majmundar AJ, Wong WJ, Simon MC (2010): Hypoxia-Inducible Factors and the Response to Hypoxic Stress. Mol Cell 40, 294-309

Marrie RA (2004): Environmental risk factors in multiple sclerosis aetiology. Lancet Neurol $\underline{3}, 709-718$

Matsushita T, Yanaba K, Bouaziz J, Fujimoto M, Tedder TF (2008): Regulatory B cells inhibit EAE initiation in mice while other B cells promote disease progression. J Clin Invest 118, 3420-3430

Matsushita T, Horikawa M, Iwata Y, Tedder TF (2010): Regulatory B Cells (B10 Cells) and Regulatory T Cells Have Independent Roles in Controlling Experimental Autoimmune Encephalomyelitis Initiation and Late-Phase Immunopathogenesis. J Immunol 185, 2240-2252

McDonald WI, Compston A, Edan G, Goodkin D, Hartung H-, Lublin FD, McFarland HF, Paty DW, Polman CH, Reingold SC et al. (2001): Recommended diagnostic criteria for multiple sclerosis: Guidelines from the international panel on the diagnosis of multiple sclerosis. Ann Neurol 50, 121-127

Mi S, Lee X, Shao Z, Thill G, Ji B, Relton J, Levesque M, Allaire N, Perrin S, Sands B et al. (2004): LINGO-1 is a component of the Nogo-66 receptor/p75 signaling complex. Nat Neurosci $\underline{7}, 221-228$

Minden SL, Frankel D, Hadden L, Perloff J, Srinath KP, Hoaglin DC (2006): The Sonya Slifka Longitudinal Multiple Sclerosis Study: methods and sample characteristics. Mult Scler $\underline{12}, 24-38$

Mumenthaler M, Mattle H: Neurologie. 226 Tabellen, 12., vollst. neu bearb. Aufl.; Thieme, Stuttgart 2008

Munger KLM, Zhang SMMS, O’Reilly EM, Hernán MAMD, Olek MJD, Willett WCMD, Ascherio AMD (2004): Vitamin D intake and incidence of multiple sclerosis. Neurology $\underline{62}, 60-65$

Murphy K, Travers P, Walport M, Ehrenstein M, Janeway C: Janeway's immunobiology, 7. Auflage; Garland Science, New York 2008

Nizet V, Johnson RS (2009): Interdependence of hypoxic and innate immune responses. Nat Rev Immunol 9, 609-617

Nockher WA, Renz H (2006): Neurotrophins in allergic diseases: From neuronal growth factors to intercellular signaling molecules. J Allergy Clin Immunol 117, 583-589

Ostrowski D, Ehrenreich H, Heinrich R (2011): Erythropoietin promotes survival and regeneration of insect neurons in vivo and in vitro. Neuroscience 188, 95-108

Page WF, Durtzke JF, Murphy FM, Norman JE (1993): Epidemiology of multiple sclerosis in U.S. veterans: V. Ancestry and the risk of multiple sclerosis. Ann Neurol $\underline{33}, 632-639$

Passino MA, Adams RA, Sikorski SL, Akassoglou K (2007): Regulation of Hepatic Stellate Cell Differentiation by the Neurotrophin Receptor p75NTR. Science $\underline{315}$, 1853-1856

Patten SBMP, Svenson LWB, Metz LMM (2005): Psychotic disorders in MS: Populationbased evidence of an association. Neurology $\underline{65}, 1123-1125$ 
Polman CH, Reingold SC, Edan G, Filippi M, Hartung H-, Kappos L, Lublin FD, Metz LM, McFarland HF, O'Connor PW et al. (2005): Diagnostic criteria for multiple sclerosis: 2005 revisions to the "McDonald Criteria". Ann Neurol 58, 840-846

Polman CH, O'Connor PW, Havrdova E, Hutchinson M, Kappos L, Miller DH, Phillips JT, Lublin FD, Giovannoni G, Wajgt A et al. (2006): A Randomized, Placebo-Controlled Trial of Natalizumab for Relapsing Multiple Sclerosis. N Engl J Med 354, 899-910

Polman CH, Reingold SC, Banwell B, Clanet M, Cohen JA, Filippi M, Fujihara K, Havrdova E, Hutchinson M, Kappos L et al. (2011): Diagnostic criteria for multiple sclerosis: 2010 Revisions to the McDonald criteria. Ann Neurol. 69, 292-302

Poser CM (1994): The epidemiology of multiple sclerosis: A general overview. Ann Neurol $\underline{36}, 180-193$

Rabizadeh S, Bredesen DE (2003): Ten years on: mediation of cell death by the common neurotrophin receptor p75NTR. Cytokine Growth Factor Rev 14, 225-239

Rabizadeh S, Oh J, Zhong LT, Yang J, Bitler CM, Butcher LL, Bredesen DE (1993): Induction of apoptosis by the low-affinity NGF receptor. Science $\underline{261}, 345-348$

Rejdak K, Jackson S, Giovannoni G (2010): Multiple sclerosis: a practical overview for clinicians. Br Med Bull 95, 79-104

Rivers TM, Sprunt DH, Berry GP (1933): Observations on attempts to produce acute disseminated encephalomyelitis in monkeys. J Exp Med 58, 39-53

Roxburgh RHSR, Seaman SR (2005): Multiple Sclerosis Severity Score: Using disability and disease duration to rate disease severity. Neurology $\underline{64}, 1144-1151$

Sadovnick ADP, Baird PA (1988): The familial nature of multiple sclerosis: age-corrected empiric recurrence risks for children and siblings of patients. Neurology 38, 990-991

Sadovnick ADP, Remick RAM, Allen JMD, Swartz E, Yee IMLM, Eisen KRN, Farquhar RRN, Hashimoto SAM, Hooge JMD, Kastrukoff LFM et al. (1996): Depression and multiple sclerosis. Neurology $\underline{46}, 628-632$

Schilling S, Linker R, König F, Koziolek M, Bähr M, Müller G, Paulus W, Gärtner J, Brück W, Chan A et al. (2006): Plasmaaustausch bei steroidresistenten Multiple-SkleroseSchüben. Nervenarzt $\underline{77}$, 430-438

Schreiner B, Heppner F, Becher B (2009): Modeling multiple sclerosis in laboratory animals. Semin Immunopathol 31, 479-495

Sellebjerg F, Barnes D, Filippini G, Midgard R, Montalban X, Rieckmann P, Selmaj K, Visser LH, Sørensen PS (2005): EFNS guideline on treatment of multiple sclerosis relapses: report of an EFNS task force on treatment of multiple sclerosis relapses. Curr Neurol Neurosci Rep 12, 939-946

Soilu-Hänninen M, Epa R, Shipham K, Butzkueven H, Bucci T, Barrett G, Bartlett PF, Kilpatrick TJ (2000): Treatment of experimental autoimmune encephalomyelitis with antisense oligonucleotides against the low affinity neurotrophin receptor. J Neurosci Res $\underline{59}, 712-721$

Solomon A, Whitham R (2010): Multiple Sclerosis and Vitamin D: A Review and Recommendations. Curr Neurol Neurosci Rep 10, 389-396 
Stone SH (1961): Transfer of Allergic Encephalomyelitis by Lymph Node Cells in Inbred Guinea Pigs. Science 134, 619-620

Torcia M, Bracci-Laudiero L, Lucibello M, Nencioni L, Labardi D, Rubartelli A, Cozzolino F, Aloe L, Garaci E (1996): Nerve Growth Factor is an Autocrine Survival Factor for Memory B Lymphocytes. Cell 85, 345-356

Trapp BD, Peterson J, Ransohoff RM, Rudick R, Mörk S, Bö L (1998): Axonal Transection in the Lesions of Multiple Sclerosis. N Engl J Med 338, 278-285

Tsunoda I, Fujinami RS (1996): Two Models for Multiple Sclerosis: Experimental Allergic Encephalomyelitis and Theiler's Murine Encephalomyelitis Virus. J Neuropathol Exp Neurol $\underline{55}, 673-686$

Viglietta V, Baecher-Allan C, Weiner HL, Hafler DA (2004): Loss of Functional Suppression by CD4+CD25+ Regulatory T Cells in Patients with Multiple Sclerosis. J Exp Med 199, 971-979

Wang KC, Kim JA, Sivasankaran R, Segal R, He Z (2002): p75 interacts with the Nogo receptor as a co-receptor for Nogo, MAG and OMgp. Nature $\underline{420} 74$

Wheeler EF, Gong H, Grimes R, Benoit D, Vazquez L (1998): p75NTR and Trk receptors are expressed in reciprocal patterns in a wide variety of non-neural tissues during rat embryonic development, indicating independent receptor functions. J Comp Neurol $\underline{391}$, 407-428

Whitacre CC (2001): Sex differences in autoimmune disease. Nat Immunol $\underline{2}$, 777-780 


\section{Danksagung}

An erster Stelle gilt mein ganz besonderer Dank Frau Prof. Dr. med. Christine Stadelmann-Nessler für ihre hervorragende Betreuung, kompetente Begleitung und die Fähigkeit, mich durch Ihre freundliche Art immer wieder aufs neue zu motivieren.

Auch Herrn Dr. Tobias Dallenga möchte ich herzlich für die geduldige Einführung in die wissenschaftlichen Techniken und seine kompetente Betreuung danken.

Ebenfalls sehr dankbar bin ich Katja Schulz für ihre stetige Bereitschaft, mich trotz ihres vollen Zeitplans zu unterstützen.

Des Weiteren auch ein herzlicher Dank an die wissenschaftlichen Mitarbeiter und Doktoranden der Abteilung Neuropathologie für das stets freundliche und angenehme Arbeitsklima in der Abteilung.

Ein besonderer Dank gilt auch Vera Krug und Maya Hasenbeck-Bücken für die ausdauernden und akribischen Korrekturen dieses Manuskripts. 